\title{
VARIABILIDADE ESPACIAL DO ARMAZENAMENTO DE ÁGUA NO SOLO VISANDO O MANEJO DA IRRIGAÇÃO POR ASPERSÃO
}

\section{CARLOS RICARDO FIETZ \\ Engenheiro Agrônomo}

Orientador: Prof. Dr. MARCOS VINICIUS FOLEGATTI Co-orientador: . Dr. SIDNEY ROSA VIEIRA

\footnotetext{
Tese apresentada à Escola Superior de Agricultura "Luiz de Queiroz", da Univeršidade de São Paulo, para obtenção do título de Doutor em Agronomia, Área de Concentração: Irrigação e Drenagem.
}

PIRACICABA

Estado de São Paulo - Brasil

Setembro - 1998 
ERRATA

\begin{tabular}{|c|c|c|}
\hline & Onde se lê & Leia-se \\
\hline p. 29, após a eq. (34) & As equações (32) ... & As equações (33) ... \\
\hline p. $31,2^{\mathrm{a}}$ linha & Equação (33), ... & Equação (36), ... \\
\hline $\begin{array}{l}\text { p. } 31,3^{a} \text { linha após } \\
\text { eq. }(38)\end{array}$ & ... equação (35). & ... equação (38) . \\
\hline p. $32,1^{a}$ linha & As expressões (37) e (38) ... & As expressões (40) e (41) ... \\
\hline $\begin{array}{l}\text { p. } 39,4^{a} \text { linha de } \\
\text { baixo p/ cima }\end{array}$ & ... expressão (39)... & ... expressão (43)... \\
\hline p. $50,2^{a}$ linha & pontos amostrais $(15 ; 35)$. & ... pontos amostrais $(15 ; 30) \ldots$ \\
\hline
\end{tabular}


Dados Internacionais de Catalogação na Publicação (CIP) DIVISĀo DE BIBLIOTECA E DOCUMENTAÇĀO - Campus "Luiz de Queiroz"/USP

Fietz, Carlos Ricardo

Variabilidade espacial do armazenamento de água no solo visando o manejo da irrigação por aspersão / Carlos Ricardo Fietz. - - Piracicaba, 1998.

97 p. : il.

Tese (doutorado) - - Escola Superior de Agricultura Luiz de Queiroz, 1998.

Bibliografia.

1. Irrigaçao por aspersāo 2. Umidade do solo 3. Variabilidade espacial I. Título 
Dedico e Ofereço esse trabalho à minha esposa Vivian e às nossas queridas filhas, Beatriz e Luiza, pelo apoio, amor e carinho. e aos meus pais Helmuth e Carmem, pelas oportunidades recebidas. 
"Feliz é a pessoa que acha a sabedoria e que consegue compreender as coisas, pois isso é melhor do que a prata e tem mais valor do que o ouro. A sabedoria é mais preciosa do que as jóias; tudo o que a gente deseja não se pode comparar com ela."

(Provérbios 3. 13-15) 


\section{AGRADECIMENTOS}

À Deus e Jesus Cristo, pelas bençãos e proteção.

À EMBRAPA, em especial ao Centro Nacional de Pesquisa Agropecuária do Oeste (CPAO), pela oportunidade de realização deste treinamento.

À Escola Superior de Agricultura "Luiz de Queiroz" (ESALQ), especialmente ao Departamento de Engenharia Rural, pelos conhecimentos adquiridos e acolhimento dos professores e funcionários.

Ao Conselho Nacional de Pesquisa (CNPq), pela concessão da bolsa de estudos.

Ao Professor Marcos Vinícius Folegatti, pela orientação com amizade, ensinamentos, apoio durante minha permanência em Piracicaba e exemplo de dedicação ao trabalho.

Ao Pesquisador Sidney Rosa Vieira, pela co-orientação, ensinamentos, amizade e pelas críticas, sempre construtívas, a esse trabalho.

Ao Professor José Antonio Frizzone, pelas sugestões, ensinamentos, amizade e pela forma acessivel de trabalho.

Ao Professor Paulo Leonel Libardi, pelos ensinamentos, sugestões e exemplo de equilíbrio entre conduta profissional e humana.

Ao Professor Antonio Saad, pelo apoio e valiosas sugetões.

Ao colega Mário Artemio Urchei, pelas sugestões e apoio constante em Dourados.

Aos colegas da EMBRAPACPAO, Luis Carlos Hernani, Cláudio Lazzaroto e Fernando Paiva, pelas sugestões ao trabalho. 
Aos colegas da ESALQ José Maria Pinto, Vilson Klein, Axel García y García, José Feitosa Filho e Fabiano Chaves da Silva, pelo prazer do convívio diário.

A todos os amigos e irmãos da Igreja Metodista Betânia de Piracicaba, pelo acolhimento. 


\section{SUMÁRIO}

Página

LISTA DE FIGURAS. viii

LISTA DE TABELAS. xii

RESUMO. xiv

SUMMARY. xvi

1 INTRODUÇÃO. 1

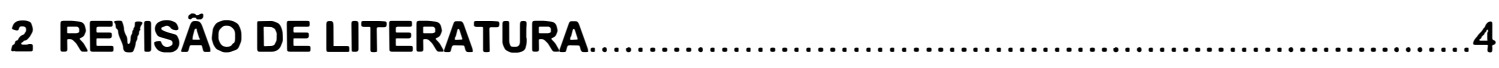

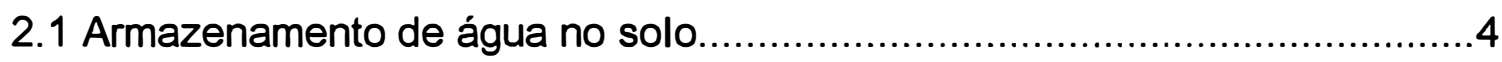

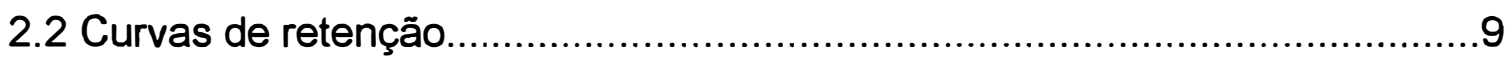

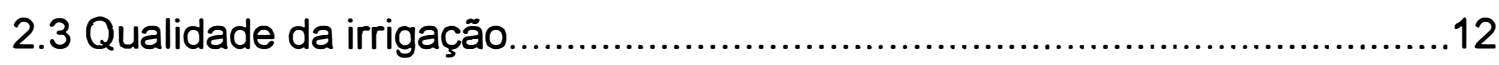

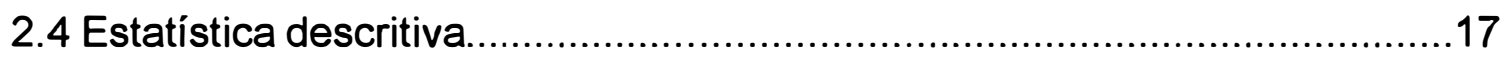

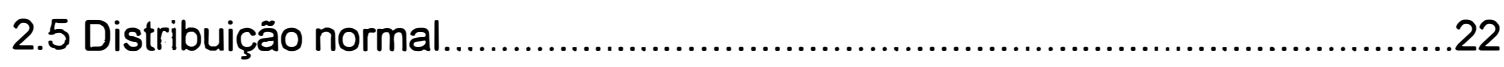

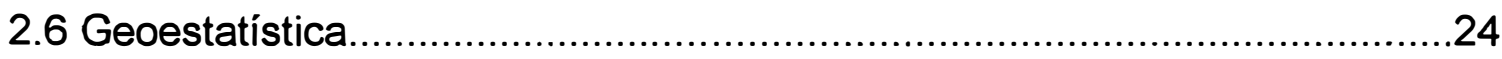

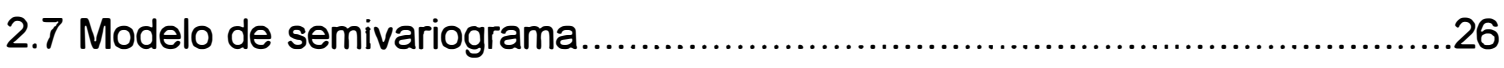

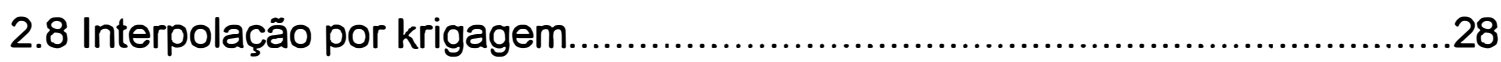

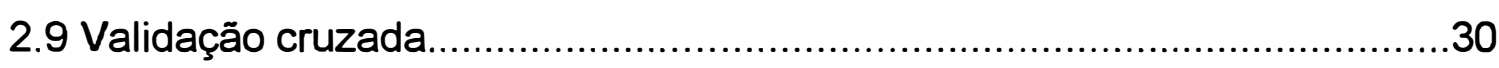

2.10 Estudos sobre variabilidade do armazenamento de água no solo............32

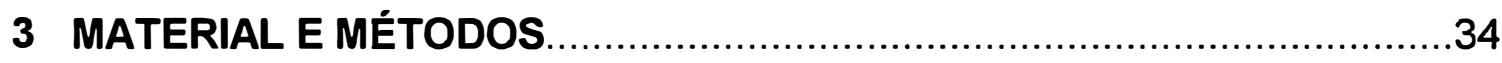

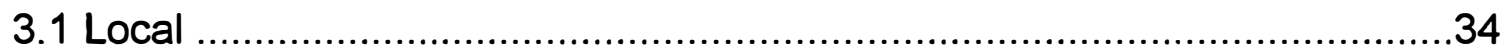

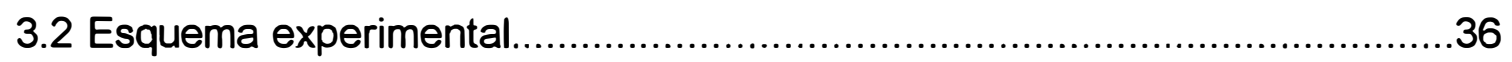

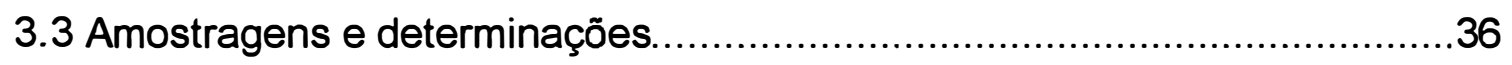




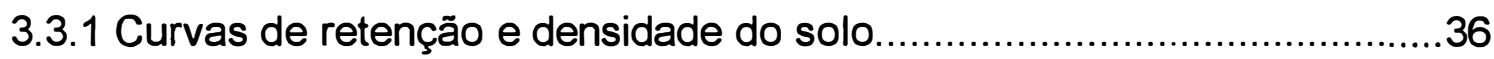

3.3.2 Densidade de partículas e umidade de saturação....................................38

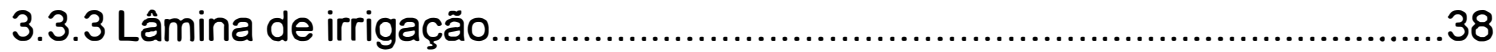

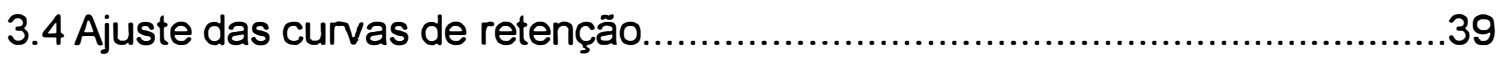

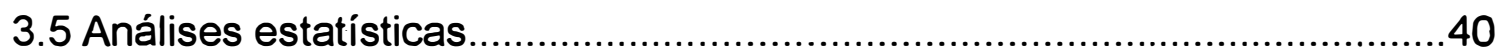

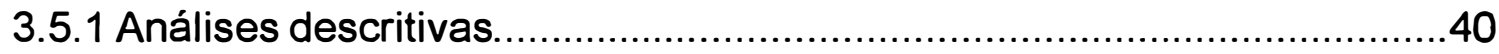

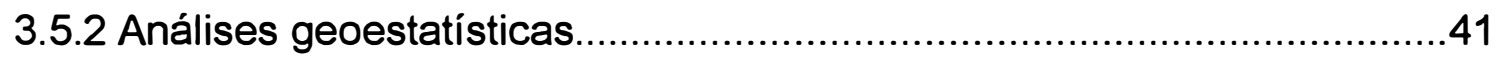

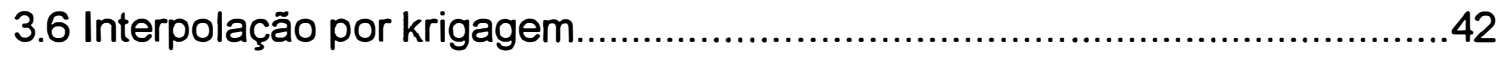

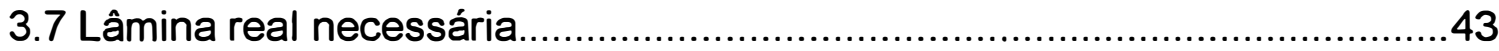

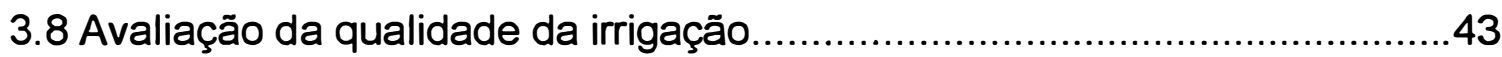

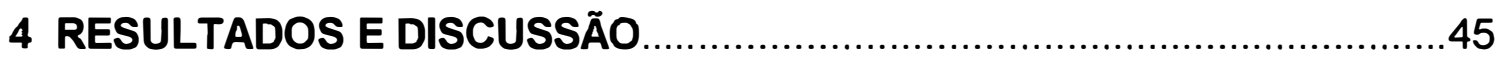

4.1 Umidade do solo nas tensões avaliadas da curva de retenção....................45

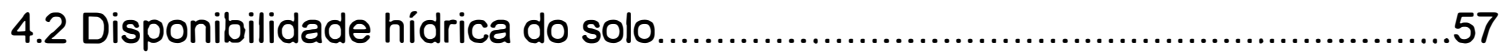

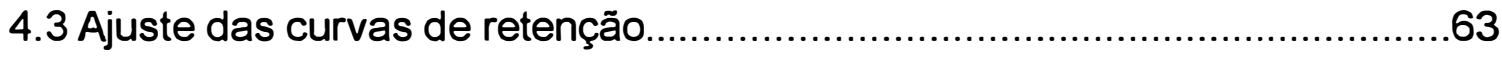

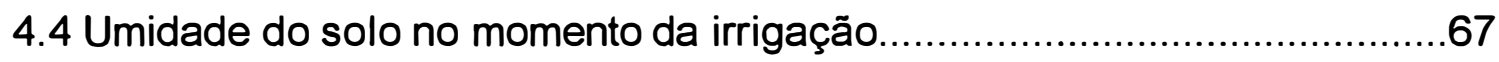

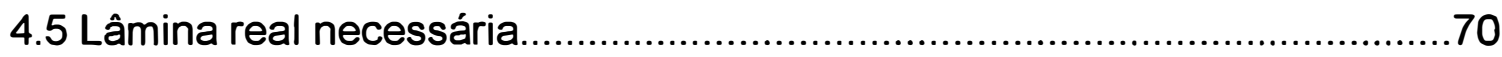

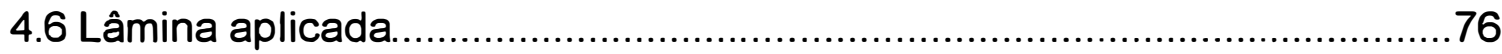

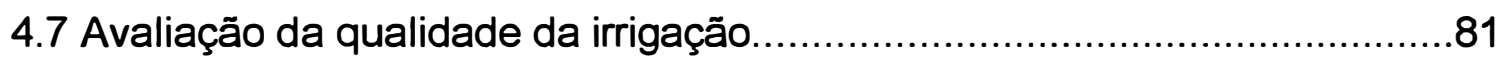

5 CONCLUSÕES

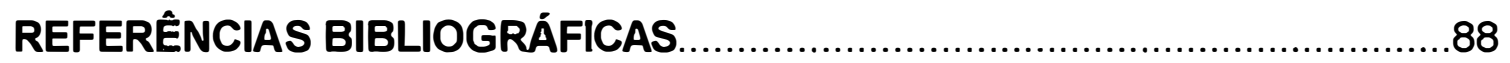




\section{LISTA DE FIGURAS}

Página

1 Representação esquemática do modelo linear, apresentando o volume de excesso $\left(V_{E X C}\right)$ e de déficit $\left(V_{D E F}\right)$, o grau de adequação $(\mathrm{GA})$ e a relação $(\Delta)$ entre lâmina média aplicada $\left(Y_{m}\right)$ e lâmina real necessária $\left(Y_{r}\right)$

2 Mapas plani-altimétrico (a) e tridimensional (b) da área do experimento......35

3 Esquema experimental com a localização dos pontos de amostragem de solo.

4 Gráfico "box-plot" dos dados de umidade volumétrica nas tensões avaliadas, antes da identificação dos valores discrepantes

5 Gráficos de probabilidade normal dos dado de umidade volumétrica nas tensões 10 (a), 33 (b), 50 (c), 100 (d), 500 (e) e $1500 \mathrm{kPa}(\mathrm{f})$, antes da identificação dos valores discrepantes

6 Distribuição espacial dos valores de umidade volumétrica (\%) nas tensões $10(\mathrm{a}), 33$ (b) e $50 \mathrm{kPa}(\mathrm{c})$, identificando os valores considerados como discrepantes (circunferência).

7 Distribuição espacial dos valores de umidade volumétrica (\%) nas tensões 100 (a), 500 (b) e $1500 \mathrm{kPa}$ (c), identificando os valores considerados como discrepantes (circunferência)

8 Gráficos de probabilidade normal dos dados de umidade volumétrica nas tensões 10 (a), 33 (b), 50 (c), 100 (d), 500 (e) e $1500 \mathrm{kPa}$ (f), após a exclusão dos valores discrepantes 
9 Semivariogramas experimentais escalonados pela variância amostral dos dados de umidade volumétrica nas tensões 10 (a), 33 (b) e $50 \mathrm{kPa}$ (c).

10 Semivariogramas experimentais escalonados pela variância amostral dos dados de umidade volumétricas nas tensões 100 (a), 500 (b) e $1500 \mathrm{kPa}(\mathrm{c})$

11 Curvas de retenção das camadas $0-15 \mathrm{~cm}$ (a) e $15-30 \mathrm{~cm}$ (b) determinadas nos laboratórios de solos da EMBRAPAVPAO e do Departamento de Engenharia Rural da ESALQ/USP.

12 Histograma e gráfico de probabilidade normal dos parâmetros do $\alpha(a), n(b)$ e umidade volumétrica residual (c) do modelo de van Genuchten .65

13 Histograma e gráfico de probabilidade normal dos parâmetros transformados do modelo de van Genuchthen $\alpha(a), n(b)$.

14 Gráfico de probabilidade normal (a) e "box-plot" (b) dos dados de umidade volumétrica na tenção $60 \mathrm{kPa}$. .68

15 Semivariograma experimental e modelo ajustado para os dados de umidade volumétrica na tensão $60 \mathrm{kPa}$.

16 Variância reduzida em função do número de vizinhos dos semivariogramas dos dados de umidade volumétrica nas tensões 10 e $60 \mathrm{kPa}$ 
17 Gráfico de dispersão dos valores observados de umidade volumétrica nas tensões 10 (a) e $60 \mathrm{kPa}$ (b) e estimados na validação cruzada.

18 Histogramas das diferenças padronizados dos dados de umidade volumétrica nas tensões 10 (a) e $60 \mathrm{kPa}$ (b) obtidas na validação cruzada, utilizando 12 vizinhos.

19 Mapa de isolinhas dos dados de umidade volumétrica armazenada nas tensões de 10 (a) e $60 \mathrm{kPa}$ (b).

20 Mapa de isolinhas dos dados de lâmina real necessária $(\mathrm{mm})$, obtido a partir dos valores de umidade nas tensões 10 e $60 \mathrm{kPa}$.

21 Semivariograma experimental e modelo ajustado para os dados de lâmina de irrigação.

22 Variância reduzida em função do número de vizinhos dos semivariogramas dos dados de lâmina de irrigação.

23 Gráfico de dispersão dos valores observados de lâmina de irrigação e estimados na validação cruzada.

24 Histograma das diferenças padronizadas dos dados de lâmina de irrigação obtido na validação cruzada utilizando 12 vizinhos

25 Mapa de isolinhas dos dados de lâmina de irrigação $(\mathrm{mm})$ obtido por interpolação pela técnica de krigagem 
26 Mapas de isolinhas dos valores ( $\mathrm{mm}$ ) de déficit (a) e excesso hídrico (b) proporcionados pela irrigação .82

27 Parâmetros de desempenho obtidos no ensaio de irrigação .83

28 Curva de freqüência acumulada das lâminas de irrigação considerando a variabilidade espacial do armazenamento de água no solo e ajustada ao modelo linear 84

29 Valores de drenagem profunda (a) e de grau de adequação (b) considerando a variabilidade espacial do armazenamento e calculado pelo modelo linear 


\section{LISTA DE TABELAS}

\section{Página}

1 Estatística descritiva dos dados de umidade volumétrica (\%) nas tensões avaliadas, antes da identificação dos valores discrepantes (144 valores)....46

2 Estatística descritiva dos dados de umidade volumétrica (\%) nas tensões avaliadas, após a exclusão dos valores discrepantes (144 valores).

3 Parâmetros dos modelos ajustados aos semivariogramas, relação efeito pepita/patamar, variância reduzida $\left(\mathrm{VAR}_{\text {red }}\right)$ e média reduzida $\left(\mathrm{MED}_{\text {red }}\right) \ldots . . .54$

4 Estatística descritiva dos dados de densidade do solo $\left(D_{s}\right)$, densidade de partículas $\left(D_{p}\right)$ e umidade de saturação $\left(\theta_{s}\right)$ (141 valores)

5 Análises granulométricas das amostras de solo realizadas com e sem dipersante químico

6 Estatística descritiva dos parâmetros ajustados do modelo de van Genuchten.

7 Estatística descritiva dos dados de umidade volumétrica do solo na tensão 60 kPa (141 valores). 
8 Estatística descritiva dos dados de lâmina real necessária para a cultura de trigo determinados para cada ponto amostral e obtidos a partir de interpolações por krigagem.

9 Estatística descritiva dos dados de lâmina de irrigação coletada e obtidas a partir de interpolações por krigagem .80 


\title{
VARIABILIDADE ESPACIAL DO ARMAZENAMENTO DE ÁGUA NO SOLO VISANDO O MANEJO DA IRRIGAÇĀO POR ASPERSÃO
}

\author{
Autor: CARLOS RICARDO FIETZ \\ Orientador: Prof. Dr. MARCOS VINICIUS FOLEGATTI \\ Co-orientador: PqC. Dr. SIDNEY ROSA VIEIRA
}

\section{RESUMO}

O conhecimento do armazenamento de água no solo tem importância fundamental para as práticas agrícolas. Quando se deseja dimensionar sistemas ou definir o manejo da irrigação, o procedimento usual é utilizar valores médios assumidos como representativos de toda a área irrigada. No entanto, a variabilidade espacial é uma característica da maioria dos atributos. Neste trabalho, valores de umidade do solo em tensões de interesse agronômico e de lâmina aplicada foram avaliados com os seguintes objetivos: (a) analisar a magnitude da variabilidade, identificar a distribuição estatística e analisar dados discrepantes; (b) verificar a existência de dependência espacial e localizar áreas de menor variabilidade; (c) definir o padrão espacial dos valores de lâmina real necessária e de lâmina aplicada e (d) avaliar o efeito da variabilidade espacial do armazenamento de água no solo na qualidade da irrigação. $O$ ensaio foi realizado na EMBRAPACPAO de 
Dourados, MS, numa área cujo solo é classificado como latossolo roxo argiloso. A área, cultivada com trigo (Triticum aestivum, L.), era dotada de um sistema de irrigação por aspersão autopropelido. Demarcaram-se 144 pontos amostrais com espaçamento regular de $5 \mathrm{~m}$, resultando numa malha regular de 8 colunas e 18 linhas. Em cada ponto foi instalado um pluviômetro e e retiradas amostras de solo indeformadas que foram submetidas às tensões de $10,33,50,100,500$ e $1500 \mathrm{kPa}$ em câmara de pressão de Richards. As curvas de retenção, após serem ajustadas, foram utilizadas para determinar a umidade na tensão $60 \mathrm{kPa}$, recomendada para a irrigação do trigo. Os semivariogramas dos dados de umidade nas tensões 10 e $60 \mathrm{kPa}$ e de lâmina aplicada foram utilizados para construir uma malha de 35 colunas e 85 linhas separadas por $1 \mathrm{~m}$, composta de 3096 pontos. Com os valores de lâmina real necessária e aplicada, determinou-se, para cada ponto da malha $1 \times 1 \mathrm{~m}$, o excesso ou déficit hídrico e calculou-se a drenagem profunda e 0 grau de adequação. Esses parâmetros de desempenho também foram estimados pelo modelo linear. $O$ solo apresentou pequena disponibildade hídrica, provavelmente, devido ao fenômeno da microagregação da fração argila. Os dados de umidade do solo apresentaram distribuição normal, baixa variabilidade e estrutura de dependência espacial com valores de efeito pepita de 14 a $56 \%$ da variação total e alcance de $22 \mathrm{~m}$. Os valores de lâmina de irrigação não se ajustaram à distribuição normal, mas apresentaram um nível médio de variabilidade e forte dependência espacial, com efeito pepita da ordem de $3 \%$ da variação total e alcance de $28 \mathrm{~m}$. As técnicas geoestatísticas detectaram e descreveram a variabilidade espacial do armazenamento de água no solo e da lâmina aplicada pelo sistema de irrigação. A variabilidade do armazenamento de água no solo não influenciou de forma relevante os índices de drenagem profunda e o modelo linear foi pouco sensível em diferenciar áreas deficientemente e adequadamente irrigadas 


\title{
SPATIAL VARIABILITY OF SOIL WATER STORAGE FOR SPRINKLER IRRIGATION MANAGEMENT
}

\author{
Author: CARLOS RICARDO FIETZ \\ Adviser: Prof. Dr. MARCOS VINICIUS FOLEGATTI \\ Co-Adviser: Dr. SIDNEY ROSA VIEIRA
}

\section{SUMMARY}

The knowledge on soil water storage is fundamental to agricultural practices. When system designing or irrigation management definition are intended the usual procedure is to use average values assumed as representative of the entire irrigated area. The spatial variability, however, is a characteristic of most attributes. In this work, soil moisture at agriculture suitable tensions and applied water depth were evaluated in order to: (a) analyze the magnitude of variability, identify the statistical distribution, and analyze discrepant data; (b) verify the existence of spatial dependence and locate areas of lesser variability; (c) define the soil water storage spatial pattern required and applied irrigation depth and (d) evaluate the effect of soil water storage spatial variability on irrigation quality. The experiment was conducted at the EMBRAPA/CPAO, in Dourados, Mato Grosso do Sul state, in a dusky red latosol. The area, cultivated with wheat (Triticum aestivum, L.), was equipped with a self-propelled sprinkler irrigation system. 144 sample spots with a regular 5-m spacing were delimited, resulting in a regular net of 8 columns and 18 rows. Each spot was provided with a rain gauge and nondeformed samples were withdrawn and submitted to tensions of $10,33,50,100,500$, and $1500 \mathrm{kPa}$ in a Richards pressure chamber. After adjustment, the resulting soil moisture retention curves were used to determine moisture at $60 \mathrm{kPa}$, as recommended 
for the wheat crop. Moisture data semivariograms in tensions of 10 and $60 \mathrm{kPa}$ and of irrigation depth were used to construct a net of 35 columns and 85 rows with one meter spacing, totalling 3096 spots. Through required and applied depth values, the water excess or deficit for each spot of $1 \times 1 \mathrm{~m}$ werw determined, and the deep drainage and adequacy of application were calculated. These performance parameters were also estimated by a linear model. The soil showed little water availability, probably due to the microaggregation phenomenon of the clay fraction. Soil moisture data had normal distribution, low variability and spatial structure dependence with nugget effect from 14 to $56 \%$ of total variation and range of $22 \mathrm{~m}$. Irrigation depth values failed to adjust to the normal distribution, but, an average variability level and a strong spatial dependence were observed with nugget effect near of $3 \%$ of total variation and range of $28 \mathrm{~m}$. Geostatistics techniques detected and described the spatial variability of the soil water storage and that of the water applied by the irrigation system. The variability of the soil water storage did not influence significantly the deep drainage indexes and the linear model was little sensitive for distinguishing deficient and adequately irrigated areas. 


\section{INTRODUÇÃO}

A irrigação é uma técnica que possibilita garantir a produção agrícola com índices superiores de produtividade, muitas vezes na entressafra. No entanto, geralmente a agricultura irrigada apresenta um custo elevado, pois aos custos de produção são adicionados os do investimento, da manutenção e da operação do sistema de irrigação.

O manejo racional da irrigação tem importância fundamental, pois além de reduzir as perdas de insumos, possibilita otimizar o uso dos recursos hídricos, diminuindo o consumo de energia e os riscos de contaminação do lençol freático com agroquímicos e fertilizantes.

O planejamento e a operação dos sistemas de irrigação devem ser decididos com base em parâmetros de desempenho que expressem sua qualidade (uniformidade, eficiência e grau de adequação), determinados a partir dos valores de lâmina aplicada, armazenada e perdida por percolação.

$\mathrm{Na}$ aplicação de muitas técnicas agronômicas, é fundamental conhecer a quantidade de água armazenada no perfil do solo. As curvas de retenção ou curvas características relacionam a umidade do solo e o seu potencial mátrico e constituem-se na forma mais usual de representar o comportamento da água armazenada no solo, podendo também ser utilizadas para indicar o nível de aeração do solo e para estimar a distribuição do tamanho dos poros.

Quando se deseja dimensionar um sistema ou definir o manejo da irrigação, o procedimento mais utilizado é determinar uma ou um conjunto de curvas de retenção consideradas como representativas de uma área. Em geral, 
são retiradas amostras em locais escolhidos aleatoriamente e, a partir das curvas determinadas, são definidos os valores de capacidade de campo e de umidade do solo no momento da irrigação, considerando-se representativos, geralmente a média aritmética dos dados.

Esse procedimento, baseado na casualização e repetição, não considera a influência da localização dos pontos de amostragem e exige que os dados apresentem distribuição normal e que as variações de um local para o outro sejam aleatórias. Além disso, muitos atributos não variam de forma aleatória, mas apresentam correlação espacial entre os pontos amostrais que pode ser identificada e quantificada. No entanto, a dependência espacial, quando ocorre, não deve ser considerada uma inconveniência, mas um benefício, pois possibilita que se obtenha informações de locais não amostrados a partir de dados coletados.

Neste trabalho formularam-se as seguintes hipóteses: (i) a variabilidade do armazenamento de água no solo pode ser identificada e descrita por técnicas descritivas da estatística e por métodos geoestatísticos; (ii) conhecendo-se o padrão espacial do armazenamento hídrico no solo e da lâmina aplicada, a qualidade da irrigação pode ser avaliada de forma precisa e (iii) a variabilidade do armazenamento da água no solo tem influência nos parâmetros de desempenho da irrigação.

Com base nessas hipóteses, este trabalho foi desenvolvido com os seguintes objetivos:

a) analisar a variabilidade dos valores de umidade do solo retida em tensões de interesse agronômico e de lâmina aplicada utilizando técnicas descritivas da estatística visando avaliar a magnitude da variabidade, identificar a distribuição estatística e analisar valores discrepantes.

b) analisar a variabilidade espacial desses atributos empregando técnicas geoestatísticas com a finalidade de verificar a existência de dependência espacial e confeccionar mapas de isolinhas com a localização de áreas de menor variabilidade. 
c) definir o padrão espacial dos valores de lâmina real necessária à cultura de trigo e de lâmina aplicada e fornecer subsídios ao manejo da irrigação com base nos parâmetros de qualidade.

d) avaliar o efeito da variabilidade espacial do armazenamento de água no solo na qualidade da irrigação. 


\section{REVISÃO DE LITERATURA}

\subsection{Armazenamento de água no solo}

A água armazenada no perfil do solo $\left(A_{L}\right)$ em um determinado instante, desde a superfície até uma profundidade $L$, é definida pela expressão (Reichardt, 1996):

$$
A_{L}=\int_{0}^{L} \theta(z) d z
$$

em que $\theta$ é a umidade do solo, $z$ é a profundidade do perfil que varia de zero (superfície) até $L$ e dz é a diferencial da variável independente $z$.

Como geralmente não se dispõem da função ou de uma forma analítica integrável de $\theta(z)$, a estimativa do armazenamento verdadeiro é obtida pela simplificação da expressão (1), utilizando-se regras de integração numérica:

$$
A_{L}=\bar{\theta} \cdot L
$$

em que $\bar{\theta}$ é a umidade média, expressa em volume, da camada 0-L.

Quanto maior o número de amostras da camada 0-L, mais o valor médio será representativo e o resultado da equação (2) se aproximará do valor verdadeiro de armazenagem (Turatti, 1990). 
A equação (2) é muito utilizada no dimensionamento e manejo da irrigação para definir a lâmina requerida para suprir o déficit hídrico ou lâmina real necessária. De acordo com as expressões (1) e (2), o armazenamento de água em um solo na capacidade de campo $\left(A_{L} C C\right)$ será:

$$
A_{L} c c=\int_{0}^{2} \theta(z) d z \cong \bar{\theta}_{c c} . L
$$

em que $\bar{\theta}_{c c}$ é a umidade média do solo $\left(\mathrm{m}^{3} \cdot \mathrm{m}^{-3}\right)$ na capacidade de campo.

Da mesma maneira, o armazenamento hídrico no momento da irrigação $\left(A_{L} i\right)$ será:

$$
A_{L} i=\int_{0}^{2} \theta(z) d z \cong \bar{\theta} i L
$$

em que $\overline{\theta i}$ é a umidade média do solo $\left(\mathrm{m}^{3} \cdot \mathrm{m}^{-3}\right)$ no momento da irrigação.

A lâmina real necessária $\left(y_{r}\right)$ pode ser determinada pela diferença das equações (3) e (4):

$$
y_{r}=A_{L} c c-A_{L} i \cong\left(\bar{\theta}_{c c}-\bar{\theta}_{i}\right) L
$$

sendo, neste caso, L igual à profundidade efetiva do sistema radicular da cultura.

Existem dois processos que explicam a retenção da água pelos solos (Libardi, 1995). No primeiro, a retenção ocorre nos microporos dos agregados e está associada a forças capilares. No segundo, a retenção ocorre nas superfícies do solo devido ao processo de adsorção. De acordo com o mesmo autor, três mecanismos principais são propostos para explicar a adsorção: (i) a superfície das partículas minerais de argila, coberta com átomos de oxigênio e grupos de oxidrilas negativamente carregados, cria ao redor das mesmas um 
campo elétrico que atrai as moléculas de água, devido à sua natureza dipolar, (ii) os pares de elétrons não compartilhados do átomo de oxigênio das moléculas de água são atraídos por cátions trocáveis que podem estar adsorvidos sobre a superfície da argila, ou seja, os cátions retidos na superfície das argilas ocasionam também a adsorsão das moléculas de água; (iii) as moléculas de água podem ainda ser atraídas às superfícies sólidas pelas forças de London-van der Waals.

Vários fatores influenciam a retenção hídrica de um solo. No entanto, a retenção de água depende primeiramente da textura do solo e da estrutura ou arranjo das partículas (Klute, 1986). Alguns desses fatores são afetados diretamente pelo manejo do solo e passíveis de controle, como por exemplo a densidade (Arya \& Paris, 1981 e Reeve et al., 1973). Outros, como a granulometria, são propriedades do solo (Arya \& Paris, 1981 e Salter \& Williams, 1965).

A capacidade de armazenamento de água geralmente está relacionada com a composição granulométrica do solo, aumentando à medida que a textura vai diminuindo. Devido a esse comportamento, alguns autores como Bernardo (1989) e Reichardt (1987) definiram limites de disponibilidade hídrica em função da classe textural dos solos. No entanto, em solos de regiões tropicais e subtropicais, como os latossolos, muitas vezes a capacidade de armazenamento é mais influenciada pela estrutura e composição mineralógica da fração argila do que pela granulometria.

Avaliando a influência da composição mineralógica de argilas no armazenamento hídrico de solos da Africa do Sul, Lambooy (1984) verificou que o conteúdo de argila, isoladamente, não se correlacionou satisfatoriamente com a capacidade de armazenamento. A relação foi melhor expressa utilizando a Capacidade de Troca dos Cátions (CTC) dos solos, que quantificou de forma satisfatória o efeito dos diferentes tipos de argila.

A mineralogia dos solos do cerrado brasileiro, em que a presença de argilas do tipo 2:1 é exceção, se reflete na baixa CTC destes solos, na alta 
fixação de fósforo, no avançado grau de agregação e, consequentemente, no alto potencial de lixiviação de bases e excessivo grau de permeabilidade (Lopes, 1983). Esta mineralogia, conforme Lopes (1983), tem estreita relação com o fato destes solos se comportarem como se tivessem textura arenosa, apesar de muitas vezes possuírem teores elevados de argila.

Kertzman (1996), com base na análise micromorfológica, observou que o latossolo roxo era constituído pelo arranjo de unidades subarredondadas, os microagregados, de tamanhos variados, mais frequentemente entre 100 e 300 $\mu \mathrm{m}$ (micra). Esses microagregados são interligados por pontos de argila e óxido, formando uma estrutura muito aberta, com grandes poros. Os microagregados são constituídos por pequenos grãos formados por micropartículas de caulinita e gibsita envelopadas e cimentadas por oxihidratados férricos. Kertzman (1996) concluiu que o microagregado é o principal elemento do latossolo roxo reconhecido pela micromorfologia.

A existência de uma porosidade interna (intra-agregada) e outra externa aos microagregados (interagregado) foi verificada por Sharma \& Uehara (1968), que estudaram a influência das porosidades intra e interagregados na retenção hídrica de dois oxissolos do Havaí. Os autores atribuíram a perda rápida de água nas baixas tensões e o maior volume hídrico armazenado nas tensões mais elevadas, respectivamente, às porosidades inter $e$ intraagregados. Tsuji et al. (1975) também estudaram a microestrutura de oxissolos e atribuíram ao fenômeno da microagregação o comportamento físico-hídrico diferenciado desses solos, observando altas umidades retidas na tensão 1500 $\mathrm{kPa}$ em oxissolos e utilssolos do Havaí. Os autores atribuíram esse comportamento à porosidade dos intra-agregados desses solos. Segundo os autores, os resultados foram mais evidentes em solos com caulinita e mineralogia óxida, indicando que a composição das argilas tem influência no desenvolvimento da porosidade intra-agregados.

Utilizando a técnica de porosimetria de mercúrio, Kertzman (1996) identificou em latossolo roxo duas classes principais de poros. Os poros com 
raio inferior a $0,1 \mu \mathrm{m}$ correspondiam aos poros internos dos microagregados $\mathrm{e}$ os superiores $0,1 \mu \mathrm{m}$ relacionavam-se à porosidade interagregados. $\mathrm{O}$ autor também observou que a porosidade intra-agregados foi pouco afetada pela compactação, que se expressa integralmente na redução dos poros interagregados.

Tognon (1992) considera que a porosidade interagregados é responsável pela boa drenabilidade e aeração e a porosidade intra-agregados confere ao latossolo roxo a alta capacidade de retenção hídrica nas tensões mais elevadas.

O tamanho dos poros esvaziados a uma determinada tensão pode ser estimado a partir da fórmula da ascensão capilar (Danielson \& Sutherland, 1986):

$$
D=\frac{10^{5} \cdot 4 \sigma}{\rho g h}
$$

em que $D$ é o diâmetro dos poros $(\mu \mathrm{m}), \sigma$ é a tensão superficial $\left(\mathrm{J} \cdot \mathrm{m}^{-2}\right), \rho$ é a densidade da água $\left(\mathrm{Mg}^{-3} \mathrm{~m}^{-3}, \mathrm{~g}\right.$ é a aceleração da gravidade $\left(\mathrm{m} \cdot \mathrm{s}^{-2}\right)$ e h é a tensão na qual a água do solo entra em equlíbrio $\left(\mathrm{cm} \cdot \mathrm{H}_{2} \mathrm{O}\right)$.

No entanto, esta relação teórica tem validade apenas para solos não expansivos e onde os poros são considerados cilíndricos, com poucas obstruções e estreitamentos, o que geralmente não ocorre em situações reais (Reeve \& Carter, 1991).

Utilizando a técnica de porosimetria de mercúrio em latossolo roxo, Tognon (1992) e Kertzman (1996) verificaram que poros com raio inferior a 0,1 $\mu \mathrm{m}$ compõem a porosidade intra-agregado. Assim, segundo esses autores, a porosidade intra-agregados corresponderia ao volume hídrico não extraído pela tensão de $1500 \mathrm{kPa}$. 


\subsection{Curvas de retenção}

A relação entre a umidade e o potencial mátrico ou tensão tem grande importância na caracterização das propriedades físico-hídricas dos solos. Essa relação recebe várias denominações, sendo curva de retenção ou curva característica as mais usuais. As curvas de retenção podem ser utilizadas na determinação da água disponível para as culturas, no cálculo da capacidade de aeração de solos drenados e, em solos não expansivos, na estimativa da distribuição do tamanho dos poros.

Experimentalmente, existem três maneiras diretas principais para medir a influência da umidade do solo sobre o potencial mátrico e todas utilizam uma placa porosa separando a(s) amostra(s) de solo de um recepiente contendo uma solução de mesma concentração que a da(s) amostra(s) de solo (Libardi, 1995).

O método tradicional de determinar, curvas de, retenção, consiste em estabelecer uma série de pontos de equilíbrio entre a umidade das amostras e um volume de água com potencial conhecido. O sistema solo-água, representado pela amostra, está em contato hidráulico com o volume de água através de uma placa porosa. Atingido o equilíbrio, determina-se a umidade da amostra e cada par umidade-potencial mátrico será um ponto da curva de retenção.

Os equipamentos utilizadados para determinar curvas de retenção são de dois tipos: sucção e pressão.

De acordo com Klute (1986), nos equipamentos que utilizam sucção, as amostras ficam em contato hidráulico com o volume de água através da placa porosa. A amostra fica submetida à pressão atmosférica e a pressão na massa de água é reduzida a níveis subatmosféricos, devido à redução da carga hidráulica e a água flui da amostra até atingir o equilíbrio hidráulico.

A câmara de pressão com placa porosa ou de Richards é entre os equipamentos que utilizam pressão o mais utilizado. Segundo Libardi (1995), 
para utilizar a câmara de Richards, as amostras de solo, após serem colocadas na superfície da placa de cerâmica, são saturadas, juntamente com a placa. $A$ seguir, o conjunto (tomando-se o cuidado de verificar o mais perfeito contato entre as amostras e a placa porosa) é colocado no interior da câmara e uma determinada pressão é aplicada, fazendo com que a solução se mova do solo para um pequeno reservatório sob a placa, gotejando no tubo de saída até parar quando atinge uma condição de equilíbrio.

As amostras de solo para determinação da curva de retenção podem ter estrutura indeformada ou deformada. Como a estrutura afeta a retenção hídrica, especialmente nas tensões mais baixas, recomenda-se utilizar amostras com estrutura indeformada (Klute, 1986).

As amostras são retiradas em anéis cilindricos, que geralmente têm diâmetros de 0,05 a 0,15 m e com 0,01 a 0,05 m de altura. Como o tempo necessário para atingir o equlibrio é proporcional ao quadrado da altura, recomenda-se utilizar amostras com a menor altura possivel, visando reduzir o tempo de determinação. No entanto, amostras com menos de 0,01 m de altura são difíceis de serem manuseadas e um valor recomendado de altura é de 0,02 a $0,03 \mathrm{~m}$ (Klute, 1986).

A altura ideal das amostras deveria ser igual ao diâmetro, mas como seria necessário muito tempo para atingir o equlíbrio, o mais usual é utilizar anéis de 0,02 a 0,03 m de altura (Reeve \& Carter, 1991).

O volume ideal de uma amostra depende da estrutura do solo, podendose utilizar anéis menores para solos arenosos com estrutura granular do que para solos argilosos com agregados maiores (Reeve \& Carter, 1991).

O diâmetro das amostras deveria ser definido em função do tamanho das unidades estruturais do solo avaliado. No entanto, esse procedimento poderia resultar em amostras com dimensões impraticáveis. Além disso, o aumento dos diâmetros reduz o núméro de amostras que podem ser colocadas em conjunto numa mesma placa porosa. Por esse motivo, as amostras mais utilizadas têm diâmetros de 0,05 a 0,08 m. No entanto, a influência da estrutura 
do solo no tamanho ideal das amostras deve ser observada nas determinações e interpretações desses resultados (Klute, 1986).

As forças que retêm a água no solo em um determinado potencial mátrico são dependentes da temperatura (Klute, 1986). A tensão superficial diminui com o aumento da temperatura, o que reduz o conteúdo hídrico retido em um determinado potencial. Segundo Klute (1986), os efeitos da temperatura nas forças adsorsivas são obscuros, mas há indicações de que o aumento da temperatura proporciona uma redução do conteúdo hídrico em um determinado potencial mátrico. Esses efeitos não são extremamente grandes, mas em alguns casos podem ser significativos.

Embora a influência da temperatura possa ser significativa, segundo Moraes et al. (1993a), muitos autores contestam a intensidade desse efeito, considerando que o principal efeito da temperatura é sobre as bolhas de ar aprisionadas na amostra, principalmente em solos de textura fina.

Outra conseqüência das flutuações de temperatura é o fenômeno da destilação da água da placa porosa e das amostras. A água evaporada condensa-se nas paredes da câmara dificultando a identificação do tempo de equilíbrio (Klute, 1986).

Moraes et al. (1993a) recomendam o controle da temperatura na sala de operação das câmaras de Richards como um cuidado mínimo que deva ser tomado, principalmente em regiões onde existem grandes variações diárias nas temperaturas extremas.

A curva de drenagem, que inicia a partir da saturação completa da amostra, é denominada curva inicial de drenagem (Klute, 1986). À medida que a água é removida, o potencial mátrico diminui (mais negativo) e a umidade da amostra aproxima-se de um limite chamado umidade residual. A curva principal de molhamento é obtida a partir do umedecimento da amostra, que inicia quando ela está com um baixo teor de água, muitas vezes na umidade residual. À medida que o solo vai sendo umedecido e o potencial mátrico aproxima-se de zero, o conteúdo hídrico da amostra aproxima-se de um valor denominado 
saturação natural $\left(\theta_{0}\right)$, inferior a umidade de saturação $\left(\theta_{\mathbf{s}}\right)$. Devido à presença de ar aprisionado, geralmente $\theta_{0}$ varia de $0,8 \theta_{\mathrm{s}}$ a $0,9 \theta_{\mathrm{s}}$. A curva de retenção obtida a partir de $\theta_{0}$ é denominada curva principal de drenagem, que nas tensões mais altas torna-se assintótica à curva inicial de drenagem.

$\mathrm{Na}$ determinação da curva principal de drenagem, a amostra deve ser umedecida até atingir a saturação natural. A forma recomendada é umedecer o solo num recepiente com uma lâmina de água próxima à borda superior da amostra. Segundo Klute (1986), a imersão brusca das amostras não é recomendada, pois pode alterar a estrutura do solo. Quando um agregado seco é umedecido de forma brusca, as forças de capilaridade e de adsorção forçam a água a penetrar no solo, comprimindo $o$ ar aprisionado na porosidade intraagregados. Muitas vezes 0 aumento de pressão pode ser suficiente para romper 0 agregado. Esse rompimento não ocorrerá se 0 umedecimento for realizado em condições de vácuo e pode ser minimizado se a embebição for feita com uma lâmina rasa de água.

Para amostras com 0,02 a 0,03 m de altura, um periodo de 2 a 3 dias deve ser suficiente para atingir o equilibrio (Klute, 1986).

\subsection{Qualidade da irrigação}

A qualidade de uma irrigação pode ser definida por três parâmetros de desempenho: a uniformidade de aplicação, a eficiência e o grau de adequação.

Os parâmetros de eficiência, além de expressar a qualidade da irrigação, também incorporam algumas conseqüências da uniformidade (Frizzone, 1998). A uniformidade depende somente do grau de dispersão que a água é aplicada, enquanto que a eficiência é função tanto da uniformidade como da forma na qual o sistema é operado. 
A eficiência de distribuição e de armazenagem estão entre os parâmetros mais utilizados na avaliação da performance de uma irrigação. $A$ eficiência de distribuição (Ed) mede a quantidade hídrica armazenada na zona radicular em relação à infiltrada:

$$
E d=\frac{V s}{(V p+V s)}
$$

em que Vs é a quantidade de água armazenada na profundidade efetiva e Vpé a água percolada.

A perda por percolação (Dp) é a razão entre a quantidade de água percolada abaixo do sistema radicular e a quantidade total de água infiltrada:

$$
D p=\frac{V p}{(V p+V s)}=1-E d
$$

A eficiência de armazenamento (Es) indica a adequação do reabastecimento na profundidade efetiva:

$$
E s=\frac{V s}{V r}
$$

em que $V r$ é a quantidade de água requerida na irrigação.

Algumas simplificações são geralmente adotadas na análise da qualidade da irrigação. Na prática, toda irrigação apresenta um certo grau de desuniformidade que resulta em áreas irrigadas em excesso ou déficit. $\mathrm{Na}$ área sem déficit hídrico, a quantidade de água que infiltra no solo em excesso à necessária é considerada perdida por percolação. $\mathrm{Na}$ área com déficit, considera-se que toda água infiltrada é armazenada na zona radicular. Além disso, assume-se que a lâmina real necessária é constante em toda a área 
irrigada, desprezando-se, portanto, a variabilidade espacial do armazenamento de água no solo.

O grau de adequação é definido como a fração da área que recebe a quantidade de água capaz de manter a qualidade do produto e a produtividade vegetal no nível econômico desejado pelo agricultor (Frizzone, 1998). Segundo o autor, como essa definição é muito ampla e requer a especificação da cultura, do solo e das condições de mercado, o grau de adequação é geralmente definido de forma simplificada como a porcentagem da área que recebe, no mínimo, a lâmina real necessária (Cuenca, 1989).

Segundo Frizzone (1998), os critérios de projetos e as estratégias de irrigação que visam elevados índices de uniformidade têm possibilidade de produzir alta eficiência de distribuição, mesmo quando a irrigação é realizada com alto grau de adequação. Contudo, deve-se observar que, mesmo para irrigações com alta uniformidade, a eficiência de distribuição depende da quantidade de água aplicada.

Há consenso de que quando a água não é limitante e a cultura é de alto valor econômico, deve-se compensar a baixa uniformidade de distribuição de água pela aplicação de uma lâmina de irrigação maior que a necessária à cultura para reduzir a área de déficit. Entretanto, há que se considerar que o aumento da lâmina de irrigação eleva os custos operacionais do sistema e aumenta as perdas de nutrientes por lixiviação. A lixiviação representa não só uma perda econômica direta, como também reduz a produção e pode contaminar o lençol freático. Como os gastos aumentam com a quantidade de água aplicada e a responsabilidade ambiental justifica um manejo racional da irrigação, pode não ser prudente irrigar com elevado grau de adequação (Frizzone, 1998).

Alguns autores consideram que a lâmina real necessária deve ser igual à lâmina mínima infiltrada, o que assegura uma lâmina aplicada igual ou superior à requerida em toda a área, proporcionando uma eficiência de armazenamento igual a $100 \%$ (Scaloppi, 1984). Essa alternativa, entretanto, 
somente poderá ser justificada em culturas de elevado valor econômico, desenvolvidas em condições tais que toda a água utilizada para a produção provenha da irrigação. Nessas condições, admite-se que o valor econômico do acréscimo da produção obtido seja superior aos custos associados às perdas de água por percolação.

A distribuição da água na zona radicular das culturas pode ser analisada de diversas maneiras. Uma forma muito utilizada é ajustar a relação lâmina de água infiltrada e área irrigada a um modelo matemático, como o normal (Walker, 1979) ou linear (Karmeli, 1978) e a partir destes avaliar a qualidade da irrigação.

O modelo linear destaca-se entre os demais por ser simples, acurado e de fácil aplicação (Souza \& Ribeiro, 1984). O modelo linear (Figura 1) relaciona a curva de freqüência acumulada da lâmina de irrigação e a fração da área irrigada, ambas adimensionais, através da regressão:

$$
\frac{y_{i}}{y_{m}}=a+b \frac{A_{i}}{A_{t}}
$$

em que $y_{i}$ é a lâmina de irrigação no coletor $i(m), y_{m}$ é a lâmina de irrigação média $(m), A_{i}$ é a área referente a cada coletor $\left(m^{2}\right), A_{t}$ é a área total irrigada $\left(m^{2}\right)$ e a e b são os coeficientes da regressão.

No modelo linear, a lâmina real necessária $\left(y_{r}\right)$ também deve ser adimensional:

$$
Y_{r}=\frac{y_{r}}{y_{m}}
$$

em que $Y_{r}$ é a lâmina real necessária adimensionalizada. 


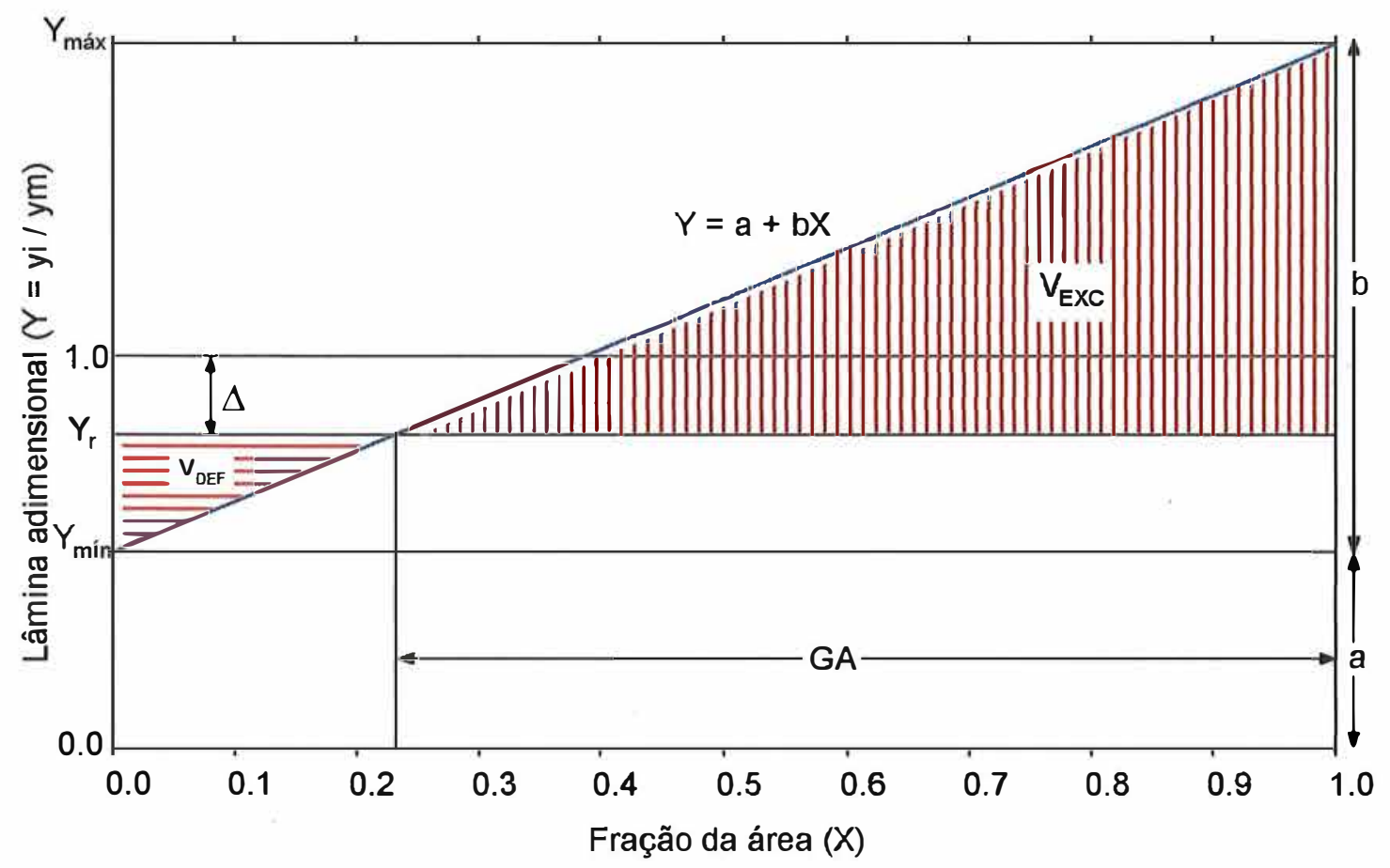

Figura 1. Representação esquemática do modelo linear, apresentando o volume de excesso $\left(V_{E X C}\right)$ e de déficit $\left(V_{D E F}\right)$, o grau de adequação $(\mathrm{GA})$ e a relação $(\Delta)$ entre lâmina média aplicada $\left(y_{m}\right)$ e lâmina real necessária $\left(\mathrm{y}_{\mathrm{r}}\right)$.

A diferença entre a lâmina adimensional média aplicada e lâmina real necessária $(\Delta)$ relaciona-se diretamente com o manejo da irrigação. Com a redução dessa diferença, haverá redução da percolação e do grau de adequação. Portanto, pode-se definir um valor de $\Delta$ que maximize o retorno econômico, estabelecendo um equilíbrio entre os benefícios proporcionados pela alta eficiência de distribuição e os danos resultantes da redução do grau de adequação.

No modelo linear, quando a lâmina média aplicada é igual à requerida ( $\Delta$ $=0$ ), o grau de adequação será de $50 \%$. Com o aumento do valor da lâmina aplicada e, portanto de $\Delta$, também haverá aumento do grau de adequação. Considerando uma situação ideal em que as irrigações sejam completamente 
uniformes $(b=0)$, o modelo não se aplica, pois não há ajuste da distribuição de freqüência das lâminas à distribuição linear. Nesse caso, o grau de adequação terá os valores extremos de 0 ou de $100 \%$, se a lâmina aplicada for, respectivamente, menor ou maior que a lâmina real necessária.

Havendo ajuste dos dados ao modelo linear, que pode ser avaliado pelo coeficiente de correlação da equação (10), com base em b e em $\Delta$ (Figura 1), pode-se determinar os seguintes parâmetros de desempenho:

$$
\begin{aligned}
& E d=1-\Delta-\frac{(0,5 b-\Delta)^{2}}{2 b} \\
& D p=\Delta+\frac{(0,5 b-\Delta)^{2}}{2 b} \\
& E s=\frac{E d}{(1-\Delta)} \\
& G A=0,5+\frac{\Delta}{b}
\end{aligned}
$$

em que GA é o grau de adequação.

\subsection{Estatistica descritiva}

Os parâmetros estatísticos que descrevem um conjunto de dados podem ser divididos em três classes: (a) de tendência ou posição central, (b) de dispersão e (c) de assimetria e curtose (Spiegel, 1993). 
Existem vários parâmetros de tendência ou posição central, cada um mais apropriado para cada circunstância. $\mathrm{O}$ mais útil é a média aritmética ou simplesmente média (Webster \& Oliver, 1990).

A média é o parâmetro mais conhecido e utilizado na estatística básica, devido, principalmente, à simplicidade de sua obtenção e às fortes propriedades matemáticas a ela inerentes, que permitem sua utilização em problemas tanto teóricos como práticos (lemma, 1992). No entanto, segundo esse autor, em certos casos a média pode não ser o parâmetro mais adequado para descrever um conjunto de dados, devido, entre outros casos, à existência de valores extremos ou discrepantes.

Outro parâmetro de tendência central é a mediana, que representa o valor central da variável quando as observações são classificadas em ordem crescente. Portanto, a quantidade de valores menores e maiores que a mediana são iguais. Matematicamente a mediana é menos tratável que a média, mas apresenta a vantagem de ser menos sensivel a valores extremos (Webster \& Oliver, 1990).

A moda de um conjunto de dados é o valor que ocorre com a maior freqüência, podendo não existir e, mesmo que exista, não ser única (Spiegel, 1993).

Em algumas situações pode-se ficar em dúvida sobre qual parâmetro de tendência central deve ser utilizado para descrever um conjunto de dados. lemma (1992) sugere alguns critérios que fornecem uma idéia inicial sobre qual dessas medidas se deve utilizar. Segundo esse autor, a média deve ser escolhida quando: (i) é necessário o tratamento matemático; (ii) os dados se distribuem, ao menos aproximadamente, de forma simétrica; (iii) for necessário obter posteriormente outros parâmetros a partir da média (variância, desvio padrão, etc). Deve-se escolher a mediana quando: (i) há valores discrepantes que podem "distorcer" a média; (ii) deseja-se conhecer o ponto central exato da distribuição; (iii) a distribuição dos dados é muito assimétrica. A moda deve ser escolhida quando: (i) a medida de interesse é o ponto mais típico dos dados; 
(ii) necessita-se apenas de uma rápida idéia sobre a tendência central dos dados.

Geralmente, as medidas de tendência central são insuficientes para descrever plenamente um conjunto de dados, sendo necessário utilizar as medidas de dispersão para enriquecer essa descrição.

Assim como as medidas de posição, as de dispersão podem ser representadas por várias estatísticas como a amplitude total, a amplitude interquartílica e o desvio padrão. Desses, o desvio padrão e o seu quadrado, a variância, são os de mais utilidade (Webster \& Oliver, 1990).

Segundo lemma (1992), a variância é um parâmetro com propriedades excelentes e muito desejáveis nas aplicaçōes teóricas. No entanto, como suas unidades são apresentadas ao quadrado, gerou insatisfação dos usuários que tratam de problemas práticos e motivou a definição de um novo parâmetro, 0 desvio padrão.

Além da posição e da dispersão, algumas vezes deseja-se descrever outras carecterísticas da distribuição dos dados, em particular seu grau de assimetria e de achatamento ou curtose. Essas estatísticas são derivadas, respectivamente, do terceiro e do quarto momentos centrados na média (Webster \& Oliver, 1990).

A assimetria é o grau de desvio ou afastamento da simetria de uma distribuição. Se a curva de freqüência de uma distribuição tem o ramo mais longo à direita, em direção a valores mais positivos, diz-se que a distribuição tem assimetria positiva. Se é o inverso que ocorre, diz-se que tem assimetria negativa (Spiegel, 1993).

Em uma distribuição com assimetria positiva, a média é maior que a mediana e esta maior que a moda. Se a assimetria for negativa, a média será menor que a mediana e esta menor que a média. Nas curvas simétricas, tanto média, quanto mediana e moda são coincidentes (Assis et al. 1996).

Uma medida importante de assimetria utiliza o terceiro momento centrado na média $\left(m_{3}\right)$, expressa sob forma adimensional (Spiegel, 1993): 


$$
a_{3}=\frac{m_{3}}{s^{3}}
$$

em que $a_{3}$ é o coeficiente do momento de assimetria e s é o desvio padrão dos dados.

Segundo Beiguelman (1994), para investigar a assimetria de uma distribuição unimodal Fischer $(1958)^{1}$ propôs um coeficiente $\left(g_{1}\right)$, função de uma quantidade $k_{3}$ e do cubo do desvio padrão:

$$
g_{1}=\frac{k_{3}}{s^{3}}
$$

sendo:

$$
k_{3}=\frac{m_{3} n^{2}}{(n-1)(n-2)}
$$

em que n é o número de dados da amostra.

As medidas de assimetria, quando expressas de forma adimensional, indicam o tipo de desvio da simetria da distribuição. Assim, duas distribuições com assimetria positiva e negativa apresentarão, respectivamente, coeficientes maior e menor que zero. Uma curva perfeitamente simétrica apresentará coeficiente de assimetria nulo.

De acordo com Isaaks \& Srivastava (1989), o coeficiente de assimetria é mais sensível a valores extremos do que a média e o desvio padrão, uma vez que um único valor pode influenciar fortemente o coeficiente de assimetria, pois os desvios entre cada valor e a média são elevados à terceira potência.

- A qurtose é uma medida do grau de achatamento da curva de distribuição de probabilidade, definida pelo quarto momento centrado na média

\footnotetext{
${ }^{1}$ FISCHER, R.A. Statistical methods for research workers. 13a ed. rev., Hafner Publ. Inc., New York,
} 1958. 
(Assis et al., 1996). Distribuições com picos relativamente altos são denominadas leptocúrticas, enquanto aquelas que tem o topo achatado são chamadas de platicúrticas. A distribuição normal, que não é muito pontiaguda nem achatada, é denominada mesocúrtica (Spiegel, 1993).

Uma medida de curtose baseada no quarto momento centrado na média $\left(m_{4}\right)$, expressa sob forma adimensional, é definida por (Spiegel, 1993):

$$
a_{4}=\frac{m_{4}}{s^{4}}
$$

em que $a_{4}$ é o coeficiente do momento de curtose, que será igual a três em uma distribuição perfeitamente normal.

Segundo Beiguelman (1994), para investigar o tipo de curtose Fisher (1958) elaborou um coeficiente $\left(g_{2}\right)$ obtido pela razão entre uma quantidade $k_{4}$ e a quarta potência do desvio padrão:

$$
g_{2}=\frac{k_{4}}{s^{4}}
$$

sendo:

$$
k_{4}=\frac{m_{4} n^{2}(n+1)-3(n-1)^{3}(s)^{4}}{(n-1)(n-2)(n-3)}
$$

O coeficiente $g_{2}$ será zero para a distibuição normal. Quando este coeficiente for positivo, indicará uma distribuição relativamente em cume e quando negativo indicará uma distribuição relativamente plana.

Para utilização da média aritmética como medida de posição representativa de um conjunto de dados, deve-se comprovar a independência entre observações e distribuição normal dos valores. 


\subsection{Distribuição normal}

A distribuição normal, também denominada de curva normal ou de gauss, é a distribuição de probabilidade contínua mais importante e utilizada (Spiegel, 1993). Conforme Assis et al. (1996), sua importância resulta do fato de que muitas técnicas estatísticas, como análise de variância, de regressão e alguns testes de hipótese assumem e exigem a normalidade dos dados.

Com base na definição teórica, a maior parte das variáveis hidrológicas não podem ter distribuição normal, pois o intervalo de variação de qualquer variável aleatória normalmente distribuída situa-se no campo dos números reais, de menos a mais infinito (Haan, 1994). Assim, variáveis que não apresentem valores negativos, como a precipitação pluviométrica e vazões, rigorosamente, não poderiam apresentar distribuição gaussiana. Entretanto, quando a média de uma variável aleatória for de três a quatro vezes maior que seu desvio padrão, a probabilidade dessa variável apresentar valores negativos é muito pequena e muitas vezes pode ser desprezada.

A função densidade de probabilidade da distribuição normal é definida pela expressão (Spiegel, 1993 e Assis et al., 1996):

$$
f(x)=\frac{1}{\sigma \sqrt{2 \pi}} e^{-\frac{(x-\mu)^{2}}{2 \sigma^{2}}}
$$

em que $f(x)$ é a freqüência teórica da variável aleatória $x, \mu$ e $\sigma$ são, respectivamente, a média e desvio padrão da população.

A probabilidade da variável $x$ ser menor ou igual a um determinado valor a pode ser estimada pela expressão (Assis et al., 1996): 


$$
F(x)=\frac{1}{\sigma \sqrt{2 \pi}} \int_{-\infty}^{a} e^{-\frac{(x-\mu)^{2}}{2 \sigma^{2}}} d x
$$

em que $F(x)$ é a função cumulativa de probabilidade.

O gráfico da função densidade de uma variável normal tem a forma de um sino e é simétrico em relação à média. Para uma mesma média, se o desvio padrão da distribuição for relativamente grande, o gráfico tende a ser achatado, enquanto se o desvio padrão for pequeno, o gráfico tende a ser mais pontiagudo.

A normalidade de uma distribuição pode ser avaliada por testes não paramétricos come o qui-quadrado e Kolmogorov-Smirnov (Campos, 1983 e Assis et al., 1996). O ajuste pode também ser avaliado pelos coeficientes de assimetria e de curtose, utilizando-se testes de hipóteses para verificar se os referidos coeficientes diferem estatisticamente dos valores ideais de uma distribuição normal.

Para verificar se os coeficientes de assimeria $\left(g_{1}\right)$ e de curtose $\left(g_{2}\right)$ se desviam significativamente de zero e, portanto da normalidade, Beiguelman (1994) apresenta um teste em que $g_{1}$ e $g_{2}$ são divididos pelos respectivos erros padrão ( $s_{g 1}$ e $s_{g 2}$ ), obtendo-se um " $t$ " que deve ser comparado a um "t "crítico com infinitos graus de liberdade.

$$
\begin{gathered}
s_{g 1}=\sqrt{\frac{6 n(n-1)}{(n-2)(n-1)(n+3)}} \\
s_{g 2}=\sqrt{\frac{24 n(n-1)^{2}}{(n-3)(n-2)(n+3)(n+5)}}
\end{gathered}
$$

Um valor de $t$ calculado igual ou maior do que 1,96 (valor de $t$ ao nivel de significância de 5\%) indicará que os coeficientes são estatisticamente maior 
do que zero e, portanto, apresentam assimetria positiva e distribuição leptocúrtica. Por outro lado, valores de $t$ calculado iguais ou menores que 1,96 , indicarão assimetria negativa e distribuição platicúrtica.

Dois testes estatísticos são largamente utilizados para se julgar se uma distribuição de probabilidade se ajusta bem a um conjunto de dados sob análise: o teste qui-quadrado e o teste de Kolmogorov-Smirnov (Assis et al., 1996).

A distribuição normal é totalmente determinada por intermédio de dois parâmetros, que são a média e o desvio padrão (Beiguelman, 1994). Nesta distribuição, a média é, simultaneamente, o valor mais freqüente (moda) e o ponto central da distribuição (mediana).

\subsection{Geoestatística}

As técnicas estatísticas baseadas na casualização e na repetição não consideram a influência da localização dos pontos de amostragem. A representação do comportamento de uma propriedade através de medidas como a média e o desvio padrão, exige que as amostras tenham distribuição normal e que não apresentem dependência espacial, ou seja, que as variações de um local para o outro sejam aleatórias

Quando se pretende identificar a existência e quantificar a correlação espacial entre os pontos amostrais, deve-se utilizar as técnicas geoestatísticas, desenvolvidas com base na teoria das variáveis regionalizadas (Matheron ${ }^{2}$ (1963) e Matheron ${ }^{3}$ (1971), citados por Vieira et al. (1983).

Uma variável regionalizada é uma função espacial numérica que varia de um local para outro, com uma continuidade ou dependência espacial, cuja

${ }^{2}$ MATHERON, G. Principles of geostatistics. Economic Geology, v. 58, p. 1246-1266, 1963.

${ }^{3}$ MATHERON, G. The teory of regionalized variables and its application. Les Cahiers du Centre de Moffologie Mathematique. Fas. 5. C. G. Fontainebleau, 1971. 
variação não pode ser representada por uma função matemática simples (Vieira, 1998).

De acordo com Vieira (1998), um dos métodos mais antigos de se estimar a dependência no espaço de amostras vizinhas é através da autocorrelação, principalmente para medições efetuadas em uma linha reta ou transeto. Porém, quando as amostras forem coletadas nas duas dimensões e deseja-se confeccionar mapas de isolinhas, será preciso usar uma ferramenta mais adequada para medir a dependência espacial, ou seja, o semivariograma.

O semivariograma é definido pela seguinte expressão:

$$
\gamma(h)=\frac{1}{2} E\left[Z\left(x_{i}-Z\left(x_{i}+h\right)\right]^{2}\right.
$$

e pode ser estimado através de:

$$
\hat{\gamma}(h)=\frac{1}{2 N(h)} \sum_{i=1}^{N(h)}\left[Z\left(x_{i}\right)-Z\left(x_{i}+h\right]^{2}\right.
$$

em que $N(h)$ é o número de pares de valores medidos $Z\left(x_{i}\right)$ e $Z\left(x_{i}+h\right)$, separados por um vetor $h$.

Idealmente, há um incremento das diferenças $\left\{Z\left(x_{i}\right)-Z\left(x_{i}+h\right)\right.$ com 0 aumento de $h$, ou seja, é esperado que medidas localizadas próximas sejam mais parecidas entre si do que as separadas por distâncias maiores.

Por definição, $\gamma(0)$ deve ser nulo. Entretanto, na prática, à medida que $\mathrm{h}$ tende para zero, $\gamma(\mathrm{h})$ se aproxima de um valor positivo chamado efeito pepita. $O$ valor do efeito pepita identifica a descontinuidade do semivariograma para distâncias menores do que as avaliadas. Parte dessa descontinuidade pode ser também devido a erros de medição, mas é impossivel destinguir o efeito dos erros de medição e da variabilidade a uma escala inferior a da amostrada (Vieira, 1998). 
Com o aumento de $h$, é esperado que $\gamma(h)$ também aumente até atingir um valor máximo no qual se estabiliza, denominado de patama, que é aproximadamente igual à variância dos dados.

A distância na qual $\gamma(h)$ atinge o patamar é chamada de alcance, que representa o limite de dependência espacial. Assim, medições realizadas a distâncias maiores que o alcance serão aleatórias e independentes entre si. Amostras separadas por distâncias menores do que o alcance, serão espacialmente correlacionadas e permitirão que se façam interpolações para espaçamentos menores do que os amostrados (Vieira, 1998).

Cambardella et al. (1994) classificaram o grau de dependência espacial de um atributo em função da relação entre o efeito pepita e o patamar. Segundo esses autores, semivariogramas que apresentam efeito pepita menor ou igual a $25 \%$ do patamar apresentam forte dependência espacial. A dependência espacial será moderada quando essa relação variar de 25 a 75 \% e será fraca quando o efeito pepita for superior a $75 \%$ do patamar.

Se o semivariograma for igual ao patamar para qualquer valor de $h$, então tem-se um efeito pepita puro ou ausência total de dependência espacial. Isto significa que o alcance é inferior ao menor espaçamento entre amostras e, portanto, tem-se uma distribuição espacial completamente aleatória (Vieira, 1998).

\subsection{Modelos de semivariograma}

Basicamente, são utilizados quatro modelos teóricos para ajustar os semivariogramas experimentais (Vieira et al., 1983): 
a) Modelo linear

$$
\begin{array}{ll}
\gamma(\mathrm{h})=\mathrm{C}_{0}+\mathrm{C}_{1} \frac{\mathrm{h}}{\mathrm{a}} & 0 \leq \mathrm{h} \leq \mathrm{a} \\
\gamma(\mathrm{h})=\mathrm{C}_{0}+\mathrm{C}_{1} & \mathrm{~h}>\mathrm{a}
\end{array}
$$

em que $\mathrm{h}$ é a distância dos pares de dados, $C_{0}$ é o efeito pepita, $C_{1}$ é o componente estrutural, $C_{0}+C_{1}$ é o patamar e a é o alcance.

b) Modelo esférico

$$
\begin{array}{ll}
\gamma(h)=C_{0}+C_{1}\left[\frac{3}{2}\left(\frac{h}{a}\right)-\frac{1}{2}\left(\frac{h}{a}\right)^{3}\right] & 0 \leq h \leq a \\
\gamma(h)=C_{0}+C_{1} & h>a
\end{array}
$$

c) Modelo exponencial

$$
\gamma(h)=C_{0}+C_{1}\left[1-\exp \left(\frac{-3 h}{a}\right)\right] \quad 0 \leq h \leq d
$$

em que d é a máxima distância em que o semivariograma é definido.

c) Modelo gaussiano

$$
\gamma(h)=C_{0}+C_{1}\left[1-\exp \left(-3\left(\frac{h}{a}\right)^{2}\right)\right] \quad 0 \leq h \leq d
$$


Uma característica importante dos modelos exponencial e gaussiano é que ambos atingem o patamar apenas assintoticamente, ao contrário dos modelos linear e esférico.

\subsection{Interpolação por krigagem}

Na maioria das situações o principal interesse da análise geoestatística é a estimativa de valores em locais não amostrados, prática que possibilita um maior detalhamento da área. Conhecido o semivariograma de um atributo, e havendo dependência espacial entre as amostras, podem-se interpolar valores em qualquer posição da área avaliada pelo método de interpolação denominado de krigagem.

$\mathrm{Na}$ técnica de krigagem, como as observações são dependentes até a uma certa distância (alcance), os vizinhos do ponto a ser predito são utilizados para obter a estimativa, atribuindo-se pesos aos mesmos:

$$
\hat{Z}\left(x_{0}\right)=\sum_{i=1}^{n} \lambda_{i} Z\left(x_{i}\right)
$$

em que: $\hat{Z}\left(x_{0}\right)$ é o valor estimado para o ponto $x_{0}, n$ é o número de vizinhos utilizados na estimativa e $\lambda_{i}$ é o peso atribuído a cada valor observado $Z\left(x_{i}\right)$.

A equação (32) não é exclusiva da krigagem. No entanto, a forma de atribuição dos pesos $\left(\lambda_{\mathrm{i}}\right)$ diferencia a krigagem dos outros métodos de interpolação.

De acordo com Ribeiro Junior (1995), no processo de krigagem não se utiliza a distância euclidiana entre os pontos, mas uma "distância estatística" que expressa tanto a distância como a estrutura de variabilidade (covariância ou semivariância). Não apenas a distância dos vizinhos ao ponto a ser 
estimado é considerado, mas também as distâncias entre os mesmos influencia a distribuição dos pesos. Assim, vizinhos agrupados têm importância individual relativamente menor do que aqueles isolados.

No método da krigagem, os pesos são atribuídos de acordo com a variabilidade espacial expressa no semivariograma, sendo esse estimador nada mais do que uma média móvel ponderada (Vieira, 1998). No entanto, o que torna a krigagem um interpolador ótimo é a maneira como os pesos são distribuídos. Para que o estimador seja ótimo, o mesmo não pode ser tendenciado e deve ter variância mínima:

$$
\begin{gathered}
E\left\{\hat{Z}\left(x_{0}\right)-Z\left(x_{0}\right)\right\}=0 \\
\text { Variância }\left\{\hat{Z}\left(x_{0}\right)-Z\left(x_{0}\right)\right\}=E\left\{\left[\hat{Z}\left(x_{0}\right)-Z\left(x_{0}\right)\right]\right\}^{2}=\text { mínima }
\end{gathered}
$$

As equações (32) e (34) representam matematicamente as condições de não tendência e de variância mínima, respectivamente, que devem ser satisfeitas (Vieira et al., 1983). A condição de não tendência significa que, em média, a diferença entre valores estimados e medidos para o mesmo ponto deve ser nula. A condição de variância mínima significa que, embora possam existir diferenças ponto por ponto entre o valor medido e o estimado, essas diferenças devem ser mínimas.

A krigagem apresenta todas as qualidades desejáveis de um método estatístico, por ser não tendenciosa, apresentar variância mínima e possibilitar que se conheça a variância da estimativa (Webster \& Olivier, 1990). Por esse motivo, muitas vezes a técnica de krigagem é denominada "BLUE", iniciais de "Best Linear Unbiased Estimation" ("melhor estimador linear não tendencioso"). 


\subsection{Validação cruzada}

No ajuste de semivariogramas experimentais, sempre existe um certo grau de incerteza sobre as hipóteses de estacionaridade assumidas, modelos selecionados e parâmetros ajustados. Esta incerteza representa o erro da estimativa que pode ser avaliado pelo procedimento denominado de validação cruzada (Isaaks \& Srivastava, 1989) ou "jack-knifing” (Vieira, 1998). Nessa técnica, cada ponto medido é excluído e seu valor estimado com os dados restantes. Com os pares de valores medidos e estimados de cada ponto amostral, pode-se avaliar a qualidade dos ajustes dos semivariogramas pelos seguintes procedimentos (Vieira, 1997 e 1998):

a) Regressão linear

Com os pares de valores medidos $Z\left(x_{i}\right)$ e estimados $\hat{Z}\left(x_{i}\right)$ de cada ponto de amostragem calcula-se a regressão linear:

$$
\hat{Z}\left(x_{i}\right)=a+b Z\left(x_{i}\right)
$$

em que a e b são, respectivamente, os coeficientes linear e angular da regressão.

Se todos os valores estimados fossem idênticos aos medidos, o valor de a seria nulo e o de b unitário. Nessa situação teórica ideal, o coeficiente de correlação seria 100 \% e o gráfico de dispersão entre os valores estimados e medidos seria uma série de pontos exatamente sobre a reta 1:1.

b) Erro absoluto

$O$ erro absoluto entre os valores medidos e estimados, $E A\left(x_{i}\right)$, é definido por:

$$
E A\left(x_{i}\right)=\hat{Z}\left(x_{i}\right)-Z\left(x_{i}\right)
$$


Aplicando-se as condições de não tendência e variância mínima na equação (33), obtem-se:

$$
\overline{E A}=E\left\{E A\left(x_{i}\right)\right\}=E\left\{\hat{Z}\left(x_{i}\right)-Z\left(x_{i}\right)\right\}=0
$$

e

$$
\operatorname{Var}(E A)=E\left\{\left(\hat{Z}\left(x_{i}\right)-Z\left(x_{i}\right)\right)^{2}\right\}=\text { mínima }
$$

em que $\overline{E A}$ e $\operatorname{Var}(E A)$ são, respectivamente, a média e a variância do erro absoluto.

A condição exigida na equação (35) torna-se bastante difícil de ser verificada devido a subjetividade na definição da variância mínima.

c) Erro reduzido

No cálculo de $\hat{Z}\left(x_{i}\right)$ sempre se tem a variância da estimativa $s^{2}{ }_{k}\left(x_{i}\right)$. Assim, o erro reduzido (ER) pode ser defido como:

$$
\operatorname{ER}\left(x_{i}\right)=\frac{\left(\hat{Z}(x)_{i}-Z\left(x_{i}\right)\right)}{s_{k}\left(x_{i}\right)}
$$

A divisão pelo desvio padrão da estimativa $\left(s_{k}\right)$ faz com que $\operatorname{ER}\left(x_{i}\right)$ seja adimensional. Aplicando-se as condições de não tendência e variância mínima, obtem-se:

$$
\overline{E R}=E\left\{\left(E R\left(x_{i}\right)\right\}=E\left\{\frac{\left(\hat{Z}\left(x_{i}\right)-Z\left(x_{i}\right)\right)}{s_{k}\left(x_{i}\right)}\right\}=0\right.
$$




$$
\operatorname{Var}(E R)=E\left\{\frac{\left(\hat{Z}\left(x_{i}\right)-Z\left(x_{i}\right)\right)}{s_{k}\left(x_{0}\right)}\right\}^{2}=1
$$

As expressões (37) e (38) têm valores fixos ideais (respectivamente, 0 e 1) e são adimensionais, o que facilita o julgamento e análise dos ajustes de semivariogramas. Quanto mais próximos dos valores ideais, melhor será o ajuste dos semivariogramas.

\subsection{Estudos sobre variabilidade do armazenamento da água no solo}

O coeficente de variação dos atributos do solo pode oscilar de valores menores que $10 \%$ a superiores a $1.000 \%$ (Warrick \& Nielsen, 1980) e, segundo esses autores, os valores de umidade a uma determinada tensão geralmente apresentam coeficientes de variação da ordem de 10 a $50 \%$.

Estudando a variabilidade dos pontos experimentais de curvas de retenção da água no solo, desconsiderando a dependência espacial das amostras, Moraes et al. (1993b) verificaram que os dados de umidade do solo nas tensões menores (0,5 e $1 \mathrm{kPa})$ apresentaram distribuição com assimetria exagerada e que os valores de umidade do solo em todas tensões avaliadas apresentaram baixo coeficiente de variação ( $\leq 10 \%)$.

A variabilidade espacial de onze atributos do solo, incluindo dados de umidade nas tensões 10 e $1500 \mathrm{kPa}$, foi avaliada por Gajem et al. (1981). Utilizando espaçamento amostral de $2 \mathrm{~m}$ de quatros transeções, os autores indentificaram dependência espacial nos dados de umidade do solo, com alcance oscilarando de 10 a valores superiores a $46 \mathrm{~m}$.

Vauclin et al. (1983) verificaram que os dados de umidade do solo na tensão $33 \mathrm{kPa}$ apresentaram dependência espacial, com alcance de $26 \mathrm{~m}$ e efeito pepita em torno de $23 \%$ do valor do patamar. 
A variabilidade espacial do armazenamento de água no solo de um latossolo vermelho-amarelo nas tensões 10, 33 e $1500 \mathrm{kPa}$, em duas profundidades, foi avaliado por Carvalho et al. (1992). Os autores observaram dependência espacial nos dados de umidade do solo que apresentaram anisotropia, valores de alcance de 25 a $80 \mathrm{~m}$ e efeito pepita da ordem de 10 a $33 \%$ da variação total.

Folegatti (1996), avaliando o armazenamento hídrico de um solo siltoso, observou estrutura de variação espacial com alcance de $10 \mathrm{~m}$, patamar crescente com o secamento do solo e efeito pepita em torno de $20 \%$ da variação total.

Estudando um podzólico vermelho escuro, Gonçalves (1997) verificou que a umidade do solo nas oito tensões avaliadas apresentou dependência espacial. Quanto maior foi a tensão, maior também foi a dependência espacial dos valores de umidade do solo. Na faixa monitorada pelo tensiômetro, a dependência espacial pôde ser descrita por um único semivariograma, com alcance de $24 \mathrm{~m}$ e efeito pepita de $35 \%$ da variação total. Para as tensões maiores, o efeito pepita foi reduzido para valores da ordem de $20 \%$ do patamar.

Shouse et al. (1995), estudando a variabidade espacial dos parâmetros do modelo de van Genuthten ajustados a curvas de retenção de água no solo, observou que todos os parâmetros do modelo apresentaram dependência espacial com alcance de 12 a 26 m e efeito pepita da ordem de 36 a $79 \%$ da variação total. Mallants et (1996) também indetificaram dependência espacial nos parâmetros do modelo de van Genuchten, com alcance de 2,3 a 4,5 m e relação efeito pepital patamar oscilando de 26 a $71 \%$. 


\section{MATERIAL E MÉTODOS}

\subsection{Local}

O ensaio foi realizado na estação experimental do Centro de Pesquisa Agropecuária do Oeste (EMBRAPA/CPAO) em Dourados, MS, cujas coordenadas geográficas são: $22^{\circ} 14^{\prime}$ de latitude sul, $54^{\circ} 49^{\prime}$ de longitude oeste e altitude média de $452 \mathrm{~m}$.

$\mathrm{Na}$ área em que o ensaio foi implantado desde maio de 1995 vem sendo conduzido o projeto de pesquisa da EMBRAPA/CPAO "Impacto ambiental de sistemas intensivos e integrados de produção de grãos e carne bovina na região Oeste do Brasil", que avalia sistemas de rotação de culturas. Em abril de 1997 essa área foi semeada com trigo (Triticum aestivum, L.), cultivar BR-40, no Sistema Plantio Direto em sucessão a soja, cultivada no verão de 1996.

O clima da região é do tipo Cwa de Köppen (mesotérmico úmido, com verão chuvoso e inverno seco). De acordo com Martorano et al. (1996), a precipitação média anual da região situa-se em torno de $1400 \mathrm{~mm}$, com um período mais chuvoso (de outubro a maio) e outro menos (de junho a setembro). A distribuição sazonal das temperaturas também define duas estações distintas: de outubro a abril (com médias mensais entre 23,1 a $25,4^{\circ} \mathrm{C}$ ) e de maio a setembro (com médias de 16,9 a $21,0^{\circ} \mathrm{C}$ ).

A área experimental apresenta relevo suave, com declividade média de aproximadamente $2 \%$ (Figura 2 ). 
(a)

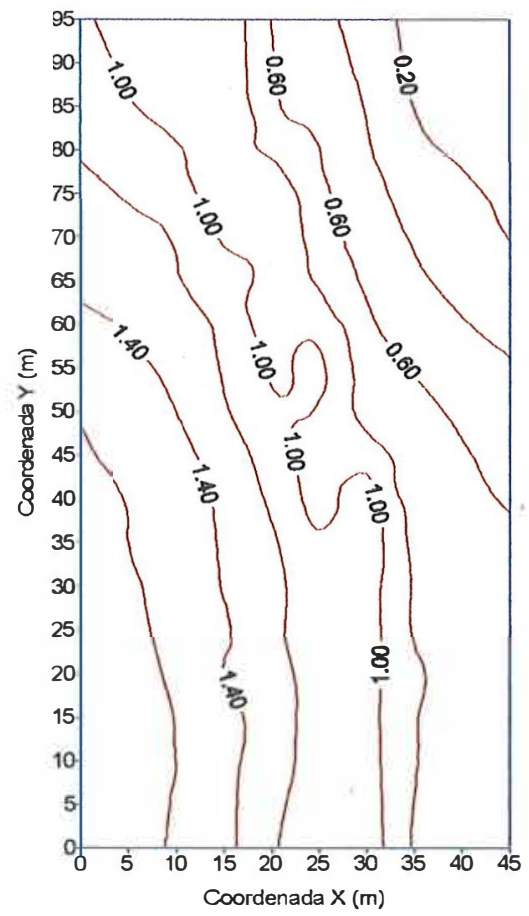

(b)

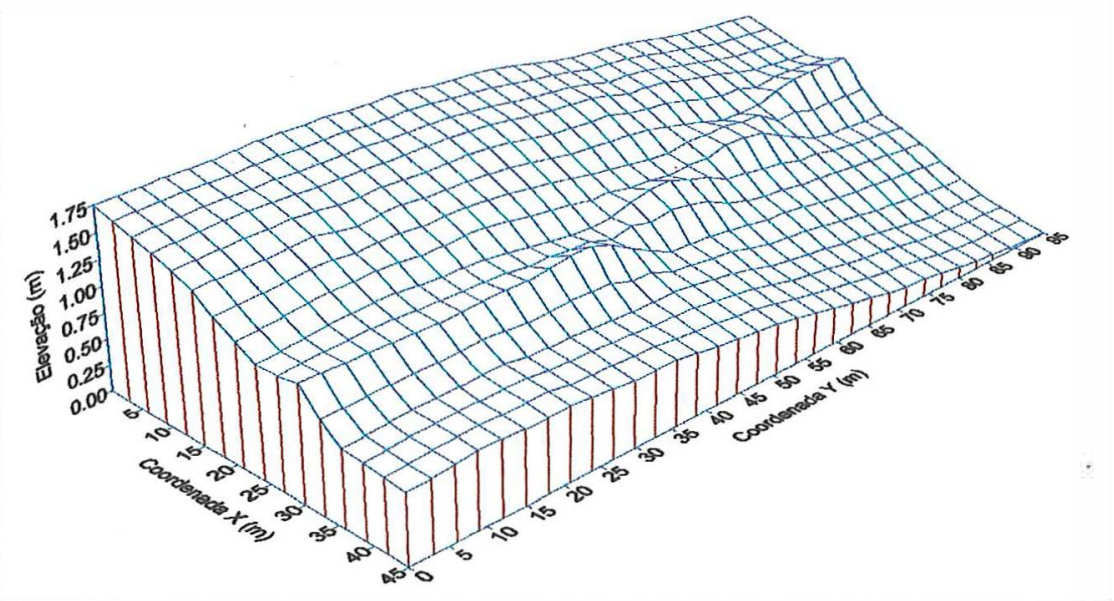

Figura 2. Mapas plani-altimétrico.(a) e tridimensional (b) da área do experimento.

O solo do local é classificado como latossolo roxo álico epieutrófico muito argiloso e constitui-se numa das principais unidades pedológicas da região. De acordo com Oliveira et al. (1992), a classe latossolo 
roxo é formada por solos profundos, porosos, bem permeáveis, mesmo quando muito argilosos, que situam-se em relevo normalmente suave ondulado, com declividade que raramente ultrapassa a $7 \%$. No Mato Grosso do Sul essa classe de solo ocupa uma extensa área, que se prolonga desde o norte de Campo Grande até o sul do Estado.

\subsection{Esquema experimental}

A área do experimento tinha $3.600 \mathrm{~m}^{2}(40 \mathrm{~m}$ por $90 \mathrm{~m})$ e foi demarcada em 29/04/97. Foram locados 144 pontos de amostragem com espaçamento regular de $5 \mathrm{~m}$, resultando numa malha retangular de 8 colunas e 18 linhas (Figura 3).

\subsection{Amostragens e determinações}

\subsubsection{Curvas de retenção e densidade do solo}

As curvas de retenção foram determinadas por secagem no laboratório de solos da EMBRAPACPAO. Para coleta das amostras indeformadas, realizada em 21/05/97, foram abertas mini-trincheiras de 0,30 $\mathrm{m} \times 0,60 \mathrm{~m}$ de área e $0,13 \mathrm{~m}$ de profundidade, em cada ponto amostral. As amostras foram coletadas com anéis de 0,055 $\mathrm{m}$ de diâmetro e 0,040 $\mathrm{m}$ de altura, utilizando-se um amostrador tipo Uhdland.

Após a coleta, as amostras foram aparadas para que suas faces ficassem planas e coincidentes com a altura do cilindro. Posteriormente, uma das faces do cilindro foi coberta com um tecido sintético permeável, a fim de evitar perdas de solo. 


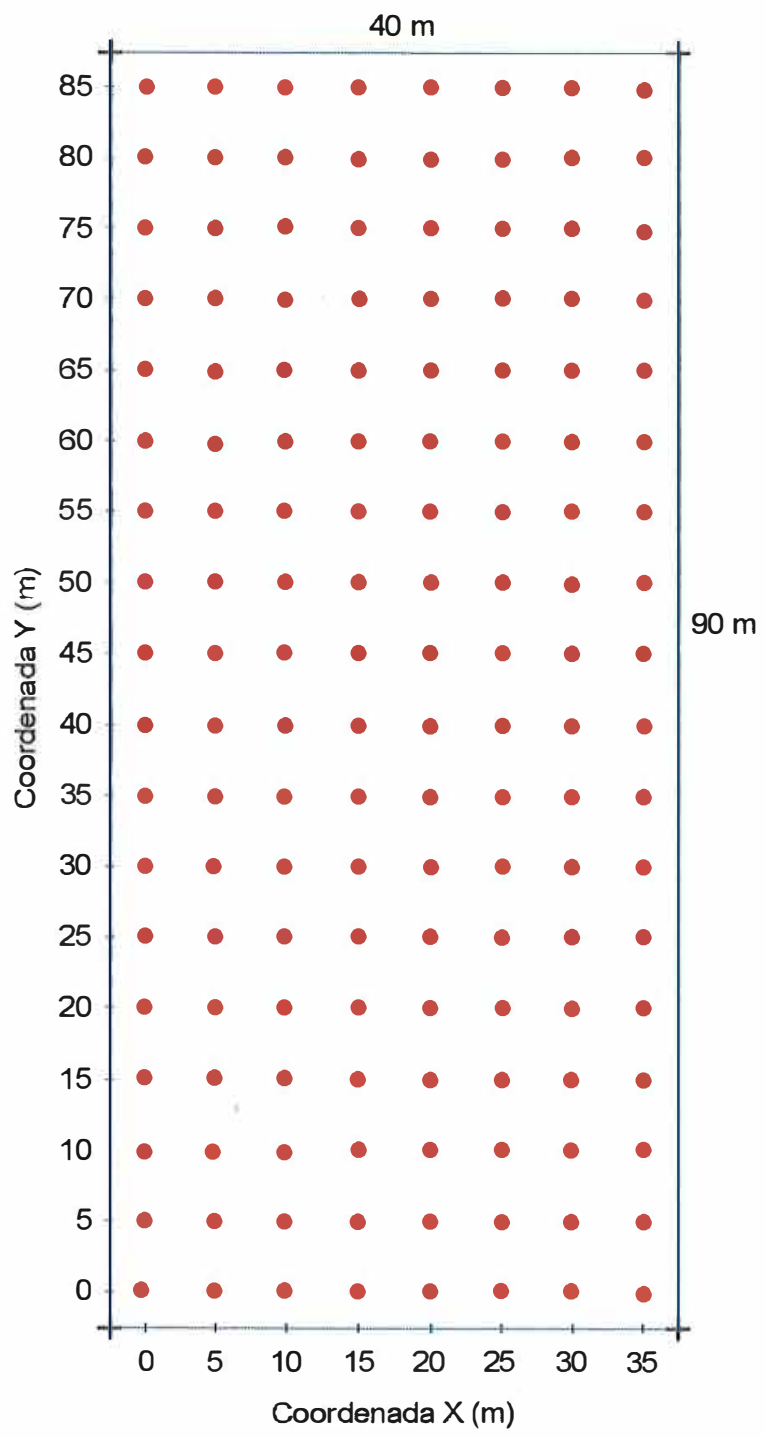

Figura 3. Esquema experimental com a localização dos pontos de amostragem de solo.

As amostras, após atingir a saturação natural, conforme sugere (Klute, 1986), foram submetidas às tensões 10; 33; 50; 100, 500 e $1500 \mathrm{kPa}$ utilizando-se câmara de pressão de Richards, conforme procedimento de rotina utilizado pela EMBRAPA/CPAO (EMBRAPA, 1997).

O momento de equilíbrio foi considerado quando cessou a drenagem, verificado visualmente pela ausência de gotas de água. 
Após serem submetidas à tensão de $1500 \mathrm{kPa}$ e pesadas, as amostras foram conduzidas à estufa onde permaneceram por 24 horas a $105^{\circ} \mathrm{C}$. Posteriormente, foram novamente pesadas para determinação da densidade do solo (EMBRAPA, 1997), sendo as umidades volumétricas obtidas pelo produto das umidades a base de massa e suas respectivas densidades.

\subsubsection{Densidade de partículas e umidade de saturação}

As amostras deformadas foram retiradas em cada ponto amostral a 0,15 $m$ de profundidade, com um trado holandês pequeno de $0,08 \mathrm{~m}$ de diâmetro.

Posteriormente, foram encaminhadas ao laboratório de Ciências do Solo da Escola Superior de Agricultura "Luiz de Queiroz" (ESALQ/USP) para determinação da densidade de partículas pelo método do balão volumétrico (EMBRAPA, 1997).

A umidade de saturação $\left(\theta_{\mathrm{s}}\right)$ foi estimada pela expressão:

$$
\theta_{s}=\left(1-\frac{D_{s}}{D_{p}}\right) 100
$$

em que $D_{s}$ é a densidade do solo $\left(\mathrm{kg} \cdot \mathrm{m}^{-3}\right)$ e $D_{p}$ é a densidade de partículas $\left(\mathrm{kg} \cdot \mathrm{m}^{-3}\right)$.

\subsubsection{Lâmina aplicada}

A área experimental possuia um sistema de irrigação por aspersão autopropelido, dotado de um aspersor do tipo canhão com mecanismo de 
reversão lenta, bocal com diâmetro de $18,5 \mathrm{~mm}$, operando com 0,5 $\mathrm{MPa}$ de pressão de serviço e com cerca de $50 \%$ da sua velocidade máxima.

O padrão de aplicação de água desse equipamento foi determinado com base nas lâminas coletadas em um ensaio realizado em 01/08/97.

As lâminas de irrigação foram coletadas em cada ponto amostral por pluviômetros com seção de coleta de $50,3 \mathrm{~cm}^{2}$, instalados a $0,60 \mathrm{~m}$ da superfície, livres de qualquer interferência da vegetação. $A$ velocidade do vento durante a irrigação foi determinada com um anemômetro totalizador de conchas, instalado a $2 \mathrm{~m}$ de altura.

\subsection{Ajuste das curvas de retenção}

Os seis pares de umidade e tensão de cada amostra foram utilizados para ajustar as curvas de retenção ao modelo de van Genuchten (1980):

$$
\theta_{i}=\theta_{r}+\frac{\left(\theta_{s}-\theta_{r}\right)}{\left[1+\left(\alpha \psi_{i}\right)^{n}\right]^{m}}
$$

em que $\theta_{\mathrm{i}}$ é a umidade volumétrica na tensão $60 \mathrm{kPa}(\%), \theta_{\mathrm{r}}$ é a umidade residual (\%) e $\alpha$, m e n são os parâmetros empíricos.

Os parâmetros do modelo foram determinados pelo programa computacional desenvolvido por Dourado Neto et al. (1990), considerando os seguintes critérios: (i) a umidade residual foi estimada pelo modelo; (ii) a umidade de saturação foi determinada pela expressão (39) e (iii) o parâmetro m foi determinado pela relação linear proposta por Mualen (1976).

0 ajuste do modelo aos dados experimentais foi avaliado individualmente para cada curva de retenção e quando foi considerado 
insatisfatório, utilizou-se a alternativa do programa de também estimar os parâmetros $\mathrm{me} \theta_{\mathrm{s}}$.

Com base nas curvas de retenção ajustadas ao modelo de van Genuchten, determinou-se para cada ponto amostral os valores de umidade do solo na tensão $60 \mathrm{kPa}$, valor recomendado como umidade do solo no momento da irrigação (Recomendações da Comissão Centro-Sul Brasileira de pesquisa de Trigo, 1995).

\subsection{Análises estatísticas}

\subsubsection{Análises descritivas}

Os atributos foram inicialmente analisados por meio da estatística descritiva. Nessa etapa, procurou-se visualizar o comportamento geral dos dados e identificar possiveis valores discrepantes.

As análises descritivas consistiram de:

a) Cálculo de medidas estatísticas

As seguintes medidas estatísticas foram determinadas e analisadas: média, mediana, mínimo, máximo, amplitude total, quartil inferior, quartil superior, amplitude interquartílica, variância, desvio padrão, coeficiente de variação, assimetria e curtose.

b) Análise de distribuição de freqüência

Foram elaborados gráficos de probabilidade normal, que possibilitaram uma avaliação visual da distribuição dos dados. A aderência dos valores à distribuição normal foi verificada pelo teste de Kolmogorov-Smirnov, a 5\% de 
probabilidade (Assis et al. , 1996) e pela análise dos coeficientes de assimetria e curtose, através do teste $t$ (Beilguelman, 1994).

c) Dados discrepantes

A análise dos valores considerados discrepantes ou atípicos foi realizada em duas etapas, seguindo o procedimento apresentado por Libardi et al. (1996), ou seja: (i) identificação de valores extremos (avaliação estatística) e (ii) análise da coerência da avaliação estatística (avaliação física ou visual). Considerou-se como prováveis dados discrepantes valores menores que a diferença entre o quartil inferior e 1,5 vezes a amplitude interquatis ou maior que a soma do quartil superior com 1,5 vezes a amplitude interquartis. Dados que se enquadraram em uma dessas duas situações foram considerados como candidatos a dados discrepantes. A decisão de excluí-los foi tomada após confrontar os candidatos com seus vizinhos mais próximos nos gráficos de distribuição espacial ("postplot"). Nesses gráficos, os valores foram divididos em quatro classes, representadas por diferentes símbolos gráficos, cujos limites foram definidos da seguinte forma: (1) do valor mínimo ao quartil inferior; (2) do quartil inferior à média; (3) da média ao quartil superior e (4) do quartil superior ao valor máximo. Como critério de decisão, estabeleceu-se que as curvas de retenção que possuiam dois ou mais valores considerados discrepantes fossem excluídas.

\subsubsection{Análises geoestatísticas}

As análises geoestatísticas foram utilizadas para avaliar a dependência espacial das umidades do solo nas tensões avaliadas e das lâminas de irrigação. As técnicas geoestatísticas também foram utilizadas para a interpolação de dados e confecção de mapas de isolinhas, quando a dependência espacial foi verificada. 
A existência de estrutura de variabilidade espacial foi avaliada pela análise de semivariogramas "omnidirecionais" determinados pelo método dos momentos ou estimador de Matheron (Vieira et al., 1983 e Vieira, 1998), conforme apresentado na equação (27).

A modelagem da estrutura de variabilidade foi ajustada pelos modelos esféricos, exponencial e gaussiano (Vieira, 1998), respectivamente, pelas equações 29,30 e 31 .

A seleção do modelo teórico e dos parâmetros de ajuste de cada semivariograma foi realizada pela técnica de validação cruzada ou "JackKnifing" (Isaaks \& Srivastava, 1989 e Vieira, 1998). Como critério de decisão considerou-se a variância e a média reduzida (Vieira, 1998). Essa técnica também foi utilizada para definir o número de vizinhos na krigagem.

No ajuste dos semivariogramas, na validação cruzada e nas interpolações por krigagem utilizaram-se os softwares desenvolvidos por Vieira et al. (1983) e o programa Geoeas (Englund \& Sparks, 1988).

Os semivariogramas foram escalonados pela variância visando facilitar as interpretações e as comparações dos padrões de variabilidade dos atributos.

\subsection{Interpolação por krigagem}

Os semivariogramas experimentais dos dados de umidade nas tensões 10 e $60 \mathrm{kPa}$ e de lâmina de irrigação foram utilizados para construir, através da técnica de krigagem, malhas de 35 colunas e 85 linhas separadas por $1 \mathrm{~m}$, totalizando 3.096 pontos. Os valores interpolados e os obtidos por sobreposição dos dados foram utilizados para confeccionar mapas de isolinhas. 


\subsection{Lâmina real necessária}

A lâmina real necessária à cultura do trigo foi determinada pela equação (5) para cada ponto da malha com espaçamento de $1 \times 1 \mathrm{~m}$. Considerou-se como capacidade de campo a umidade do solo no potencial mátrico $-10 \mathrm{kPa}$ (Fietz \& Hernai, 1992) e 0,30 m como profundidade efetiva do sistema radicular do trigo (Doorenbos \& Kassan, 1979).

\subsection{Avaliação da qualidade da irrigação}

A partir dos dados de lâmina real necessária e de lâmina aplicada determinou-se $o$ déficit ou excesso hídrico nos pontos da malha com espaçamento de $1 \times 1 \mathrm{~m}$, que também foram utilizados para confeccionar mapas de isolinhas.

A qualidade da irrigação foi avaliada com base nos valores de lâmina aplicada em cada ponto amostral da malha $1 \times 1 \mathrm{~m}$, considerando duas situações:

a) Armazenamento da água no solo variável: determinou-se o valor do excesso ou déficit hídrico em cada ponto da malha com espaçamento de $1 \times 1 \mathrm{~m}$. A eficiência de distribuição e a drenagem profunda foram determinadas, respectivamente, pelas equações (7) e (8). O grau de adequação foi calculado pela relação do somatório das quadrículas de $1 \mathrm{~m}^{2}$ que receberam, no mínimo, uma lâmina igual à necessária e a área total.

b) Armazenamento da água no solo constante: considerou-se que a lâmina necessária em toda a área era constante e igual à média dos 3.096 pontos. Neste caso, a qualidade da irrigação dependeu unicamente da uniformidade das lâminas e os parâmetros eficiência de distribuição, drenagem profunda e 
grau de adequação foram avaliados pelo modelo linear (Karmeli, 1978), utilizando, respectivamente, as expressões (12), (13) e (15). 


\section{RESULTADOS E DISCUSSÃO}

\subsection{Umidade do solo nas tensões avaliadas da curva de retenção}

$\mathrm{Na}$ Tabela 1 estão apresentadas as estatísticas descritivas das umidades nas tensões avaliadas, antes da identificação e exclusão dos dados discrepantes.

Os coeficientes de variação das umidades foram inferiores a $5 \% \mathrm{em}$ todos os potenciais mátricos e, portanto, podem ser considerados baixos pelo critério de Warrick \& Nielsen (1980). Apresentaram um pequeno crescimento com o aumento da tensão de 50 para $1.500 \mathrm{kPa}$. Essa mesma tendência de crecimento do coeficiente de variação com o aumento das tensões foi verificado por Gonçalves (1997) e, de forma mais nítida, por Shouse et al. (1995) e Mallants et al. (1996).

A pequena dispersão dos valores de umidade também foi expressa pela amplitude interquartílica, que indicou uma grande concentração de dados próximos à média. As relações amplitude interquartílica/amplitude total foram todas inferiores a $22 \%$, ou seja, a participação de $50 \%$ dos dados representou menos de um terço da dispersão total dos valores, evidenciando a grande suscetibilidade da amplitude total a valores extremos.

Em todas as tensões, as pequenas diferenças entre médias e medianas sugerem que as umidades apresentavam distribuições relativamente simétricas. No entanto, analisando-se os gráficos "box-plot" (Figura 4) 
percebe-se que isso de fato não ocorreu, principalmente nos dados de umidade do solo nas tensões 10 e $33 \mathrm{kPa}$, onde observa-se que as distâncias dos quartis superiores aos valores máximos são maiores que entre os quartis inferiores e os valores mínimos. Esses resultados foram confirmados pelo teste $t$ (Beiguelman, 1994) que considerou os coeficientes de assimetria dos valores de umidade nas tensões 10 e $33 \mathrm{kPa}$ como significativamente maiores que zero.

Tabela 1. Estatística descritiva dos dados de umidade volumétrica (\%) nas tensões avaliadas, antes da identificação dos valores discrepantes (144 valores).

\begin{tabular}{lrrrrrr}
\hline Estatística & \multicolumn{7}{c}{ Tensão (kPa) } \\
\cline { 2 - 7 } & \multicolumn{1}{c}{$\mathbf{1 0}$} & $\mathbf{3 3}$ & $\mathbf{5 0}$ & $\mathbf{1 0 0}$ & $\mathbf{5 0 0}$ & $\mathbf{1 5 0 0}$ \\
\hline Média & 41,76 & 39,54 & 38,65 & 37,78 & 36,88 & 36,20 \\
Mediana & 41,65 & 39,60 & 38,80 & 37,90 & 37,00 & 36,30 \\
Mínimo & 38,60 & 36,10 & 34,80 & 33,90 & 33,10 & 31,50 \\
Máximo & 48,10 & 45,00 & 42,60 & 41,70 & 40,90 & 39,90 \\
Amplitude total & 9,50 & 8,90 & 7,80 & 7,80 & 7,80 & 8,40 \\
Quartil inferior & 40,80 & 38,70 & 37,80 & 36,95 & 36,05 & 35,40 \\
Quartil superior & 42,40 & 40,30 & 39,40 & 38,60 & 37,80 & 37,10 \\
Amplitude interquartílica & 1,60 & 1,60 & 1,60 & 1,65 & 1,75 & 1,70 \\
Variância & 2,36 & 1,92 & 1,82 & 1,98 & 2,12 & 2,20 \\
Desvio padrão & 1,54 & 1,39 & 1,35 & 1,41 & 1,45 & 1,48 \\
CV & 3,69 & 3,51 & 3,49 & 3,73 & 3,93 & 4,09 \\
Assimetria & 1,29 & 0,51 & $-0,08^{2}$ & $-0,14^{2}$ & $-0,17^{2}$ & $-0,27^{2}$ \\
Curtose & 3,43 & 1,87 & $0,33^{2}$ & $0,14^{2}$ & $0,13^{2}$ & $0,41^{2}$ \\
$D^{3}$ & 0,12 & 0,06 & 0,06 & 0,08 & 0,07 & 0,07 \\
\hline Thyyyyyyyy
\end{tabular}

Coeficiente de variação (\%).

${ }^{2}$ Não difere estatisticamente de zero pelo teste t em $5 \%$ de significância.

${ }^{3}$ Valores de máxima divergência do teste de Kolmogorov-Smirnov para distribuição normal. 0 nivel crítico em $5 \%$ de significância é 0,11 .

Exceto os valores de umidade na tensão $10 \mathrm{kPa}$, todas os demais apresentaram desvios máximos do teste Kolmogorov-Smirnov inferiores ao nível crítico e, portanto, ajustaram-se à distribuição normal. Resultados similares também foram obtidos por Gonçalves (1997). No entanto, analisandose os gráficos de probabilidade normal (Figura 5), percebe-se que na tensão 
$33 \mathrm{e}$, principalmente, $10 \mathrm{kPa}$ os dados de umidade apresentaram uma grande dispersão em relação à reta normal, principalmente nas extremidades devido à presença de valores provavelmente discrepantes.

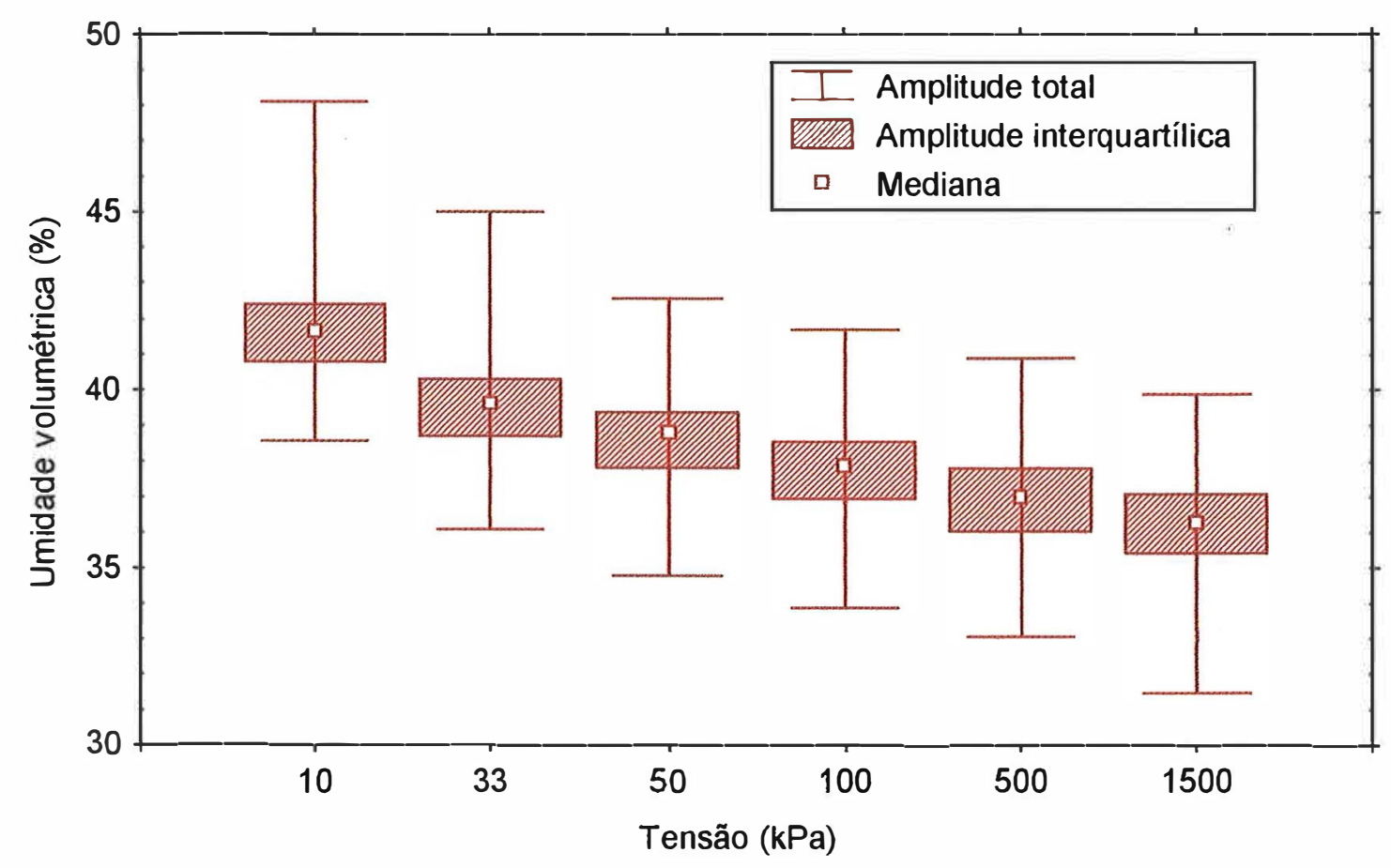

Figura 4. Gráfico "box-plot" dos dados de umidade volumétrica nas tensões avaliadas, antes da identificação dos valores discrepantes.

Esses resultados foram confirmados pelo teste $t$, mais rigoroso que $o$ de Kolmogorov-Smirnov. Pela avaliação do teste $t$, os dados de umidade nas tensões 10 e $33 \mathrm{kPa}$ apresentaram coeficientes de assimetria e de curtose significativamente maiores que zero e, portanto, assimetria positiva e distibuição leptocúrtica. Nas demais tensões, os valores de umidade apresentaram distribuição simétrica e mesocúrtica, ajustando-se à normalidade, o que também foi confirmado pelo teste de Kolmogorov-Smirnov. 
(a)

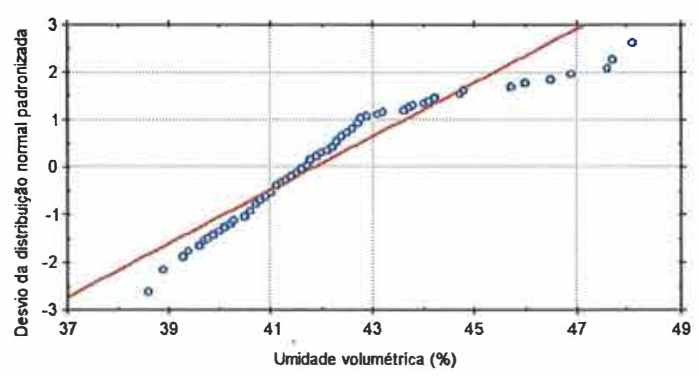

(c)

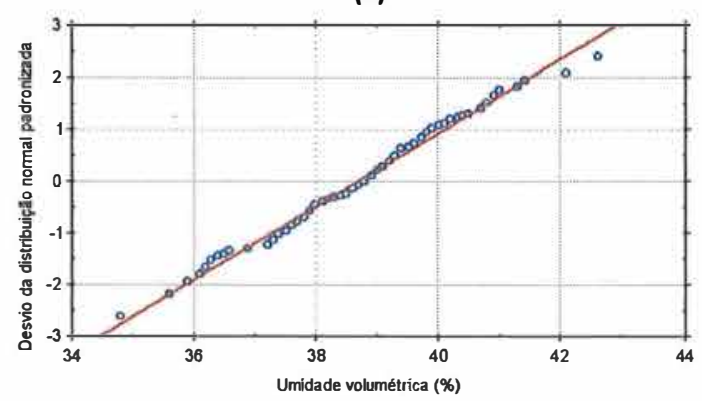

(e)

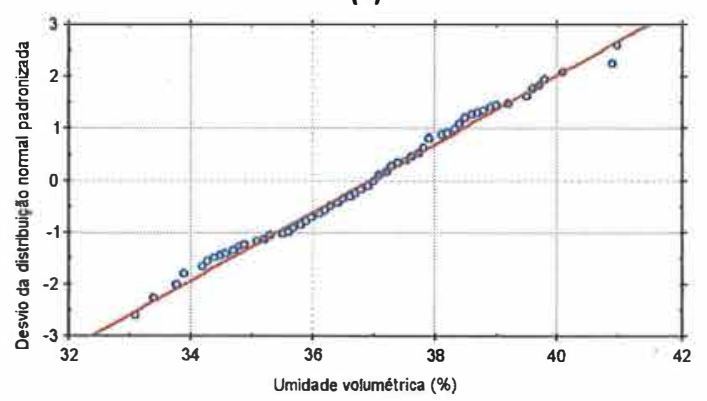

(b)

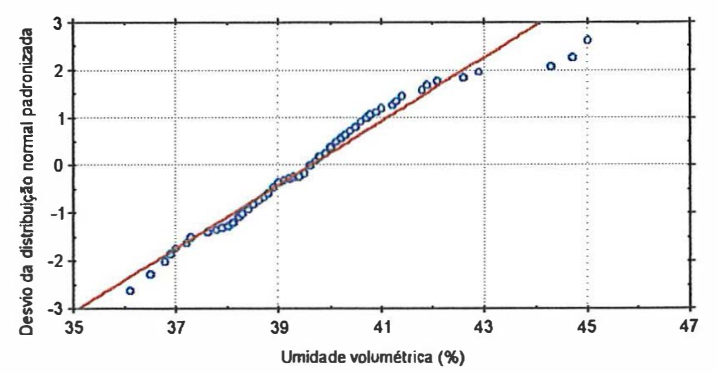

(d)

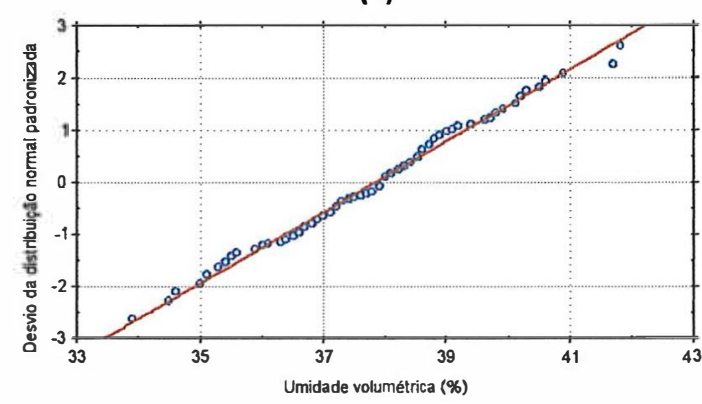

(f)

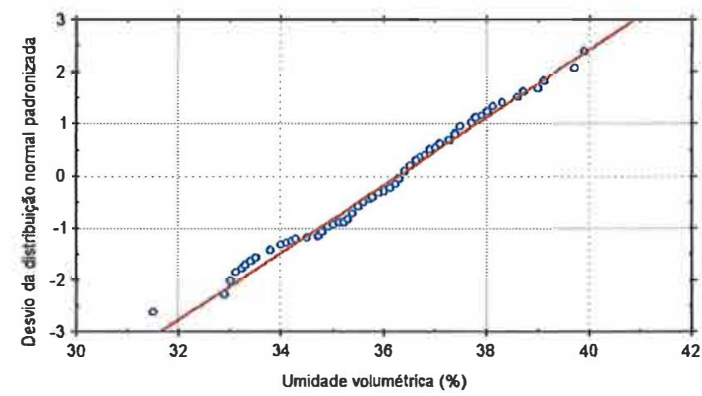

Figura 5. Gráficos de probabilidade normal dos dados de umidade volumétrica nas tensões 10 (a), 33 (b), 50 (c), 100 (d), 500 (e) e 1.500 kPa (f), antes da identificação dos valores discrepantes.

Nas Figuras 6 e 7 estão apresentadas as distribuições espacial dos valores de umidade nas várias tensões. Seguindo a metodologia preconizada por Libardi et al. (1996), os dados identificados pela estatística como discrepantes foram comparados com seus vizinhos mais próximos. Após a análise individual desses dados, tomou-se a decisão de excluí-los ou não. 


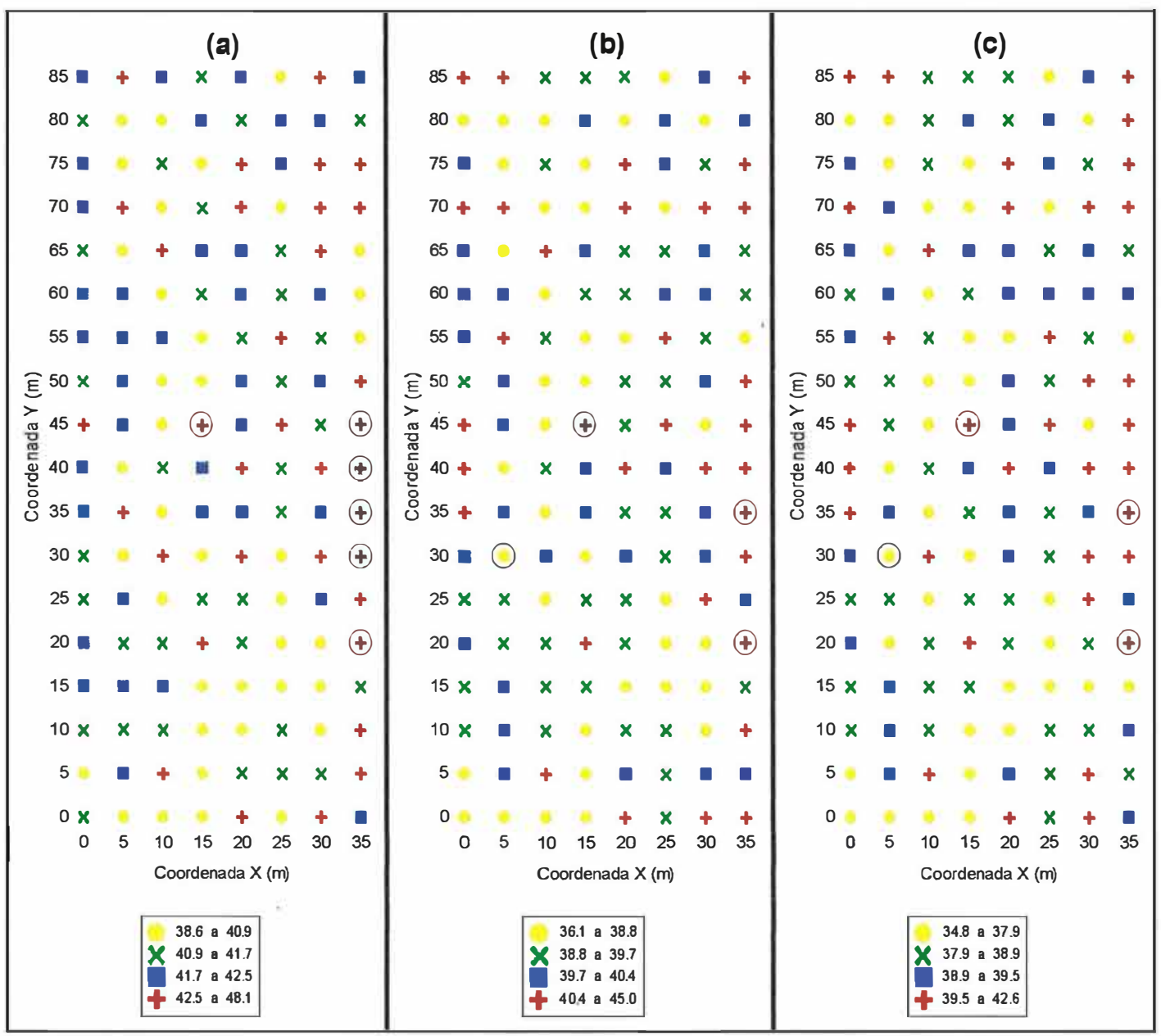

Figura 6. Distribuição espacial dos valores de umidade volumétrica (\%) nas tensões 10 (a), 33 (b) e $50 \mathrm{kPa}$ (c), identificando os valores considerados como discrepantes (circunferência).

Adotando essa metodologia, nem todos os dados identificados pela estatística como discrepantes foram excluídos. Assim, os dados de umidade do ponto amostral de coordenadas $(35 ; 35)$, considerados discrepantes em todas as tensões, não foram excluídos, pois localizavam-se em uma região com predomínio de valores altos, havendo coerência entre os valores e suas localizações. Os dados de umidade dos pontos amostrais $(35 ; 30),(35 ; 40)$ e $(35 ; 45)$ também não foram excluídos, pois foram considerados como discrepantes apenas na tensão $10 \mathrm{kPa}$ e, além disso, esses valores também 
apresentaram coerência com a sua localização. Pela mesma razão, os dados de umidade dos pontos amostrais $(15 ; 35)$ na tensão $500 \mathrm{kPa}$ e $(30 ; 5)$ na tensão 1.500 kPa não foram excluídos.

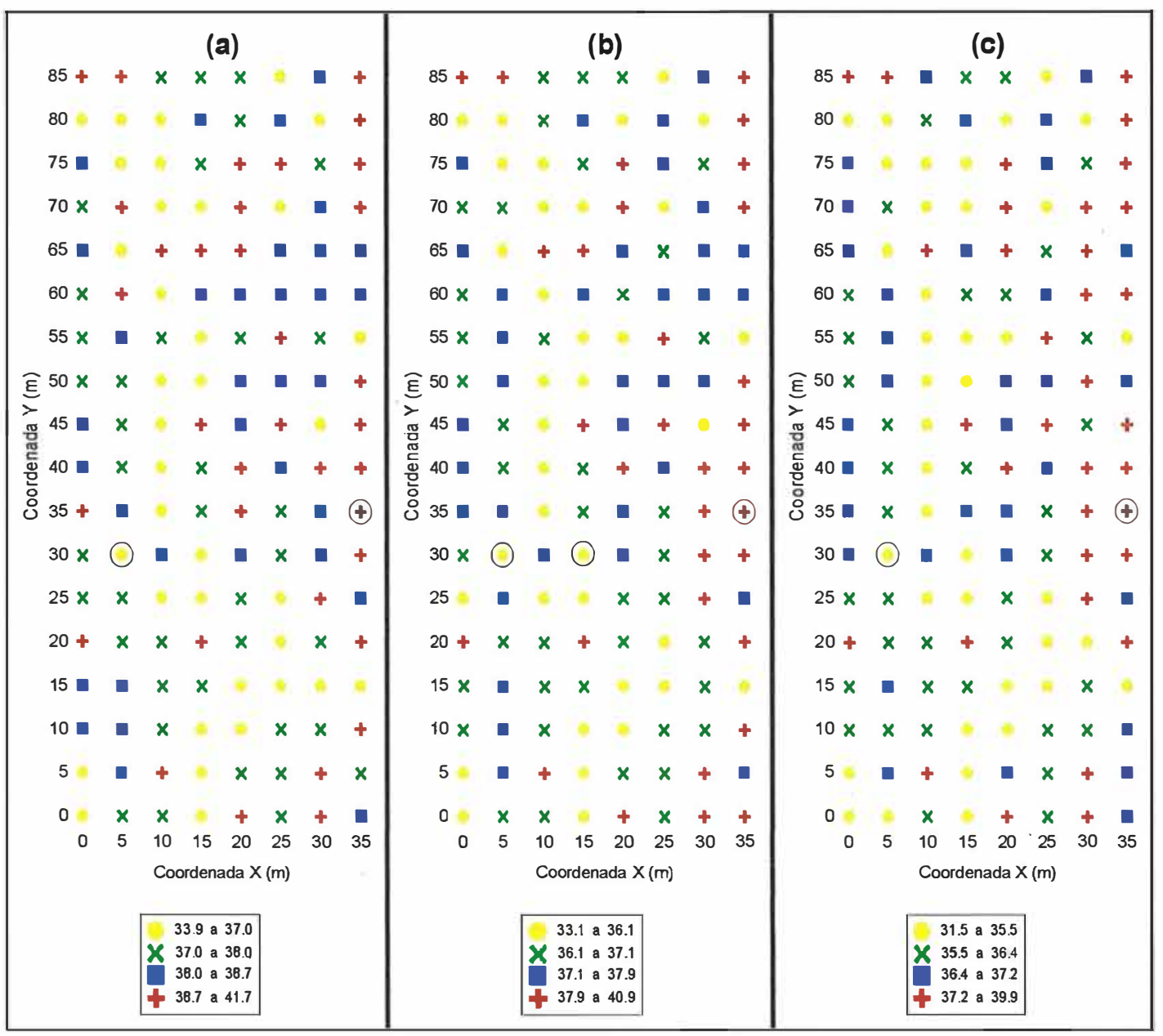

Figura 7. Distribuição espacial dos valores de umidade volumétrica (\%) nas tensões 100 (a), 500 (b) e $1.500 \mathrm{kPa}$ (c), identificando os valores considerados como discrepantes (circunferência).

Os valores de umidade dos pontos de amostragem $(5 ; 30),(15 ; 45)$ e $(35 ; 20)$, foram identificados pela estatística como discrepantes em pelo menos três tensões e apresentaram diferenças consideráveis dos seus vizinhos mais 
próximos. Portanto, com base nos critérios adotados, as curvas de retenção desses três pontos amostrais foram excluídas.

Os gráficos de distribuição espacial também podem ser utilizados para avaliar a existência de sub-regiões (símbolos iguais de forma concentrada) elou tendência (variações gradativas em alguma direção), situações incompativeis com a hipótese intrínseca assumida na análise geoestatística (Ribeiro Junior, 1995).

Não foram identificadas variações gradativas em nenhuma direção, mas ocorreram algumas concentrações de dados. As mais visiveis foram pontos pertencentes à primeira classe, com valores mais baixos, que concentraram-se na parte inferior da área. No entanto, concentrações de valores em determinados niveis geralmente ocorrem e podem ser justificadas pela própria continuidade espacial do atributo. Como não existe teste estatístico para analisar estacionaridade, o enquadramento dos dados à hipótese intrínseca deve ser avaliado de forma indireta, através da confecção de semivariogramas e pela técnica da validação cruzada (Vieira, 1998).

A remoção dos dados discrepantes praticamente não influenciou as medidas de posição e de dispersão (Tabela 2), devido ao pequeno número de dados excluídos, que representaram apenas $2,1 \%$ do total.

Com a remoção do ponto amostral $(5 ; 35)$, que apresentou os valores mínimos de umidade em todas as tensões, exceto a $10 \mathrm{kPa}$, houve redução da amplitude total. No entanto, a eliminação desse ponto amostral praticamente não afetou a amplitude interquartílica, o que evidencia a pouca influência que os valores extremos exercem nesta estatística.

Houve redução dos coeficientes de assimetria dos valores de umidade em todas as tensões, o que pode ser justificado pela grande sensibilidade dessa estatística aos valores extremos (Isaaks \& Srivastava, 1989). 
Tabela 2. Estatística descritiva dos dados de umidade volumétrica (\%) nas tensões avaliadas, após a exclusão dos valores discrepantes (141 valores).

\begin{tabular}{lrrrrrr}
\hline Estatística & \multicolumn{7}{c}{ Tensão (kPa) } \\
\cline { 2 - 7 } & $\mathbf{1 0}$ & $\mathbf{3 3}$ & $\mathbf{5 0}$ & $\mathbf{1 0 0}$ & $\mathbf{5 0 0}$ & $\mathbf{1 5 0 0}$ \\
\hline Média & 41,72 & 39,51 & 38,63 & 37,77 & 36,87 & 36,20 \\
Mediana & 41,60 & 39,60 & 38,80 & 37,90 & 37,00 & 36,30 \\
Mínimo & 38,60 & 36,50 & 35,60 & 34,50 & 33,40 & 32,90 \\
Máximo & 48,10 & 45,00 & 42,60 & 41,70 & 40,90 & 39,90 \\
Amplitude total & 9,50 & 8,50 & 7,00 & 7,20 & 7,50 & 7,00 \\
Quartil inferior & 40,80 & 38,70 & 37,80 & 36,90 & 36,00 & 35,40 \\
Quartil superior & 42,40 & 40,20 & 39,40 & 38,60 & 37,80 & 37,05 \\
Amplitude interquartílica & 1,60 & 1,50 & 1,60 & 1,70 & 1,80 & 1,65 \\
Variância & 2,05 & 1,67 & 1,63 & 1,81 & 1,96 & 2,00 \\
Desvio padrão & 1,43 & 1,28 & 1,28 & 1,34 & 1,40 & 1,41 \\
CV & 3,43 & 3,24 & 3,31 & 3,55 & 3,80 & 3,90 \\
Assimetria & 1,22 & $0,37^{2}$ & $-0,05^{2}$ & $-0,10^{2}$ & $-0,12^{2}$ & $-0,14^{2}$ \\
Curtose & 3,59 & 1,77 & $0,16^{2}$ & $0,06^{2}$ & $0,15^{2}$ & $0,16^{2}$ \\
$\mathrm{D}^{3}$ & 0,10 & 0,07 & 0,06 & 0,08 & 0,07 & 0,07 \\
\hline
\end{tabular}

'Coeficiente de variação (\%).

${ }^{2}$ Não diferem estatisticamente de zero pelo teste t em $5 \%$ de significância.

${ }^{3}$ Valores de máxima divergência do teste de Kolmogorov-Smirnov para distribuição normal. 0 nível crítico em $5 \%$ de significância é 0,11 .

Com a remoção dos três pontos amostrais, a distribuição dos valores de umidade na tensão $33 \mathrm{kPa}$ apresentou assimetria estatisticamente nula (teste t) e a distribuição dos dados de umidade na tensão $10 \mathrm{kPa}$ ajustou-se à normalidade (teste de Kolmogorov-Smirnov).

Apesar de ainda permanecerem alguns valores extremos, pode-se perceber pela Figura 8 que houve menor dispersão dos dados em relação à reta normal, principalmente nos dados de umidade das tensões 10 e $33 \mathrm{kPa}$.

Para verificar se os dados de umidade do solo apresentavam dependência espacial, foram confeccionados semivariogramas experimentais sem os valores considerados discrepantes. 
(a)

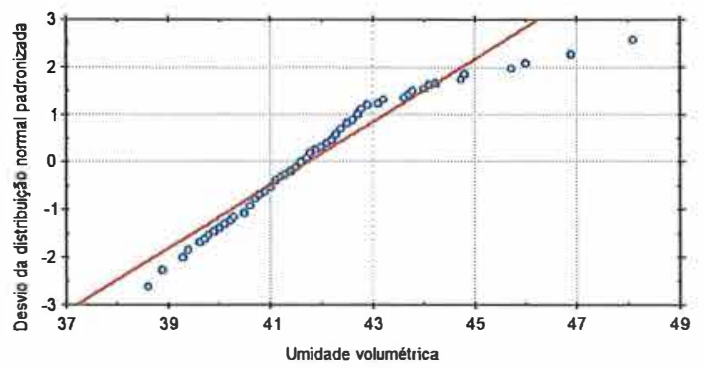

(c)

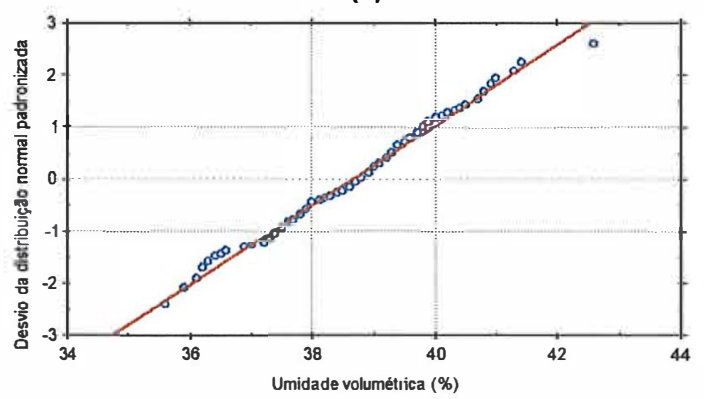

(e)

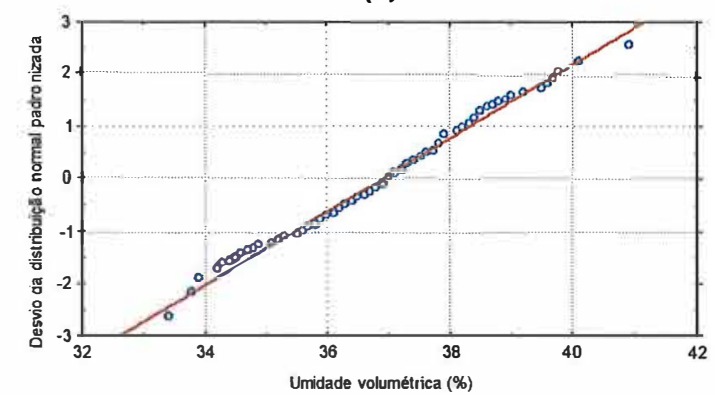

(b)

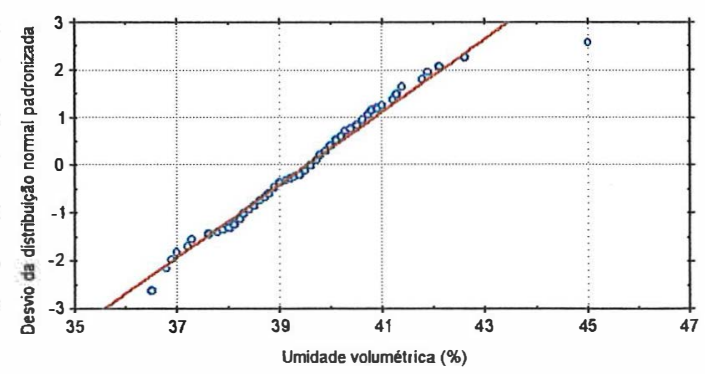

(d)

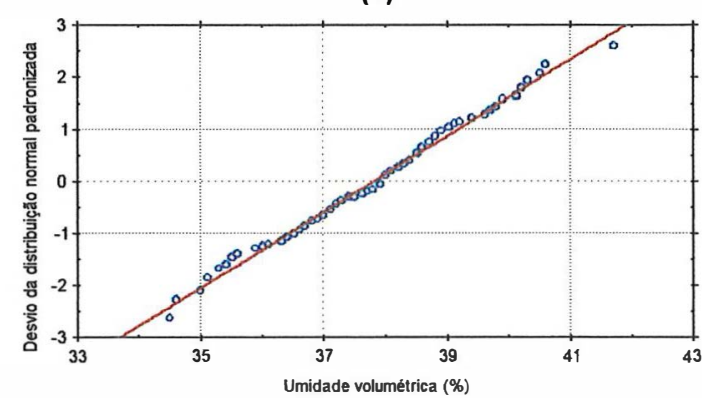

(I)

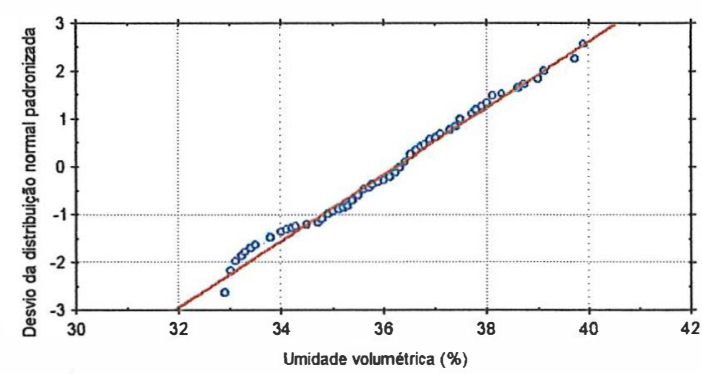

Figura 8. Gráficos de probabilidade normal dos dados de umidade volumétrica nas tensões 10 (a), 33 (b), 50 (c), 100 (d), 500 (e) e 1.500 kPa (f), após a exclusão dos valores discrepantes.

Os dados de umidade de todas as tensões apresentaram dependência espacial (Tabela 3). Os semivariogramas experimentais ajustaram-se satisfatoriamente ao modelo exponencial, todos com alcance de 22,0 m e com valores diferenciados de efeito pepita e de patamar. Resultados similares foram obtidos por Gonçalves et al. (1996) e Gonçalves (1997), que verificaram em um podzólico vermelho-escuro dependência espacial nos valores de umidade em várias tensões. 
Tabela 3. Parâmetros dos modelos ajustados aos semivariogramas, relação efeito pepita/patamar, variância reduzida $\left(V R_{\text {red }}\right)$ e média reduzida (MED ${ }_{\text {red }}$ ).

\begin{tabular}{cccccccc}
\hline $\begin{array}{c}\text { Tensão } \\
(\mathrm{kPa})\end{array}$ & Modelo & $\mathrm{C}_{0}{ }^{1}$ & $\left(\mathrm{C}_{0}+\mathrm{C}_{1}\right)^{2}$ & $\begin{array}{c}\mathrm{a}^{3} \\
(\mathrm{~m})\end{array}$ & $\begin{array}{c}\mathrm{C}_{0} \\
\left(\mathrm{C}_{0}+\mathrm{C}_{1}\right)\end{array}$ & VAR $_{\text {red }}{ }^{4}$ & MED $^{{ }^{4}{ }^{4}}$ \\
\hline 10 & Exponencial & 0,329 & 2,435 & 22,0 & 0,14 & $1,001^{i}$ & $-0,014$ \\
33 & Exponencial & 0,665 & 1,838 & 22,0 & 0,36 & 1,001 & $-0,028$ \\
50 & Exponencial & 0,937 & 1,682 & 22,0 & 0,56 & 0,999 & $-0,035$ \\
100 & Exponencial & 1,008 & 1,893 & 22,0 & 0,53 & 0,999 & $-0,030$ \\
500 & Exponencial & 0,962 & 2,042 & 22,0 & 0,47 & 1,001 & $-0,027$ \\
1.500 & Exponencial & 1,095 & 2,030 & 22,0 & 0,54 & 1,001 & $-0,023$ \\
\hline
\end{tabular}

'Efeito pepita

${ }^{2}$ Patamar

${ }^{3}$ Alcance

${ }^{4}$ Obtidos na validação cruzada com doze vizinhos.

Os modelos apresentaram pequenas variações nos valores de efeito pepita e de patamar. No entanto, com os semivariogramas escalonados pela variância amostral os dados de umidade de todas as tensões apresentaram um padrão de variabilidade muito aproximado (Figuras 9 e 10).

$O$ alcance é um parâmetro que fornece informações de muita utilidade prática, pois representa o limite da correlação espacial entre observações. Pontos amostrais separados por distâncias superiores a $22,0 \mathrm{~m}$ não apresentaram correlação espacial e, portanto, amostragens realizadas na área do experimento a distâncias maiores que esta, podem ser consideradas aleatórias e independentes entre si. Por outro lado, locais separados por distâncias menores que $22,0 \mathrm{~m}$ apresentaram dependência espacial e permitem que se façam interpolações para espaçamentos menores que 0 amostrado $(5 \mathrm{~m})$. Esse valor de alcance deve ser utilizado na área avaliada para o planejamento de novas amostragens. Apesar dos parâmetros de ajuste não poderem ser extrapolados, podem servir como uma referência da correlação espacial das áreas adjacentes. 
(a)

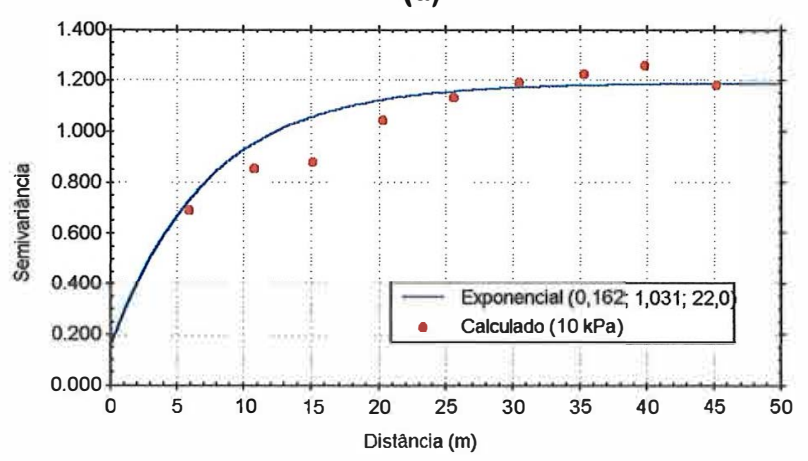

(b)

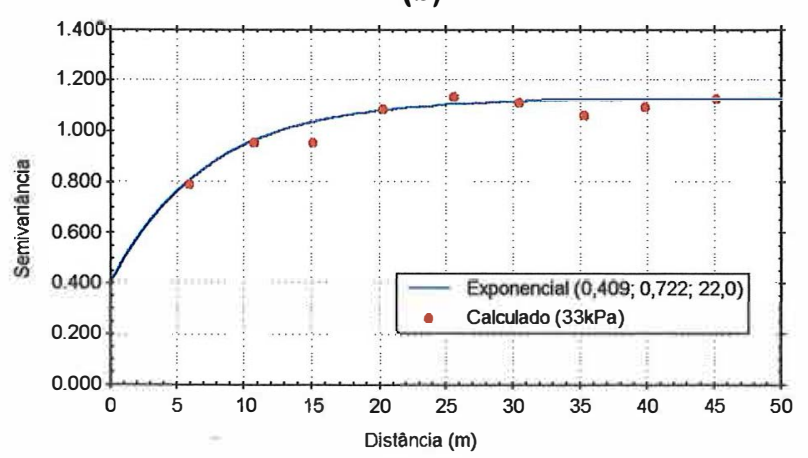

(c)

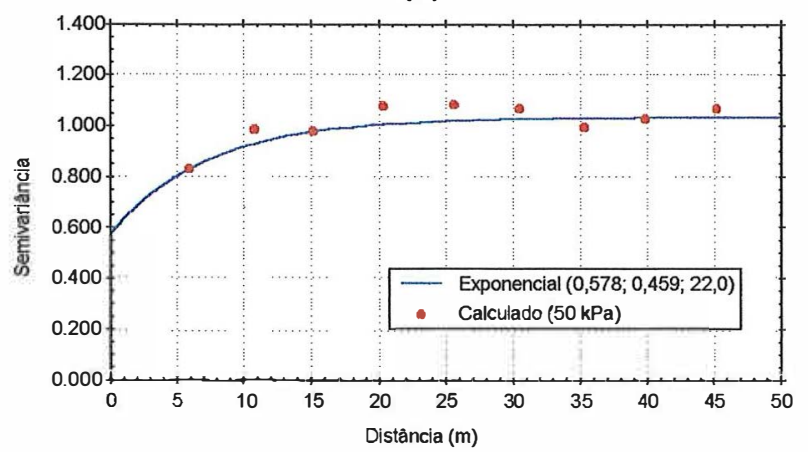

Figura 9. Semivariogramas experimentais escalonados pela variância amostral dos dados de umidade volumétrica nas tensões 10 (a), 33 (b) e 50 $\mathrm{kPa}(\mathrm{c})$. 
(a)

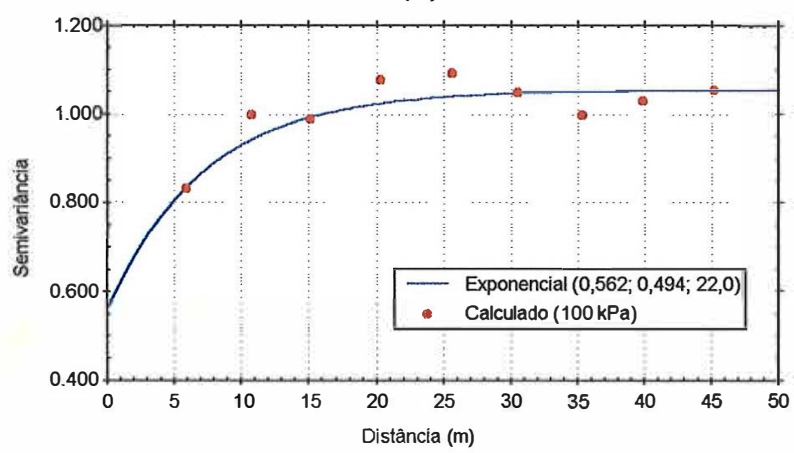

(b)

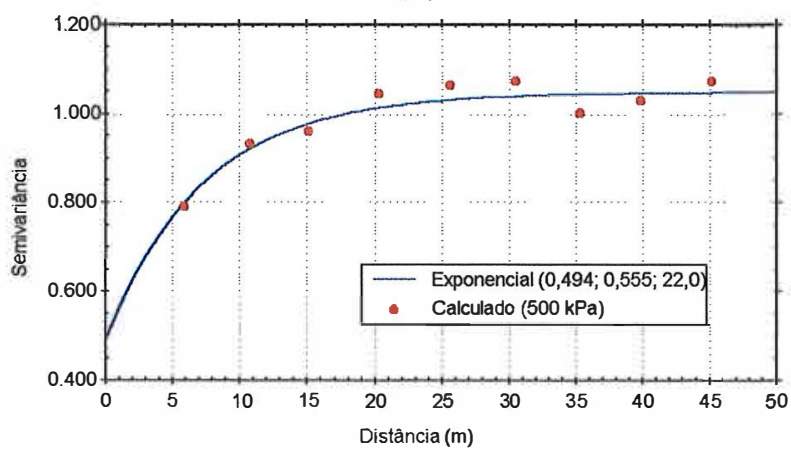

(c)

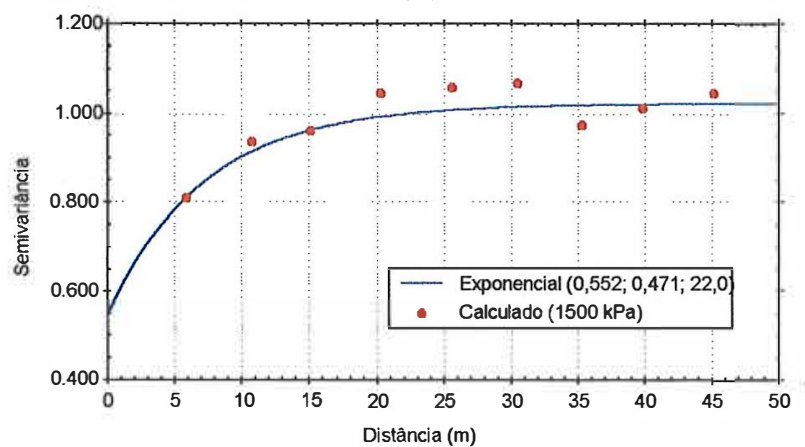

Figura 10. Semivariogramas experimentais escalonados pela variância amostral dos dados de umidade volumétrica nas tensões 100 (a), 500 (b) e $1.500 \mathrm{kPa}(\mathrm{c})$.

Segundo a classificação de Cambardella et al. (1994), os semivariogramas apresentaram moderada dependência espacial, exceto o dos valores de umidade na tensão $10 \mathrm{kPa}$, que apresentou forte continuidade espacial. É desejável que os valores dessa relação sejam pequenos, pois quanto menor a proporção do efeito pepita para o patamar, maior será a 
continuidade do fenômeno e menor a variância da estimativa e, portanto, maior a confiança que se pode ter nas estimativas (Vieira, 1998).

Analisando-se as Tabela 2 e 3 pode-se verificar que os semivariogramas com maior e menor patamar (respectivamente, 10 e $50 \mathrm{kPa}$ ), também apresentaram a maior e a menor variância amostral. Esse comportamento deve-se aos valores de patamar serem aproximadamente iguais à variância dos dados.

\subsection{Disponibilidade hídrica do solo}

Os valores de umidade volumétrica foram altos em todos os potenciais mátricos avaliados, apresentando apenas uma pequena redução com o aumento da tensão. Esse comportamento resultou em um solo com pequena disponibilidade hídrica, similar à de solos arenosos, apesar do latossolo possuir textura muito argilosa.

Considerando o método da câmara de pressão de Richards como padrão para determinação de curvas características, os resultados obtidos podem ser atribuídos a uma das seguintes razões: (i) houve algum problema metodológico ou com o equipamento utilizado nas determinações; (ii) os resultados estão corretos e refletem a pequena disponibilidade hídrica do latossolo.

Visando responder essa questão, foram confeccionadas mais doze curvas de retenção de água no solo, seis da camada $0-15 \mathrm{~cm}$ e seis da $15-30$ $\mathrm{cm}$. As amostras foram coletadas o mais próximas possível, de acordo com a metodologia descrita no item 3.3.1.

As amostras, após serem divididas aleatoriamente em dois grupos com três amostras de cada camada, foram submetidas a cinco tensões em câmara de pressão de Richards (10, 33, 50, 500 e 1.500 kPa). As determınaçöes de um dos grupos de amostras foram realizadas novamente em Dourados, no 
laboratório de solos da EMBRAPA/CPAO. As curvas de retenção do segundo conjunto de amostras foram determinadas em Piracicaba, no laboratório de solos do Departamento de Engenharia Rural da ESALQ/USP.

Comparando-se as curvas de retenção (Figura 11), verifica-se que apresentaram resultados muito próximos, principalmente na camada $15-30 \mathrm{~cm}$, com diferenças que oscilaram de zero a $0,034 \mathrm{~kg}^{\mathrm{kg}}{ }^{-1}$ e que podem ser consideradas pequenas.

Os valores de umidade das curvas confeccionadas na EMBRAPAVCPAO foram sempre menores que os das curvas da ESALQ/USP, exceto na tensão $500 \mathrm{kPa}$ da camada 0-15 cm (Figura 11a). Pode-se também perceber que as diferenças dos valores de umidade tenderam a diminuir com o aumento das tensões, sendo nulas ou desprezíveis a $1.500 \mathrm{kPa}$.

As pequenas diferenças nos valores de umidade das curvas de retenção podem ser atribuídas ao efeito da temperatura, pois apenas o laboratório de Piracicaba tinha a temperatura do ar controlada. Segundo Klute (1986), o aumento da temperatura diminui a tensão superficial águalar o que reduz 0 conteúdo hídrico retido em um determinado potencial mátrico. No entanto, essas diferenças podem também ser conseqüência da variabilidade espacial do solo e a erros de determinação.

Tanto nas determinações realizadas em Dourados como em Piracicaba, não foram observados problemas metodológicos como, por exemplo, mau contato da amostra com a placa porosa ou tempo insuficinte para atingir o equilíbrio. Portanto, pode-se concluir que as curvas características confeccionadas com base nas determinações do laboratório da EMBRAPA/CPAO refletiram a baixa disponibilidade hídrica do latossolo roxo. 
a

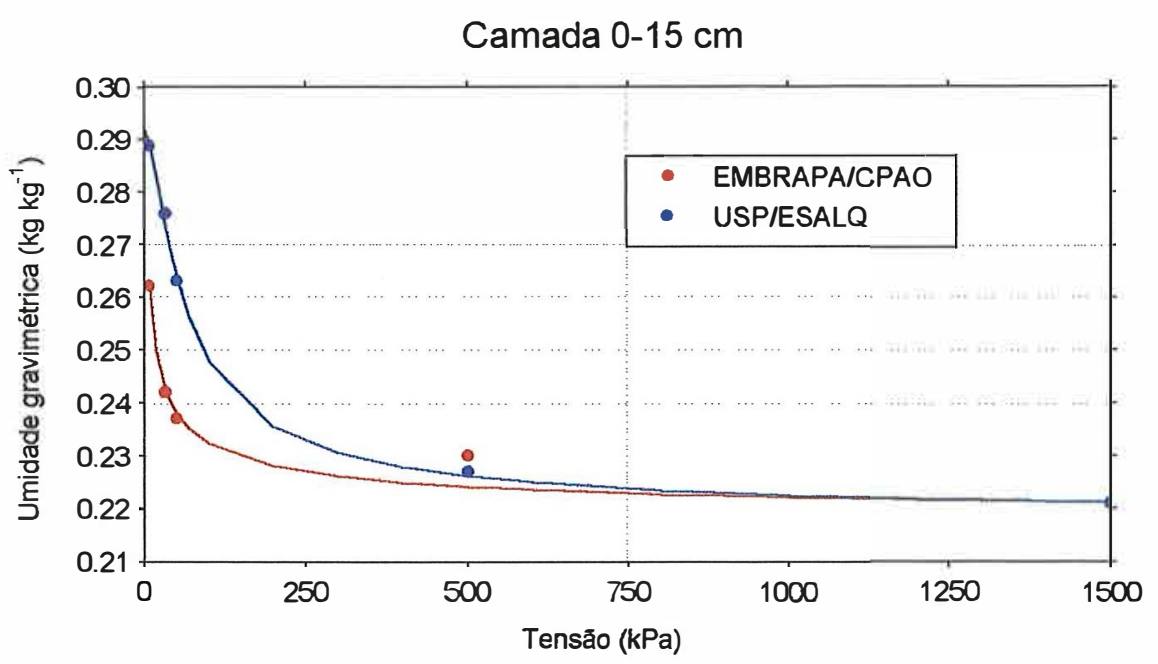

b

Camada $15-30 \mathrm{~cm}$

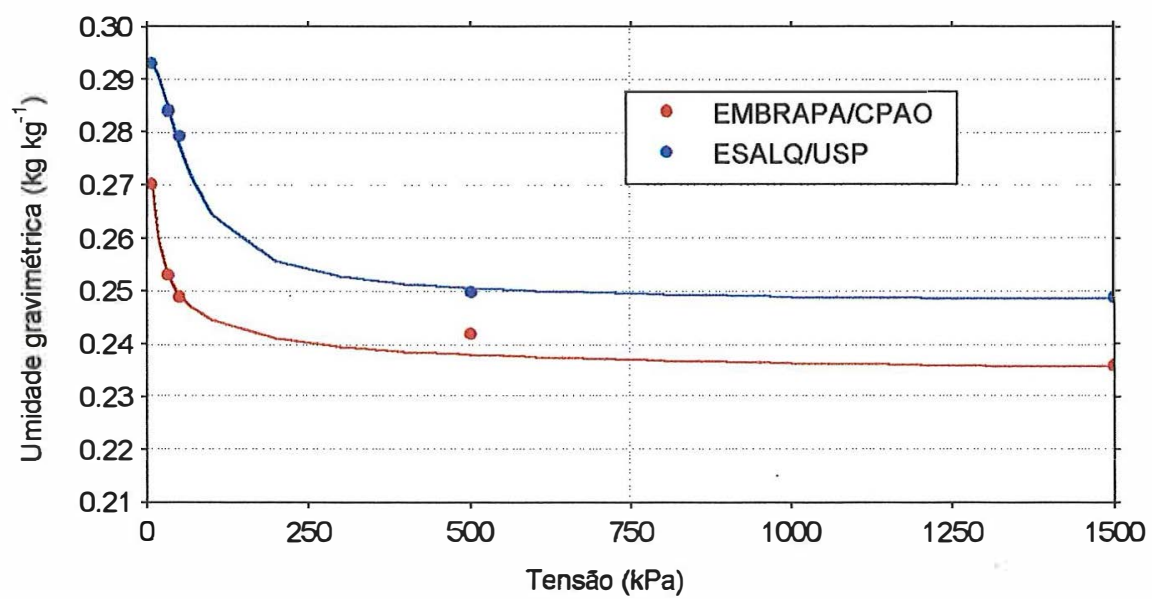

Figura 11. Curvas de retenção das camadas $0-15 \mathrm{~cm}$ (a) e $15-30 \mathrm{~cm}$ (b) determinadas nos laboratórios de solos da EMBRAPA/CPAO e do Departamento de Engenharia Rural da ESALQ/USP.

Outros trabalhos com latossolo roxo apresentaram resultados similares aos aqui obtidos. Fietz \& Hernani (1992) e Urchei et al. (1997) atribuíram a pequena disponibilidade hídrica à composição mineralógica da fração argila desse tipo de latossolo, constituída principalmente por caulinita e sesquióxidos 
de ferro (goethita e hematita) e de alumínio (gibsita). Lopes (1983) também atribuiu à mineralogia o fato de latossolos, nos quais a presença de argilas do tipo 2:1 ocorre raramente, apresentarem retenção hídrica similar a solos arenosos, apesar de possuírem teores extremamente elevados de argila.

A pequena disponibilidade hídrica do solo estudado pode ser explicada também pela microagregação (Sharma \& Uehara, 1968), que tem seu desenvolvimento influenciado pela composição mineralógica da fração argila (Tsuji et al., 1975). Tognon (1992) e Kertzman (1996) consideraram que poros com raio inferior a $0,1 \mu \mathrm{m}$ faziam parte da porosidade intra-agregados. Estabelecendo este mesmo valor para o solo avaliado e com base na equação 6 , pode-se verificar que a umidade retida nos poros internos dos microagregados não seria extraída pela tensão de $1.500 \mathrm{kPa}$. Portanto, as altas umidades retidas em todas as tensões, principalmente nas mais elevadas, podem ser atribuídas à água retida na porosidade intra-agregados. Assim como verificaram Tognon (1992) e Kertzman (1996), a alta capacidade de retenção do latossolo nas tensões mais elevadas pode ser justificada pelo fato do solo possuir uma grande quantidade de poros com raio inferior a 0,1 $\mu \mathrm{m}$.

De acordo com Menezes et al. (1992), a pequena disponibilidade hídrica da classe latossolo roxo exige que se estabeleça um manejo da irrigação semelhante a de solos arenosos, com irrigações leves e freqüentes, a fim de reduzir as perdas de nutrientes por lixiviação e os gastos com energia.

A compactação do solo, provavelmente, também influenciou os resultados. A densidade do solo na área do experimento oscilou de 1,26 a 1,58 $\mathrm{kg} \cdot \mathrm{m}^{-3}$, com média de $1,41 \mathrm{~kg} \cdot \mathrm{m}^{-3}$ (Tabela 4). Esses valores elevados podem ser atribuídos ao fato de que o sistema plantio direto geralmente promove um aumento na densidade da camada arável mais superficial do solo. Além disso, devido a amostragem ter sido realizada de forma sistematizada em pontos eqüidistantes de uma malha, é possivel que muitas amostras tenham sido retiradas em locais de translocação de máquinas e implementos. As altas 
densidades do solo, associadas às baixas densidades de partículas, resultaram em valores muito baixos de umidade de saturação, novamente evidenciando a compactação do solo da área experimental.

A porosidade interna dos microagregados é pouco afetada pelo adensamento do solo (Kertzman, 1996). No entanto, a compactação promove um aumento da quantidade de microagregados por unidade de volume do solo e, conseqüentemente, da porosidade intra-agregados. Assim, a compactação do solo, alterando a porosidade intra-agregados, aumentou a retenção de água e, provavelmente, foi o fator responsável pelos altos teores de umidade observados nas tensões mais elevadas (500 e $1500 \mathrm{kPa}$ ).

Tabela 4. Estatística descritiva dos dados de densidade do solo $\left(D_{s}\right)$, densidade de partículas $\left(D_{\mathrm{p}}\right)$ e umidade de saturação $\left(\theta_{\mathrm{s}}\right)(141$ valores).

\begin{tabular}{|c|c|c|c|}
\hline Estatística & $\begin{array}{c}D_{s} \\
\left(k g \cdot m^{3}\right)\end{array}$ & $\begin{array}{c}D_{p} \\
\left(\mathrm{~kg}^{-3} \mathrm{~m}^{-3}\right)\end{array}$ & $\begin{array}{c}\theta_{s} \\
(\%)\end{array}$ \\
\hline Média & 1,41 & 2,60 & 45,67 \\
\hline Mediana & 1,41 & 2,60 & 45,80 \\
\hline Mínimo & 1,26 & 2,35 & 38,50 \\
\hline Máximo & 1,58 & 2,78 & 51,10 \\
\hline Amplitude total & 0,32 & 0,43 & 12,60 \\
\hline Quartil inferior & 1,37 & 2,54 & 43,80 \\
\hline Quartil superior & 1,44 & 2,67 & 47,55 \\
\hline Amplitude interquartílica & 0,07 & 0,13 & 3,75 \\
\hline Variância & 0,002 & 0,007 & 6,406 \\
\hline Desvio padrão & 0,053 & 0,085 & 2,531 \\
\hline $\mathrm{CV}^{1}$ & 3.76 & 3.27 & 5,54 \\
\hline Assimetria & $-0,12^{2}$ & $-0,25^{2}$ & $-0,17^{2}$ \\
\hline Curtose & 0,26 & $-0,01$ & $-0,16$ \\
\hline$D^{3}$ & 0,07 & 0,08 & 0,04 \\
\hline
\end{tabular}

'Coeficiente de variação (\%).

${ }^{2}$ Não difere estatiscamente de zero pelo teste t em $5 \%$ de significância.

${ }^{3}$ Valores de máxima divergência do teste de Kolmogorov-Smirnov para distribuição normal. 0 nivel crítico em $5 \%$ de significância é 0,11 .

A compactação produz um aumento dos índices de microporos e redução na macroporosidade, devido à aproximação dos agregados (Silva et 
al., 1986). O rearranjo dos agregados diminui o volume de macroporos que em parte é reduzida e em parte é transformada em microporosidade. Essa influência da compactação na microporosidade pode justificar as altas umidades nas tensões mais baixas (10, 33 e $50 \mathrm{kPa})$.

Visando realizar uma avaliação inicial da microagregação, a granulometria do latossolo roxo foi determinada de duas maneiras. Coletou-se, ao longo de uma transeção da área experimental, em pontos separados em 10 $\mathrm{m}$, oito amostras da camada $0-30 \mathrm{~cm}$. A composição granulométrica dessas amostras foi determinada por peneiramento e sedimentação, sem dispersante (somente água destilada) e com dispersante químico (hidróxido de sódio em água destilada), utilizando-se o método do densímetro descrito por Kiehl (1979).

Com dispersante químico, os teores de argila e de silte foram, respectivamente, 74,6 e 16,7\% (Tabela 5). Nas análises sem dispersante, a fração silte apresentou um aumento substancial (cerca de 18\%), em detrimento da redução dos teores de argila. A fração areia praticamente não sofreu alteração.

Os resultados da análise textural sem dispersante revelam, provavelmente, a organização dos constituintes do solo de uma forma mais próxima da que ocorre a nível de campo, com a presença de microagregados de tamanho similar ou próximo ao da fração silte. Rodrigues Netto (1996) também observou que o silte dos latossolos era constituído, principalmente, por microagregados de minerais da fração argila resistentes à dispersão.

Apesar da redução dos teores de argila não ter sido tão intensa quanto a obtida por Kertzman (1996), esses resultados demonstram que as frações granulométricas variam muito em função do método de análise e nem sempre refletem a natureza mineralógica dos solos. Também estão de acordo com a observação de Tsuji et al. (1975), de que as determinações granulométricas realizadas em laboratório nem sempre correspondem à textura do solo em condições de campo, especialmente no caso de oxissolos e ultissolos. 
Tabela 5. Análises granulométricas das amostras de solo realizadas com e sem dipersante químico.

\begin{tabular}{|c|c|c|c|c|}
\hline \multirow[t]{2}{*}{ Amostra } & \multicolumn{4}{|c|}{ Com dispersante químico } \\
\hline & Areia grossa (\%) & Areia fina (\%) & Silte (\%) & Argila (\%) \\
\hline 1 & 3,9 & 4,7 & 16,4 & 75,0 \\
\hline 2 & 3,8 & 4,9 & 17,3 & 74,0 \\
\hline 3 & 3,8 & 4,8 & 17,4 & 74,0 \\
\hline 4 & 3,2 & 4,7 & 15,1 & 77,0 \\
\hline 5 & 3,6 & 5,3 & 16,1 & 75,0 \\
\hline 6 & 3,4 & 4,9 & 16,7 & 75,0 \\
\hline 7 & 3,8 & 5,3 & 15,9 & 75,0 \\
\hline 8 & 4,0 & 5,5 & 18,5 & 72,0 \\
\hline Média & 3,7 & 5,0 & 16,7 & 74,6 \\
\hline \multirow[t]{2}{*}{ Amostra } & \multicolumn{4}{|c|}{ Sem dispersante químico } \\
\hline & Areia grossa (\%) & Areia fina (\%) & Silte (\%) & Argila (\%) \\
\hline 1 & 3,8 & 4,9 & 35,3 & 56,0 \\
\hline 2 & 3,8 & 4,7 & 37,5 & 54,0 \\
\hline 3 & 3,9 & 4,9 & 35,2 & 56,0 \\
\hline 4 & 3,3 & 4,7 & 33,0 & 59,0 \\
\hline 5 & 3,8 & 5,4 & 31,8 & 59,0 \\
\hline 6 & 3,4 & 4,7 & 34,9 & 57,0 \\
\hline 7 & 3,6 & 5,4 & 34,0 & 57,0 \\
\hline 8 & 4,1 & 5,4 & 33,5 & 57,0 \\
\hline Média & 3,7 & 5,0 & 34,4 & 56,9 \\
\hline
\end{tabular}

Todas as justificativas atribuídas a esses resultados somente poderão ser comprovadas através de estudos detalhados da microestrutura e da composição mineralógica do latossolo roxo. Esses estudos poderão identificar e quantificar os tipos de poros e de argila que constituem esse solo.

\subsection{Ajuste das curvas de retenção de água no solo}

Na Tabela 6 estão apresentadas as estatísticas dos parâmetros do modelo de van Genuchten. Os parâmetros $\alpha$ e $n$ apresentaram assimetria positiva e distribuição leptocúrtica. Nos gráficos de probabilidade normal e 
histogramas (Figura 12), pode-se visualizar a grande dispersão e a alta assimetria desses dois parâmetros. Com base no teste de KolmogorovSmirnov, apenas os valores de $\theta_{\mathrm{r}}$ ajustaram-se à distribuição normal.

O parâmetro $n$ apresentou um nivel médio de variabilidade, segundo o critério de Warrick \& Nielsen (1980), com coeficiente de variação muito próximo aos obtidos por Shouse et al. (1995) e Mallants et al.(1996). A variabilidade de $\alpha$ foi bem maior e refletiu-se num alto coeficiente de variação, superior a $100 \%$, muito maior que os obtidos por esses autores.

O parâmetro $\alpha$ apresentou distribuição log-normal, uma vez que os logaritmos naturais de seus valores ajustaram-se à normalidade (Tabela $6 \mathrm{e}$ Figura 13a). Esse comportamento também foi verificado por Greminger et al. (1985), mas diverge dos resultados obtidos por Shouse et al. (1995), que observaram melhor aderência dos valores de $\alpha$ à distribuição gaussiana.

Tabela 6. Estatística descritiva dos parâmetros ajustados do modelo de van Genuchten.

\begin{tabular}{lccccc}
\hline Estatística & $\begin{array}{c}\boldsymbol{\alpha} \\
(\mathbf{1 / c m})\end{array}$ & $\mathbf{n}$ & $\begin{array}{c}\theta_{\mathbf{r}} \\
\mathbf{( \% )}\end{array}$ & $\mathbf{I n ( \alpha )}$ & $\operatorname{In(n)}$ \\
\hline Média & 0,4303 & 1,5604 & 35,4 & 0,5185 & 1,5582 \\
Variância & 0,2163 & 0,0993 & 2,833 & 0,9541 & 0,0732 \\
Desvio padrão & 0,4650 & 0,3151 & 1,683 & 0,9768 & 0,2705 \\
CV $^{1}$ & 108,1 & 20,2 & 4,8 & 188,4 & 17,4 \\
Assimetria & 2,4132 & 2,4126 & $-0,432$ & $-0,899$ & 1,6906 \\
Curtose & 7,4198 & 7,2909 & 1,108 & 1,484 & 3,4404 \\
$\mathrm{D}^{2}$ & 0,179 & 0,201 & 0,097 & 0,086 & 0,175 \\
\hline
\end{tabular}

Coeficiente de variação (\%).

${ }^{2}$ Valores de máxima divergência do teste de Kolmogorov-Smirnov para distribuição normal. 0 nível crítico em $5 \%$ de significância é 0,11 .

A transformação logarítmica reduziu substancialmente os coeficientes de assimetria e de curtose dos parâmetros, mas praticamente não influenciou a distribuição de n (Figuras 12b e 13b) que também não apresentou distribuição log-normal. Esse resultado diverge dos obtidos por Greminger et al. (1985) e 
Shouse et al. (1995) que, respectivamente, encontraram distribuições lognormal e normal para esse parâmetro.

(a)
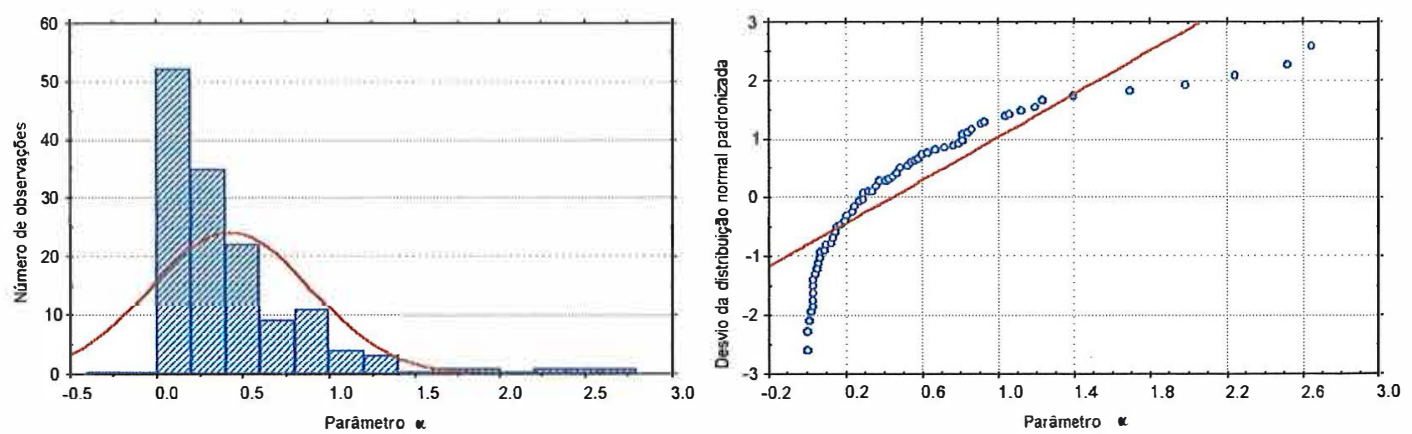

(b)
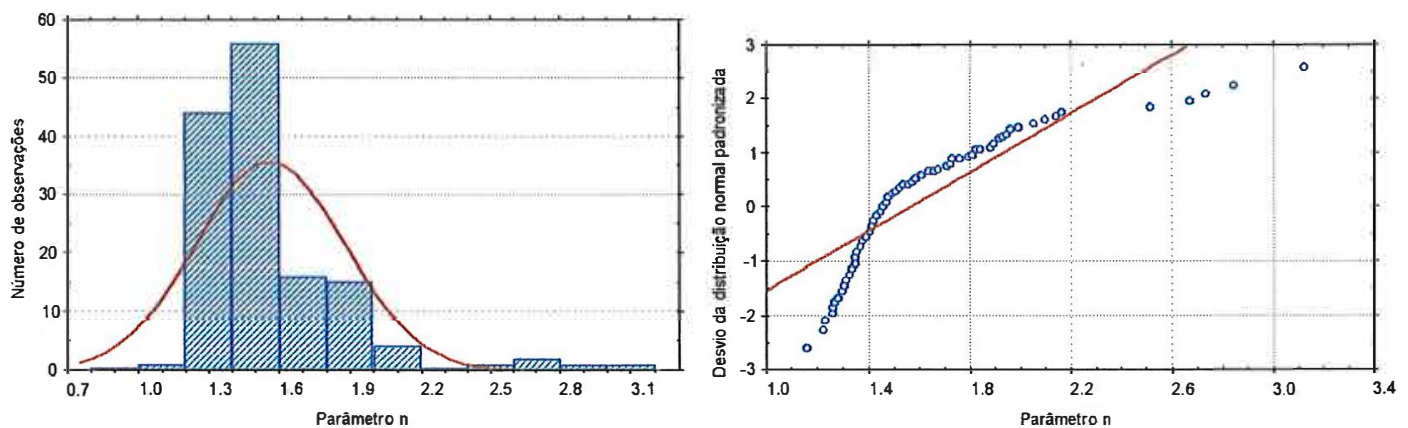

(c)
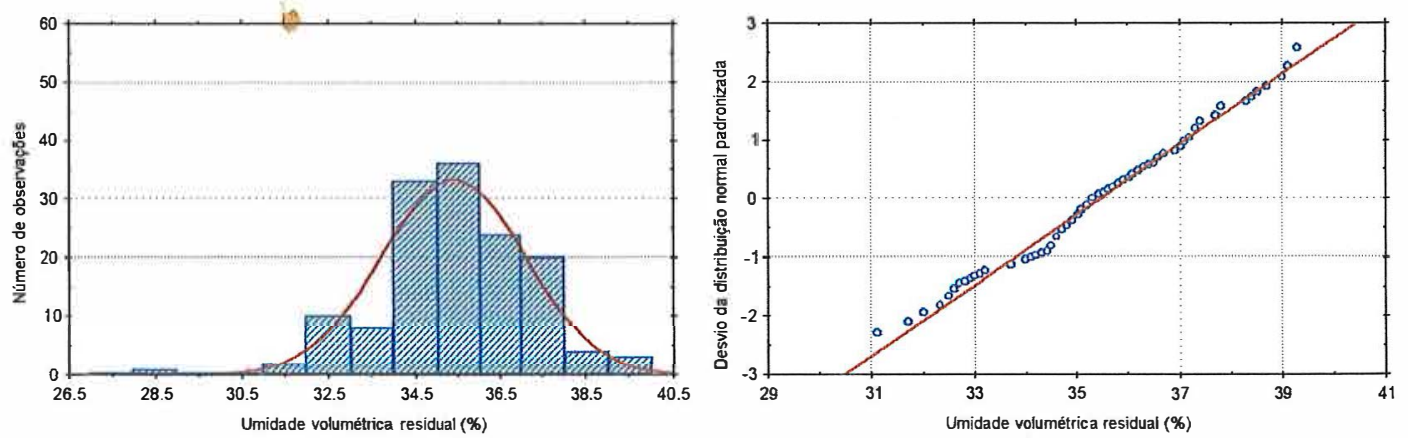

Figura 12. Histograma e gráfico de probabilidade normal dos parâmetros $\alpha$ (a), $\mathrm{n}$ (b) e umidade volumétrica residual (c) do modelo de van Genuchten. 
Os resultados mostram que os parâmetros do modelo de van Genuchten apresentaram alta assimetria, principalmente $\alpha$ e $n$, que também não se ajustaram à distribuição normal. Para fins de manejo da irrigação da área avaliada, a adoção de uma única curva com os valores médios dos parâmetros não é uma prática recomendável, pois poderia conduzir a grandes erros na estimativa dos valores de umidade.

(a)
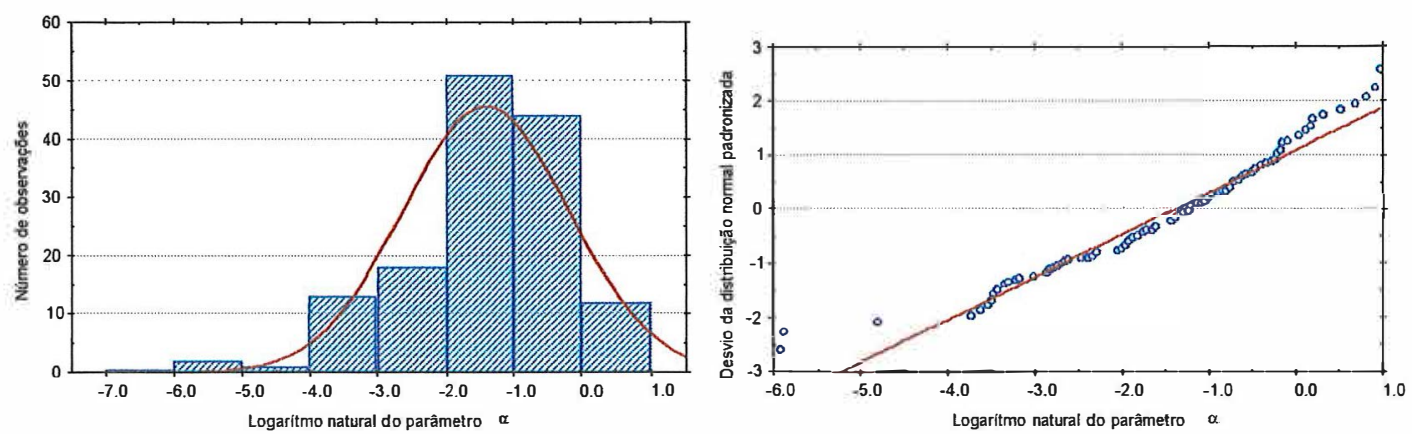

(b)
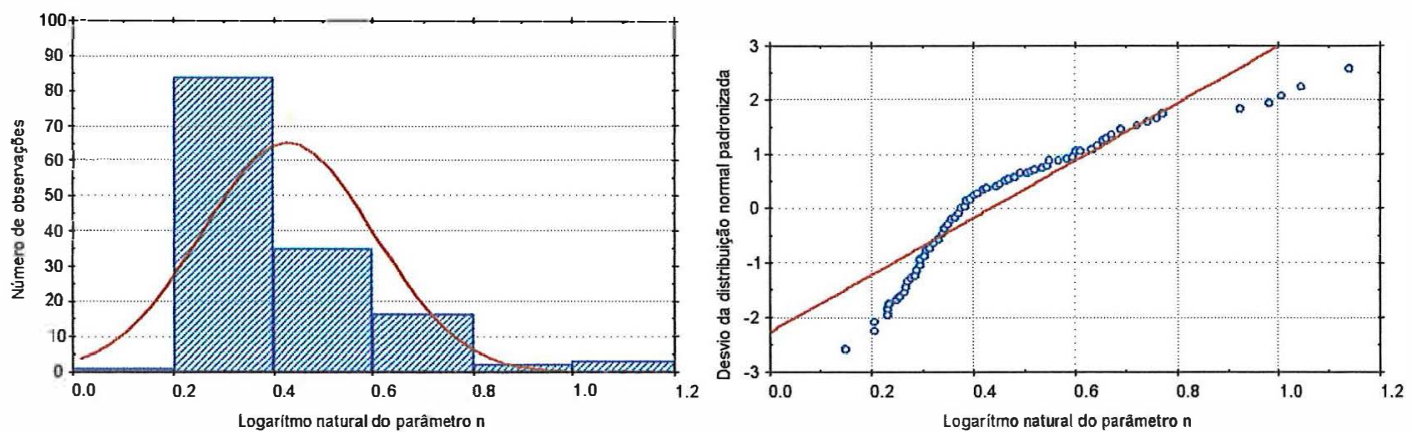

Figura 13. Histograma e gráfico de probabilidade normal dos parâmetros transformados do modelo de van Genuchten $\alpha$ (a) e $n$ (b). 


\subsection{Umidade do solo no momento da irrigação}

A partir das curvas de retenção de água no solo ajustadas ao modelo de van Genuchten, foram determinados para cada ponto amostral os valores de umidade do solo na tensão $60 \mathrm{kPa}$. As estatísticas desses valores estão apresentadas na Tabela 7 .

Tabela 7. Estatística descritiva dos dados de umidade volumétrica do solo na tensão $60 \mathrm{kPa}$ (141 valores).

\begin{tabular}{lc}
\hline Estatística & $\begin{array}{c}\text { Umidade volumétrica } \\
\text { (\%) }\end{array}$ \\
\hline Média & 38,5 \\
Mediana & 38,6 \\
Mínimo & 35,4 \\
Máximo & 42,1 \\
Amplitude total & 6,7 \\
Quartil inferior & 37,6 \\
Quartil superior & 39,3 \\
Amplitude interquartílica & 1,7 \\
Variância & 1,6429 \\
Desvio padrão & 1,2817 \\
CV & 3,3 \\
Assimetria & $-0,103^{2}$ \\
Curtose & $-0,027^{2}$ \\
$D^{3}$ & 0,08 \\
\hline Coeficiente de variação (\%). & \\
${ }^{2}$ Não difere estatisticamente de zero pelo teste t em 5\% de significância. \\
3 Valores de máxima divergência do teste de Kolmogorov-Smirnov para \\
distribuição normal. O nivel crítico em 5\% de significância é 0,11.
\end{tabular}

O coeficiente de variação dos dados de umidade foi inferior a $5 \%$ e, portanto, pode ser considerado baixo (Warrick \& Nielsen, 1980). Os valores muito próximos da média e mediana indicam que os dados de umidade apresentaram uma distribuição simétrica, comportamento confirmado pelo gráfico "box-plot" (Figura 14b), no qual as distâncias entre o valor máximo e o quartil superior e entre o quartil inferior e o valor mínimo são praticamente iguais. 
Os dados de umidade na tensão $60 \mathrm{kPa}$ apresentaram desvio máximo do teste Komogorov-Smirnov inferior ao nível crítico e, portanto, ajustaram-se à distribuição normal. A análise pelo teste $t$ também indicou que a distribuição desses valores foi simétrica e mesocúrtica. No gráfico de probabilidade normal (Figura 14a) pode-se visualizar a aderência desses valores à distribuição gaussiana, através da pequena dispersão dos dados em relação à reta normal.

(a)

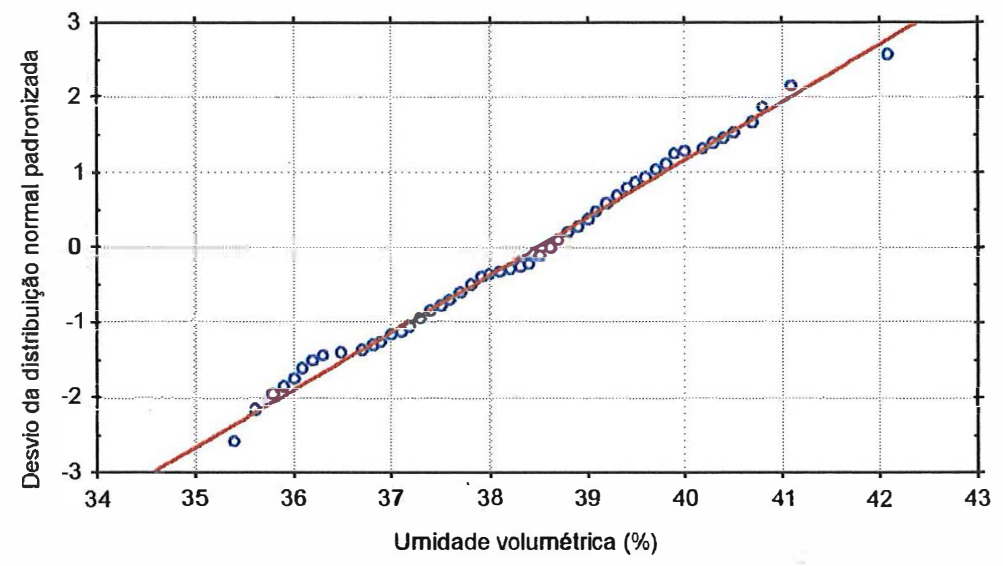

(b)

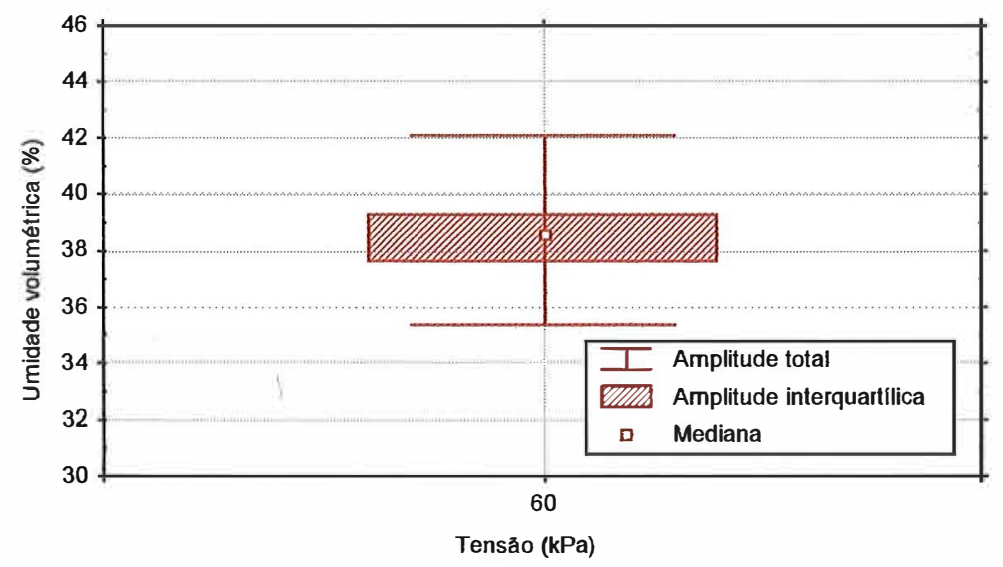

Figura 14. Gráfico de probabilidade normal (a) e "box-plot" (b) dos dados de umidade volumétrica na tensão $60 \mathrm{kPa}$. 
O semivariograma experimental dos dados de umidade na tensão 60 $\mathrm{kPa}$ foi ajustado a um modelo exponencial com alcance de $22,0 \mathrm{~m}$ e efeito pepita e patamar de, respectivamente, 0,903 e 1,719 (Figura 15). Segundo a classificação de Cambardella et al. (1994), esse semivariograma apresentou nível moderado de dependência espacial, com relação efeito pepita/patamar de $52 \%$.

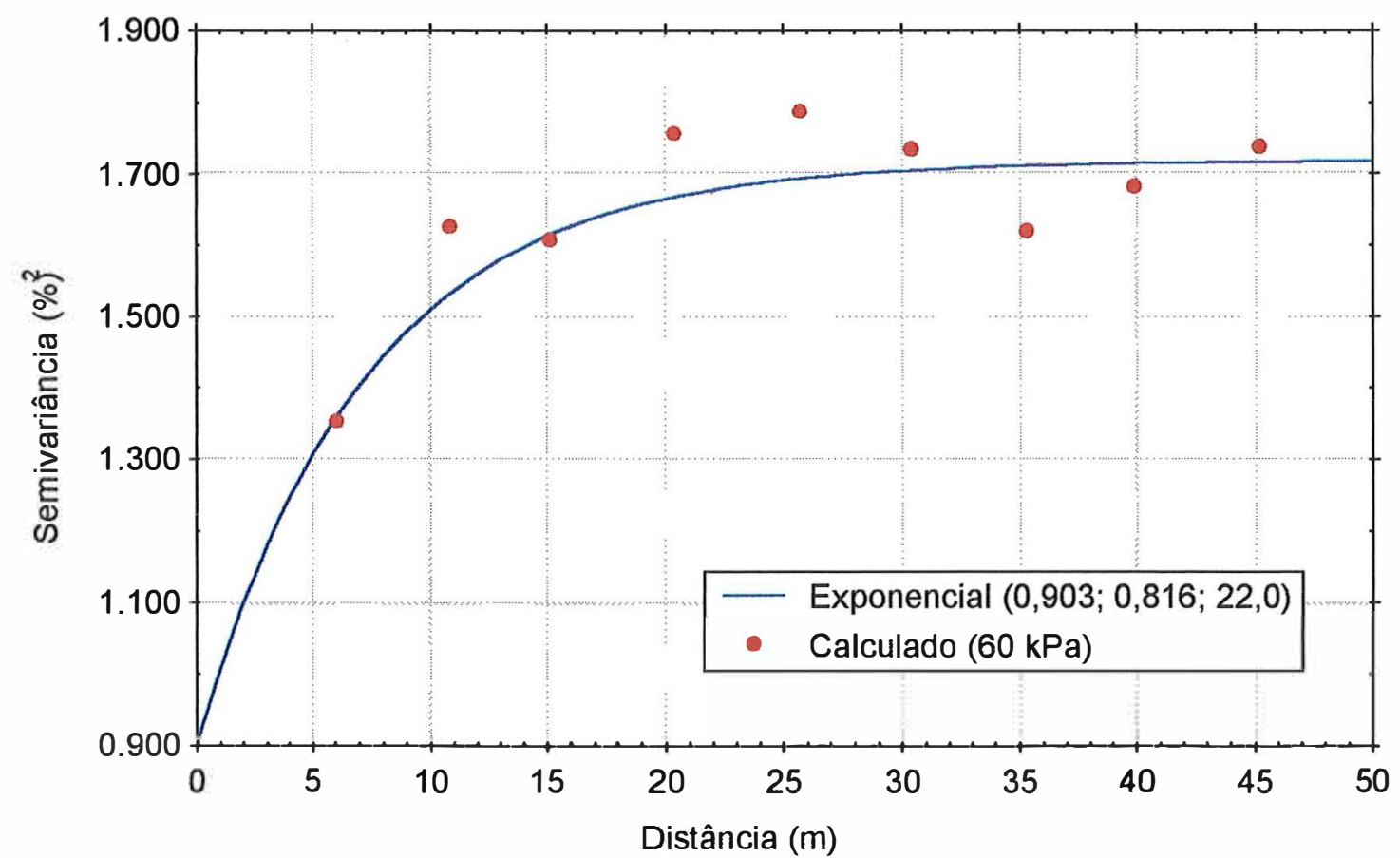

Figura 15. Semivariograma experimental e modelo ajustado para os dados de umidade volumétrica na tensão $60 \mathrm{kPa}$.

Tanto a análise descritiva como a variográfica dos valores de umidade na tensão $60 \mathrm{kPa}$ apresentaram resultados muito próximos dos obtidos nos potenciais mátricos $-100 \mathrm{e}$, principalmente, $-50 \mathrm{kPa}$. Esses resultados evidenciam o ajuste satisfatório das curvas de retenção. 


\subsection{Lâmina real necessária}

Os semivariogramas experimentais dos dados de umidade nas tensões 10 e $60 \mathrm{kPa}$ foram utilizados para construir uma malha retangular de $35 \times 85 \mathrm{~m}$ com valores espaçados em $1 \mathrm{~m}$, composta de 3.096 pontos, através de interpolações pela técnica de krigagem.

O número de vizinhos utilizados no processo de krigagem foi definido pela técnica da validação cruzada. Na Figura 16 estão apresentados os valores da variância reduzida, considerada como critério de decisão, em função do número de vizinhos utilizados na krigagem. Comparando-se os resultados com a situação ideal (variância unitária), pode-se perceber que os resultados mais satisfatórios foram obtidos com a utilização de 12 vizinhos. No entanto, as diferenças foram pequenas e até mesmo desprezíveis, como pode ser observado na krigagem com 12, 16, 20 ou 24 vizinhos na tensão $10 \mathrm{kPa}$. A Figura 16 também evidencia o melhor ajuste do semivariograma experimental dos dados de umidade na tensão $10 \mathrm{kPa}$ que, em relação ao da tensão $60 \mathrm{kPa}$, apresentou valores de variância reduzida menores para todos os números de vizinhos avaliados.

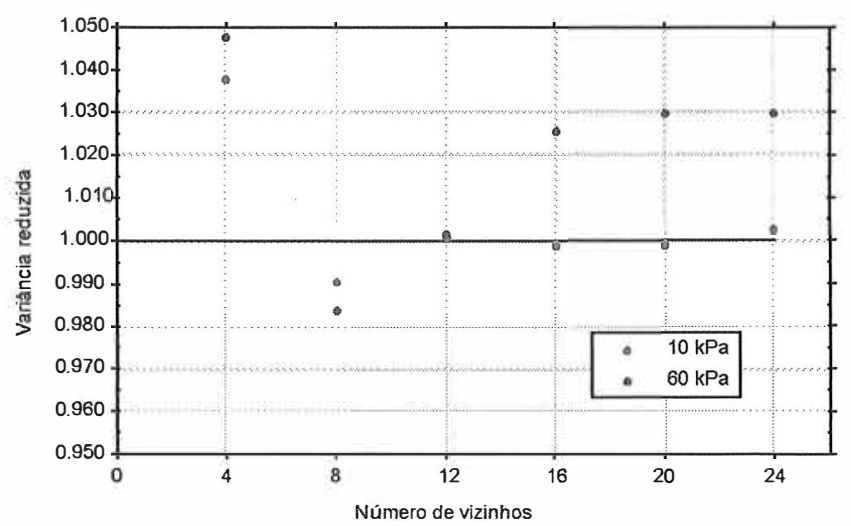

Figura 16. Variância reduzida em função do número de vizinhos dos semivariogramas dos dados de umidade volumétrica nas tensões 10 e $60 \mathrm{kPa}$. 
Nos gráficos de dispersão (Figura 17) pode-se observar duas características dos resultados da validação cruzada que, de acordo com Ribeiro Junior (1995), são desejáveis: (i) o equilíbrio entre valores sub e superestimados, com os dois lados da diagonal da reta apresentando um número aproximado de valores e (ii) a tendência apresentada pelos pontos de acompanhar a reta 1:1, apesar dos coeficientes de correlação não serem altos. Nos dois gráficos pode-se também observar o "poder amaciante" da krigagem, ou seja, a tendência dessa técnica de superestimar os valores menores e subestimar os maiores. Esse "amaciamento" será tanto maior, quanto maior for o valor do efeito pepita em relação ao patamar.

(a)

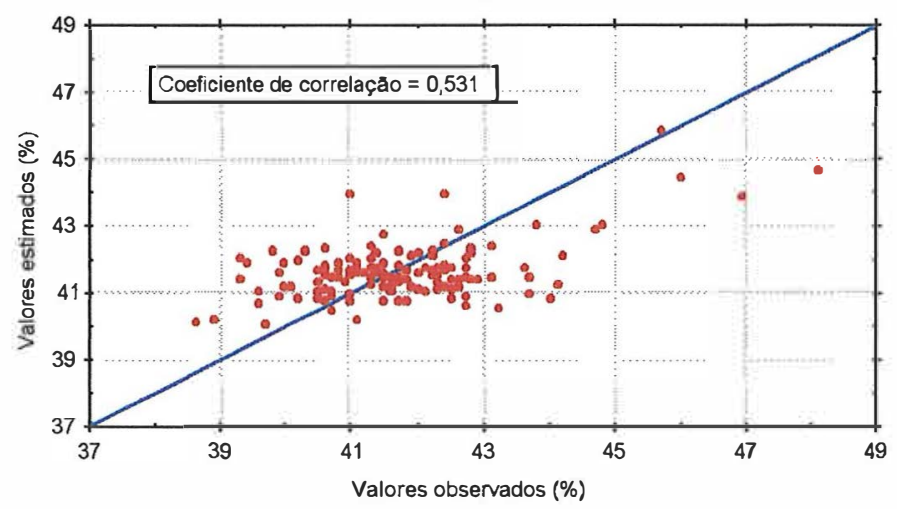

(b)

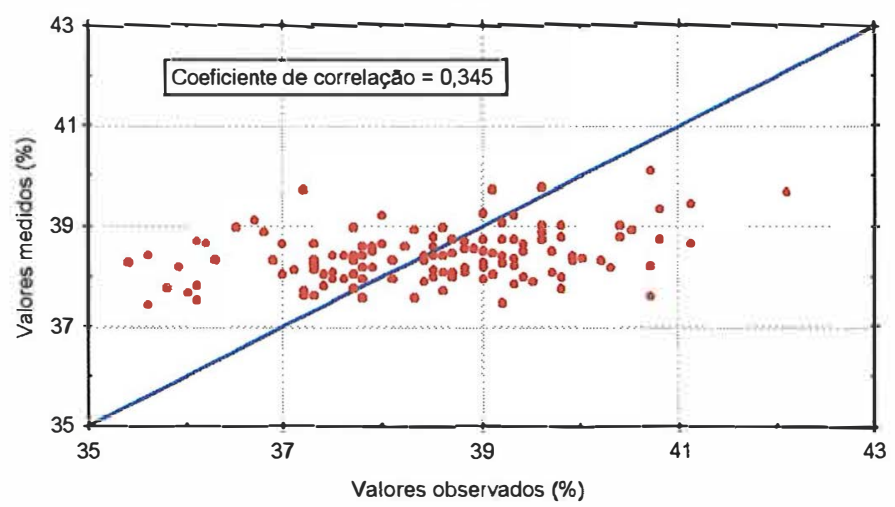

Figura 17. Gráfico de dispersão dos valores observados de umidade volumétrica nas tensões 10 (a) e $60 \mathrm{kPa}$ (b) e estimados na validação cruzada. 
$\mathrm{Na}$ Figura 18 estão apresentados os histogramas dos erros padronizados obtidos na validação cruzada. Pela avaliação do teste $t$, a distribuição desses valores foi simétrica e mesocúrtica, ajustando-se à distribuição normal, resultado confirmado pelo teste de Kolmogorov-Smirnov. Segundo Ribeiro Junior (1995), o ajuste dos erros padronizados à normalidade também é uma característica desejável nos resultados da validação cruzada.

(a)

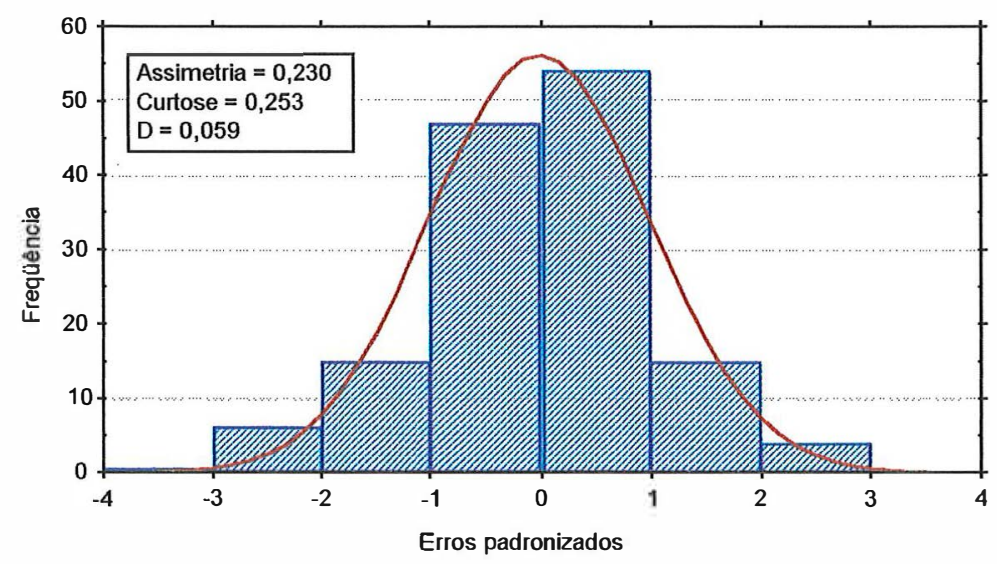

(b)

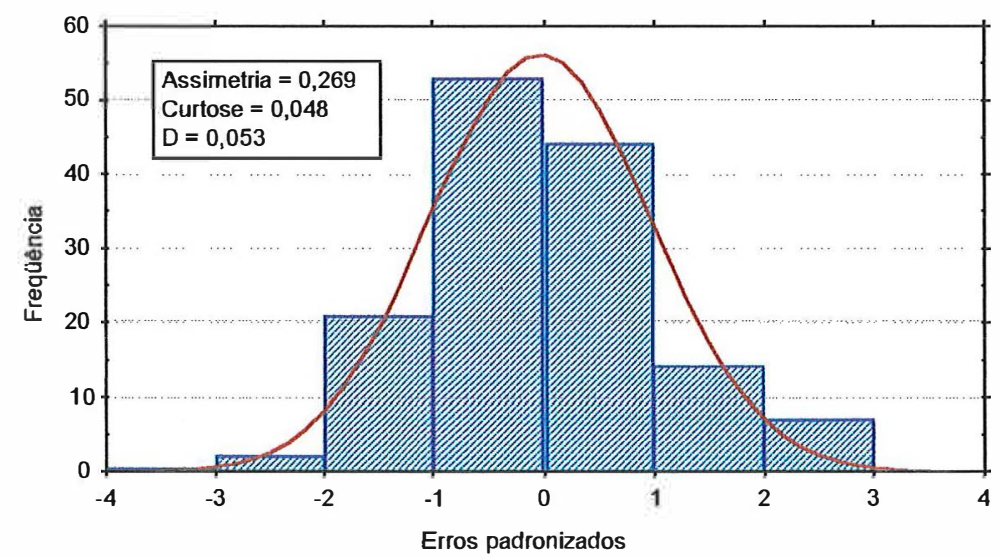

Figura 18. Histogramas das diferenças padronizadas dos dados de umidade volumétrica nas tensões 10 (a) e $60 \mathrm{kPa}$ (b) obtidas na validação cruzada, utilizando 12 vizinhos. 
Os dados de umidade volumétrica da malha $1 \times 1$ foram utilizados para construir mapas de isolinhas.

(a)

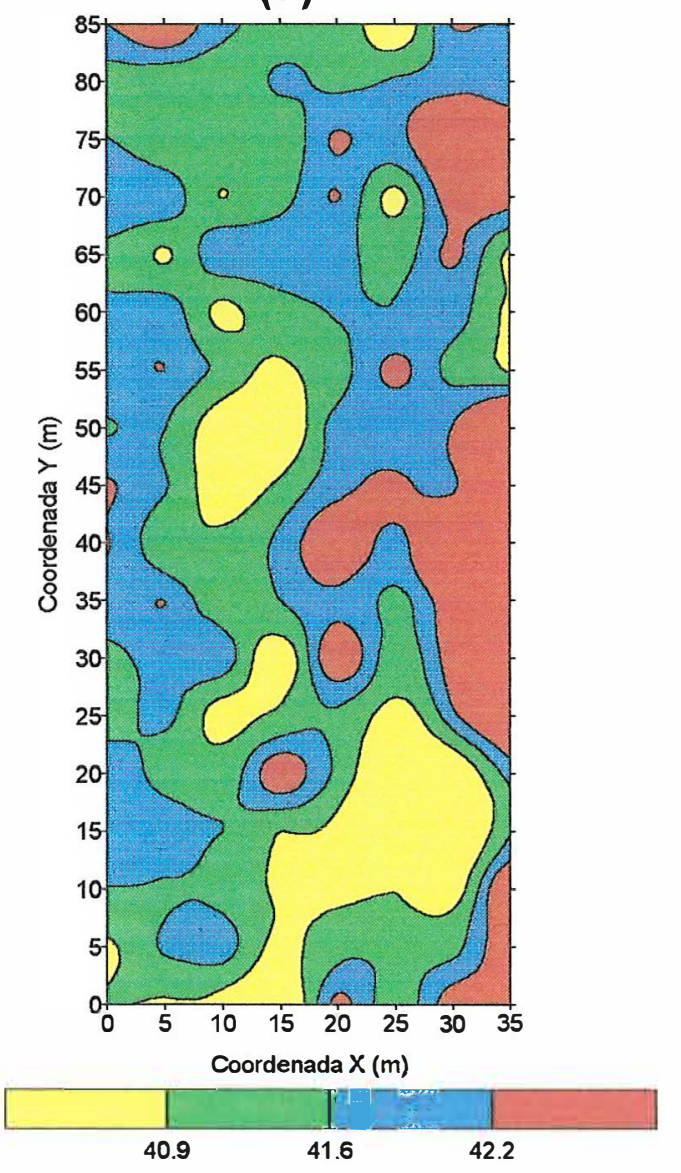

(b)

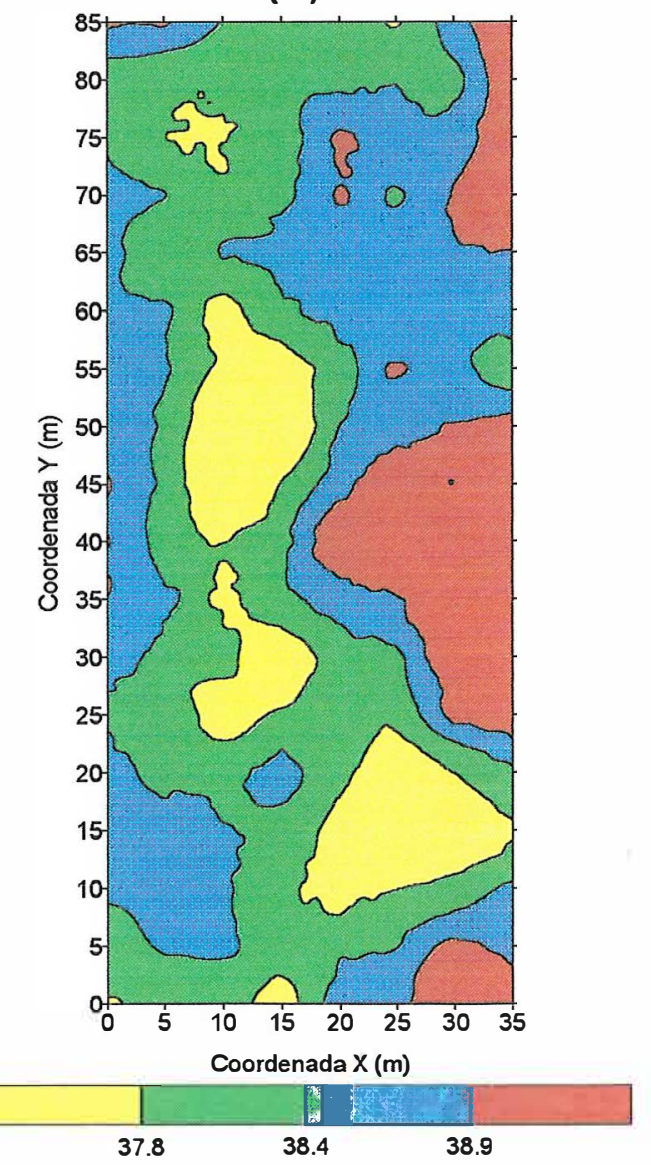

Figura 19. Mapa de isolinhas dos dados de umidade volumétrica (\%) armazenada nas tensões de 10 (a) e $60 \mathrm{kPa}(\mathrm{b})$.

Os valores de umidade volumétrica do solo nas tensões 10 e $60 \mathrm{kPa}$ apresentaram padrões espacial aproximados (Figura 19). Nas duas tensões os maiores valores de umidade concentraram-se na faixa do terreno de abscissas 25 a $30 \mathrm{~m}$ e ordenadas 25 a $50 \mathrm{~m}$. Os menores índices de umidade ocorreram, principalmente, em três subáreas, estando a maior situada entre as ordenadas 0 e $25 \mathrm{~m}$. 
As maiores diferenças entre os valores de umidade nas duas tensões e, consequentemente, os maiores valores de lâmina real necessária ocorreram na subárea com coordenadas $X$ e $Y$, respectivamente, de 30 a $35 \mathrm{~m}$ e 25 a $55 \mathrm{~m}$ (Figura 20). Os menores valores ocorreram, principalmente, na faixa de terreno com abscissas 25 a $30 \mathrm{~m}$ e ordenadas de 0 a $40 \mathrm{~m}$.

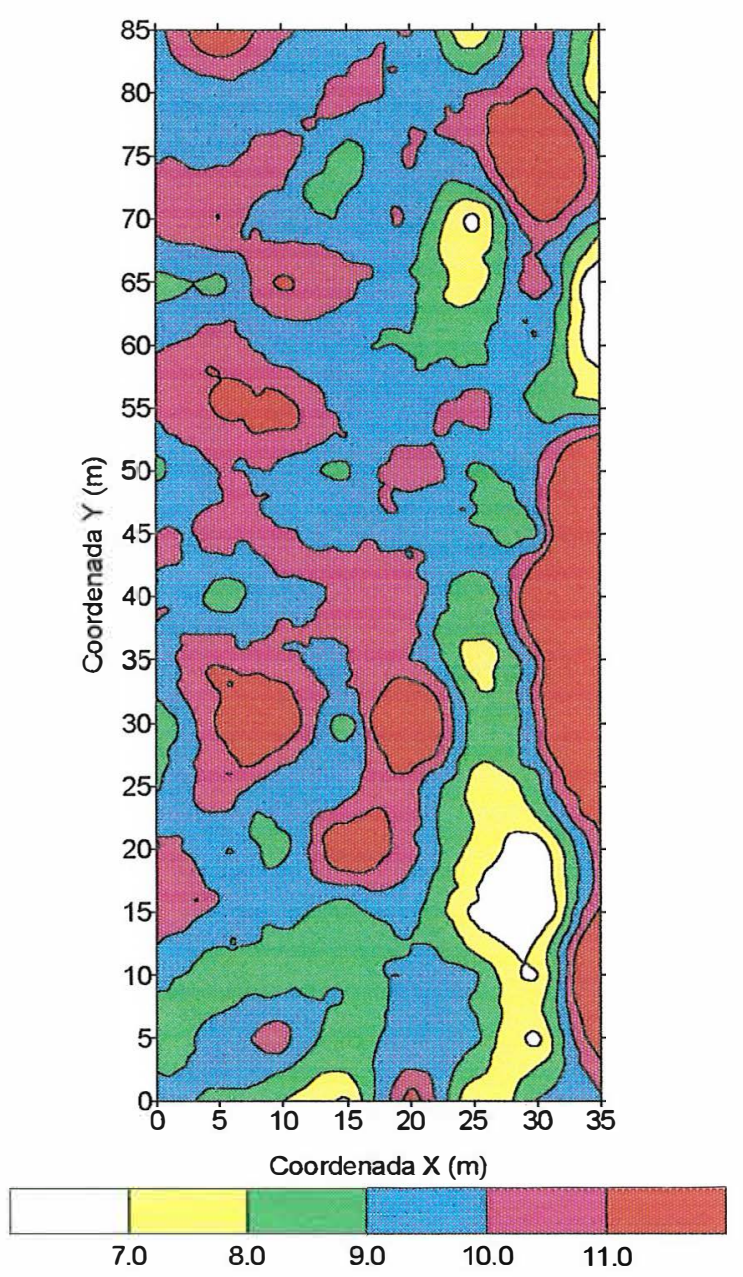

Figura 20. Mapa de isolinhas dos dados de lâmina real necessária ( $\mathrm{mm}$ ), obtido a partir dos valores de umidade nas tensões 10 e $60 \mathrm{kPa}$.

Os valores de lâmina real necessária, determinados para cada ponto amostral, diferiram pouco dos valores interpolados pela técnica de krigagem 
em termos de medidas de posição (Tabela 8). As maiores diferenças ocorreram nas medidas de dispersão, com os dados da malha $1 \times 1 \mathrm{~m}$ apresentando menor variabilidade, que se expressou pela redução das amplitudes e, principalmente, da variância e do coeficiente de variação. Esse comportamento é esperado, pois no processo de krigagem os valores estimados são médias dos vizinhos, sendo as oscilações suavizadas.

Tabela 8. Estatística descritiva dos dados de lâmina real necessária determinados para cada ponto amostral e obtidos a partir de interpolações por krigagem.

\begin{tabular}{lcc}
\hline Estatística & \multicolumn{2}{c}{ Lâmina real necessária (mm) } \\
\cline { 2 - 3 } & Medido & Krigado \\
\hline Número de valores & 141 & 3096 \\
Média & 9,8 & 9,8 \\
Mediana & 9,6 & 9,7 \\
Mínimo & 4,5 & 5,4 \\
Máximo & 19,5 & 19,5 \\
Amplitude total & 15,0 & 14,1 \\
Quartil inferior & 8,7 & 9,0 \\
Quartil superior & 10,8 & 10,2 \\
Amplitude interquartílica & 2,1 & 1,2 \\
Variância & 6,597 & 2,373 \\
Desvio padrão & 2,568 & 1,541 \\
CV & 26,2 & 15,7 \\
Assimetria & 1,13 & 1,72 \\
Curtose & 3,19 & 6,90 \\
$D^{2}$ & 0,12 & 0,14 \\
\hline
\end{tabular}

'Coeficiente de variação (\%).

${ }^{2}$ Valores de máxima divergência do teste de Kolmogorov-Smirnov para distribuição normal. 0 nível crítico em $5 \%$ de significância é 0,11 (141 valores) e 0,02 (3096 valores).

A lâmina real necessária determinada para cada ponto amostral e valores obtidos por interpolação não se ajustaram à distribuição normal de acordo com o teste Kolmogorov-Smirnov. Os valores da malha com espaçamento de $1 \mathrm{~m}$, obtidos pela técnica de krigagem, apresentaram maiores coeficientes de assimetria e de curtose. 


\subsection{Lâmina aplicada}

O semivariograma experimental dos dados de lâmina de irrigação (Figura 21) foi ajustado a um modelo gaussiano com alcance de $28 \mathrm{~m}$ e valores de efeito pepita e patamar de, respectivamente, 0,5 e 20,8. O modelo gaussiano é utilizado para ajustar fenômenos extremamente contínuos (Isaaks \& Srivastava, 1989), o que demonstra o alto grau de dependência espacial dos dados de lâmina aplicada, comportamento que também foi evidenciado pela relação efeito pepita/patamar, inferior a $3 \%$.

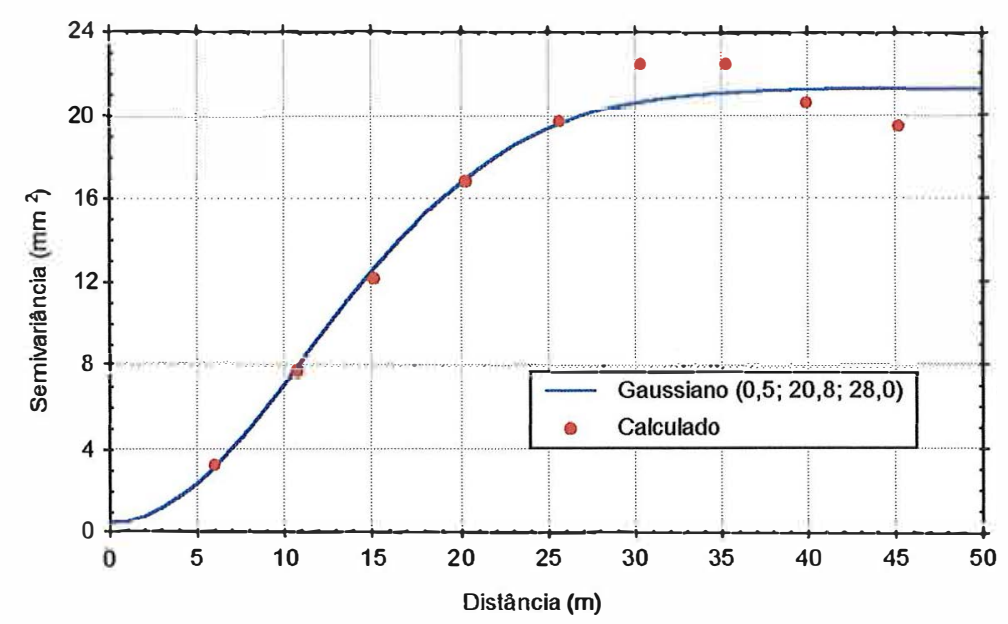

Figura 21. Semivariograma experimental e modelo ajustado para os dados de lâmina de irrigação.

O semivariograma dos valores de lâmina de irrigação foi utilizado para confeccionar uma malha retangular de $35 \times 85 \mathrm{~m}$, com espaçamento de $1 \mathrm{~m}$ composta de 3.096 pontos interpolados pela técnica de krigagem.

Na Figura 22 estão apresentados os valores da variância reduzida em função do número de vizinhos, obtidos pela validação cruzada. Assim como nos semivariogramas dos dados de umidade nas tensões 10 e $60 \mathrm{kPa}$, os melhores resultados foram obtidos com a utilização de 12 vizinhos no processo 
de krigagem. Também nesse caso as diferenças foram despreziveis em relação à krigagem com 16, 20 e 24 vizinhos.

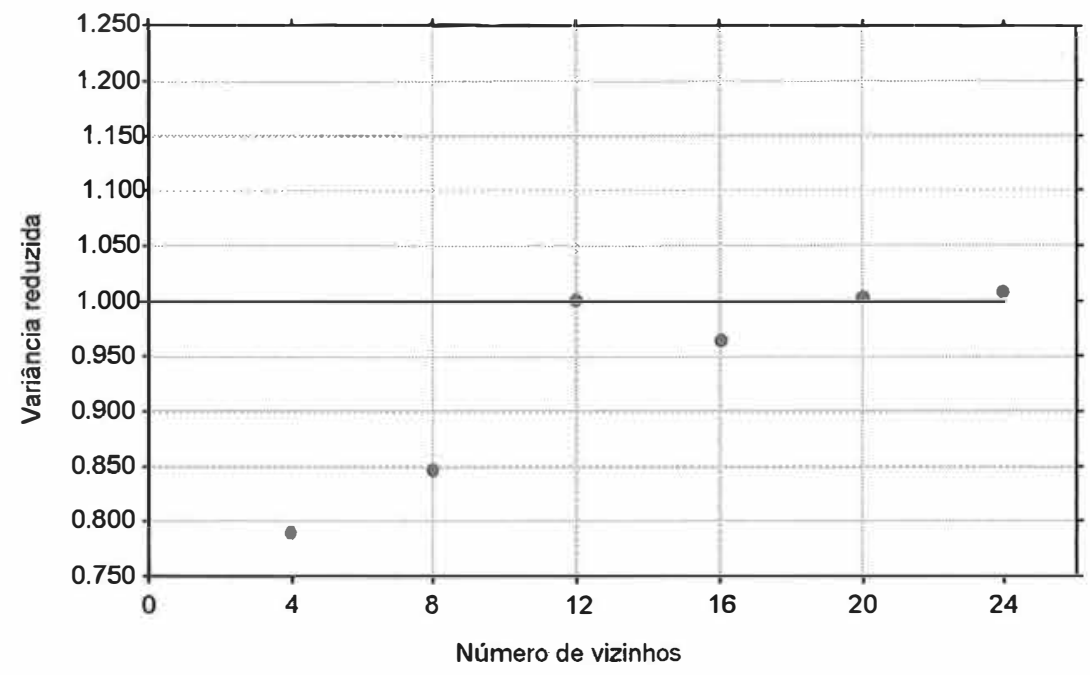

Figura 22. Variância reduzida em função do número de vizinhos dos semivariogramas dos dados de lâmina de irrigação.

No gráfico de dispersão (Figura 23) pode-se observar que houve equilíbrio entre valores de lâminas de irrigação sub e superestimados e que os pontos apresentaram uma pequena dispersão em relação à reta $1: 1$, comportamento que se refletiu num alto coeficiente de correlação entre valores medidos e observados.

O ajuste satisfatório do semivariograma também pode ser visualizado no histograma dos erros padronizados (Figura 24), que apresentou distribuição normal, de acordo com os testes t e de Kolmogorov-Smirnov. 


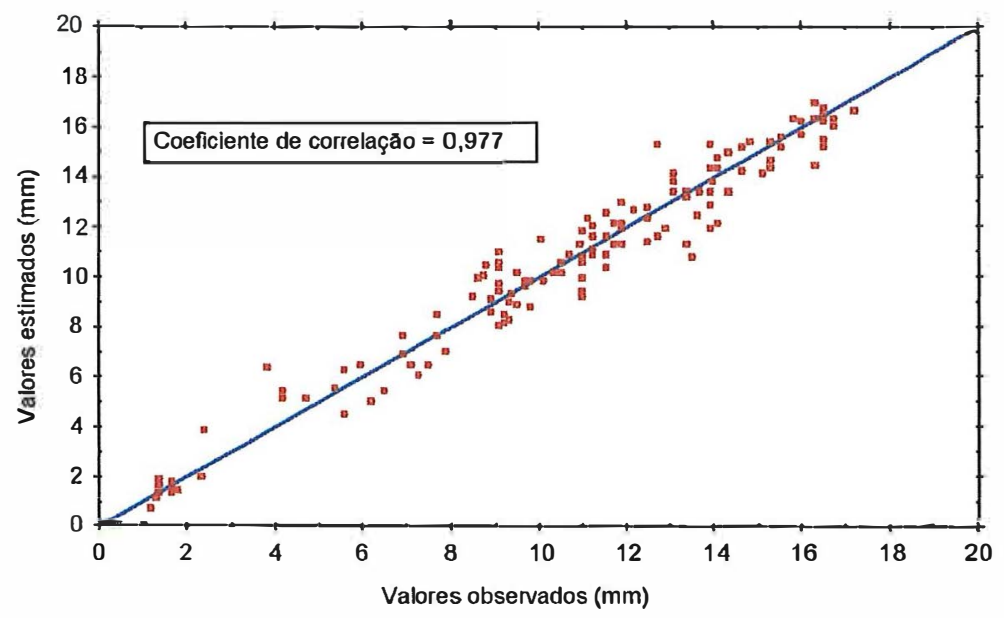

Figura 23. Gráfico de dispersão dos valores observados de lâmina de irrigação e estimados na validação cruzada.

A partir dos valores interpolados da malha $1 \times 1 \mathrm{~m}$ foi contruído o mapa de isolinhas das lâminas de irrigação (Figura 25). Os menores valores de lâmina de irrigação ocorreram na faixa lateral de terreno delimitada pelas abscissas 30 a $35 \mathrm{~m}$ e as ordenadas 0 a $70 \mathrm{~m}$. As maiores lâminas concentraram-se na subárea definida aproximadamente pelas abscissas 5 a 20 $\mathrm{m}$ e ordenadas 0 a $15 \mathrm{~m}$.

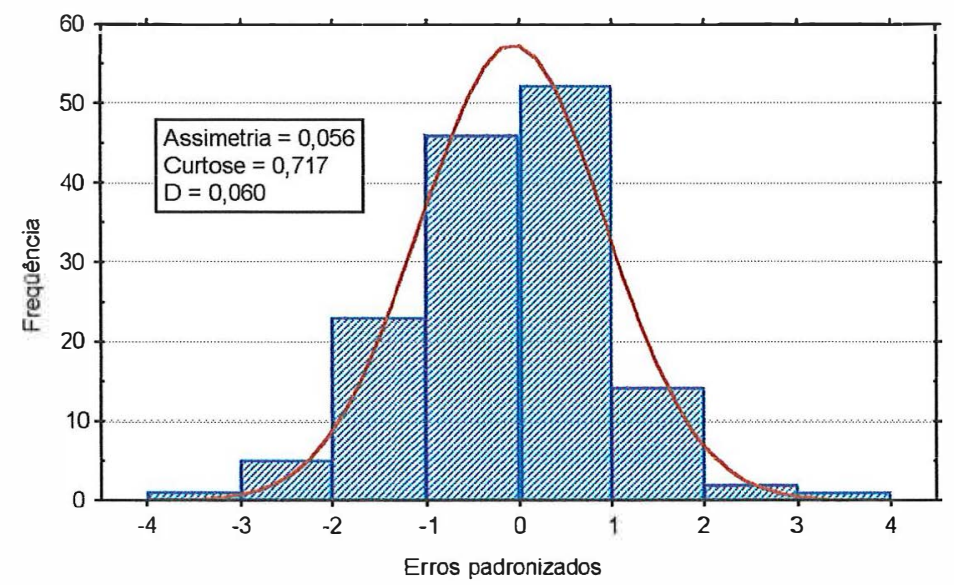

Figura 24. Histograma das diferenças padronizadas dos dados de lâmina de irrigação obtido na validação cruzada utilizando 12 vizinhos. 


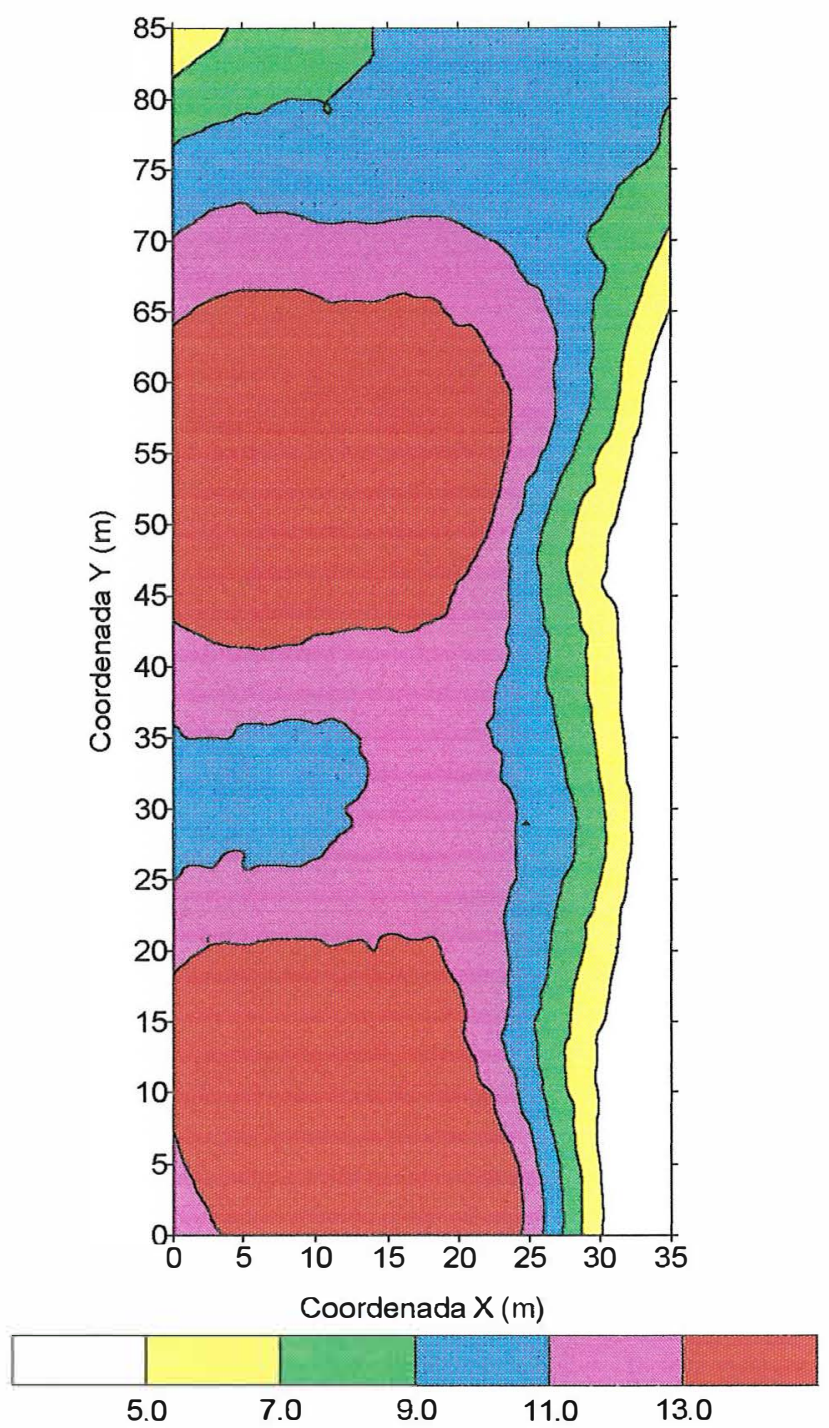

Figura 25. Mapa de isolinhas dos dados de lâmina de irrigação $(\mathrm{mm})$ obtido por interpolação pela técnica de krigagem.

As estatísticas descritivas das lâminas de irrigação coletadas e obtidas por krigagem estão apresentadas na Tabela 9. De acordo com o teste Kolmogorov-Smirnov, as lâminas coletadas apresentaram distribuição normal. No entanto, pela avaliação do teste $t$ a distribuição desses dados apresentou assimetria significativamente menor que zero. Os dados obtidos por interpolação não se ajustaram à normalidade. 
Os valores de lâmina de irrigação interpolados diferiram pouco dos observados, em termos de medida de posição. Houve um pequeno aumento nos valores de média e mediana, mas que para fins práticos pode ser considerado desprezível. Como conseqüência do processo de krigagem, houve redução na variabilidade dos dados, que se expressou pelos valores menores de amplitude interquartílica e, principalmente, de variância e de coeficiente de variação.

Tabela 9. Estatística descritiva dos dados de lâmina de irrigação coletadas e obtidas a partir de interpolações por krigagem.

\begin{tabular}{lcc}
\hline Estatística & \multicolumn{2}{c}{ Lâmina aplicada $(\mathbf{m m})$} \\
\cline { 2 - 3 } & Medido & Krigado \\
\hline Número de valores & 144 & 3096 \\
Média & 10,6 & 11,0 \\
Mediana & 11,2 & 11,3 \\
Mínimo & 0,4 & 0,4 \\
Máximo & 17,2 & 17,1 \\
Amplitude total & 16,8 & 16,7 \\
Quartil inferior & 8,9 & 9,2 \\
Quartil superior & 13,8 & 13,8 \\
Amplitude interquartílica & 4,9 & 4,6 \\
Variância & 17,46 & 13,94 \\
Desvio padrão & 4,2 & 3,7 \\
CV' & 39,4 & 33,9 \\
Assimetria & $-0,70$ & $-0,64$ \\
Curtose & $0,05^{2}$ & 0,04 \\
$D^{2}$ & 0,10 & 0,07 \\
\hline
\end{tabular}

'Coeficiente de variação (\%).

${ }^{2}$ Valores de máxima divergência do teste de Kolmogorov-Smirnov para distribuição normal. 0 nivel crítico em $5 \%$ de significância é 0,11 (144 valores) e 0,02 (3096 valores).

O coeficiente de uniformidade de Christiansen dos dados coletados de lâmina de irrigação foi de $70 \%$, índice que pode ser considerado satisfatório, pois sistemas autopropelidos geralmente proporcionam uma baixa uniformidade de aplicação (Frizzone, 1992). O nível razoável de uniformidade pode ser atribuído à baixa velocidade do vento durante a realização do ensaio, inferior a $1 \mathrm{~m} \cdot \mathrm{s}^{-1}$. 
A redução da variabilidade das lâminas aplicadas obtidas por interpolação também influenciou a uniformidade. O coeficiente de uniformidade de Christiansen determinado para a malha $1 \times 1 \mathrm{~m}$ foi de $73 \%$, apresentando um pequeno acréscimo em relação aos valores observados de lâminas.

\subsection{Avaliação da qualidade da irrigação}

A partir dos dados de lâmina real necessária e de lâmina aplicada determinou-se o déficit ou excesso hídrico de cada ponto da malha $1 \times 1 \mathrm{~m} e$ calculou-se os parâmetros de desempenho da irrigação. Através dos mapas de isolinhas confeccionados com esses valores, pode-se identificar áreas onde a irrigação proporcionou déficit (figura 26a) ou excesso hídrico (Figura 26b).

A região delimitada pelas abscissas 30 a $35 \mathrm{~m}$ e ordenadas 0 a $55 \mathrm{~m}$ apresentou os maiores índices de défict hídrico, enquanto os maiores excessos concentraram-se em duas regiões com abscissas 0 a $25 \mathrm{~m}$ e ordenadas 0 a 20 m (região 1) e 45 a 65 m (região 2).

A localização e a quantificação dessas áreas tem grande importância para o manejo da irrigação, pois possibilita definir a lâmina de aplicação e os locais de monitoramento da umidade do solo e de instalação de pluviômetros.

O manejo racional da irrigação deve ser definido com base na relação entre $\circ$ índice de drenagem profunda e o grau de adequação. Quando se pretende reduzir os índices de drenagem profunda, a lâmina de aplicação deve ser definida visando diminuir as áreas de excesso hídrico. Por outro lado, quando o objetivo é aumentar o grau de adequação, deve-se incrementar a lâmina de aplicação. 
(a)

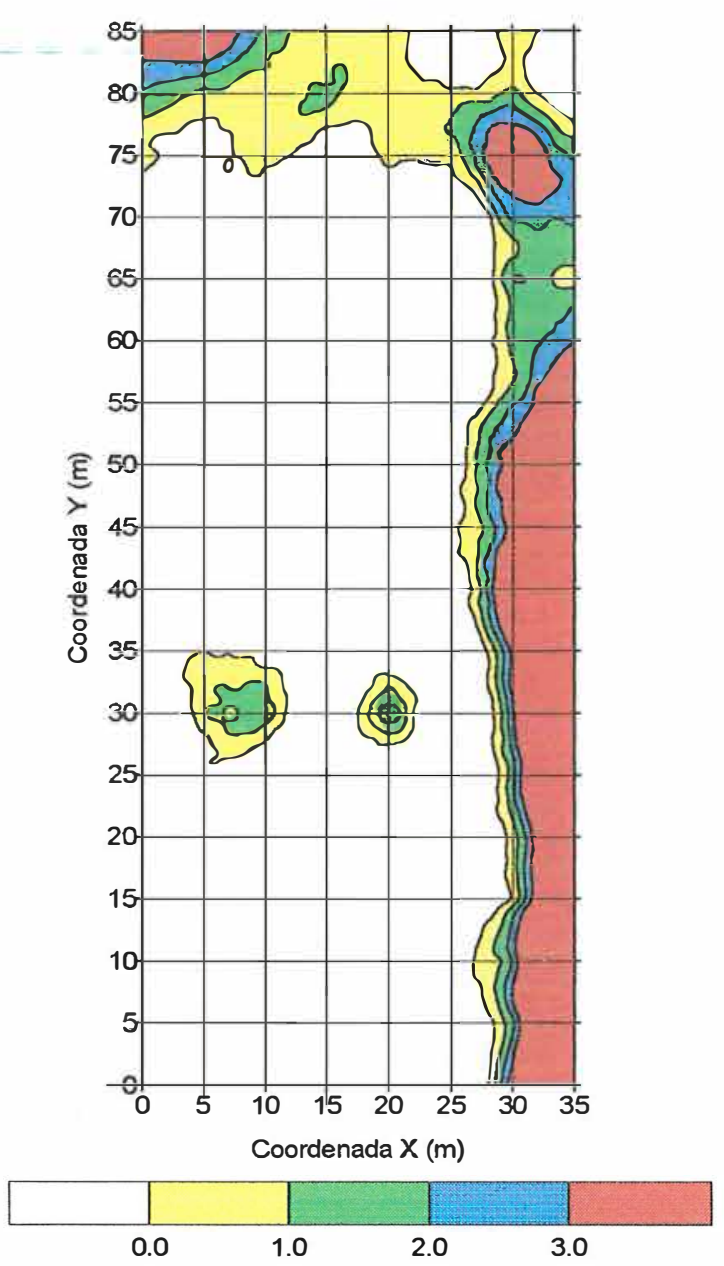

(b)

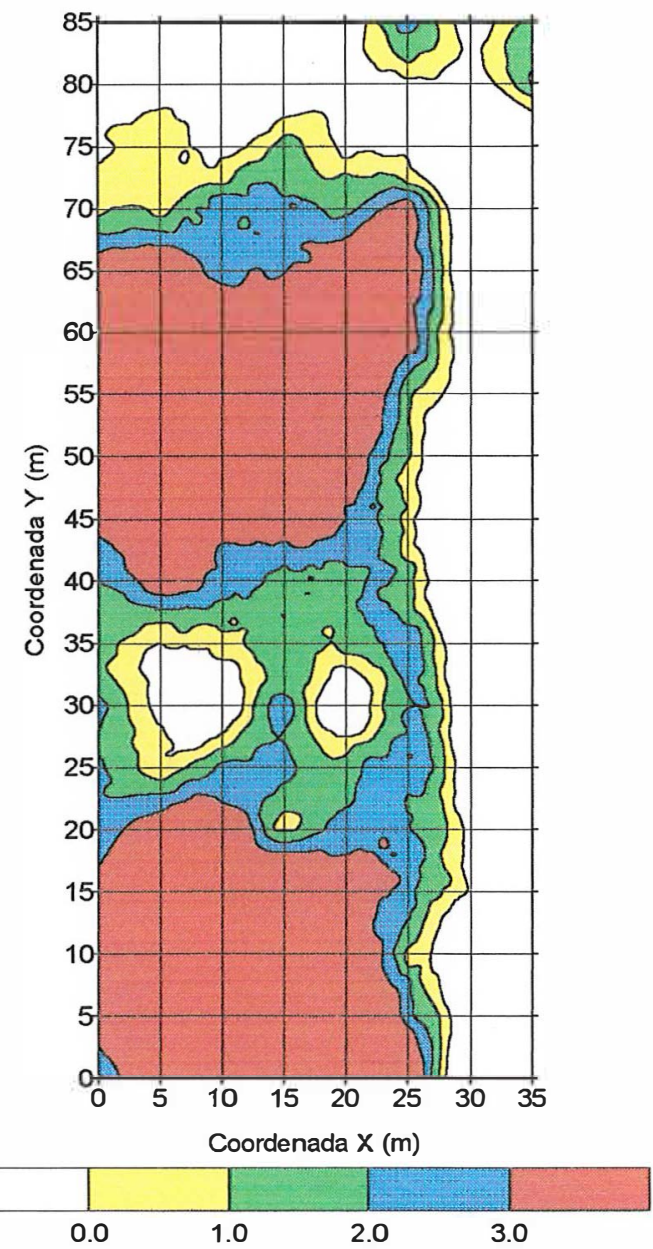

Figura 26. Mapas de isolinhas dos valores $(\mathrm{mm}$ ) de déficit (a) e excesso hídrico (b) proporcionados pela irrigação.

Na Figura 27 estão apresentados o grau de adequação e os índices de eficiência de distribuição e de drenagem profunda da irrigação e as alterações nesses parâmetros devido à redução ou incremento da lâmina média aplicada. Pode-se perceber que a eliminação total da área subirrigada não é uma prática recomendável. A aplicação de uma lâmina média de $18 \mathrm{~mm}$ (incremento de 7 $\mathrm{mm}$ ) resultaria num grau de adequação de $90 \%$, mas com altos índices de drenagem profunda, próximos a $50 \%$. Por outro lado, a definição de um manejo visando minimizar os índices de drenagem profunda, implicaria na redução 
substancial do grau de adequação. Assim, a aplicação de uma lâmina média de $9 \mathrm{~mm}$ (redução de $2 \mathrm{~mm}$ ) proporcionaria índices de drenagem profunda de $10 \%$, mas com grau de adequação de apenas $45 \%$.

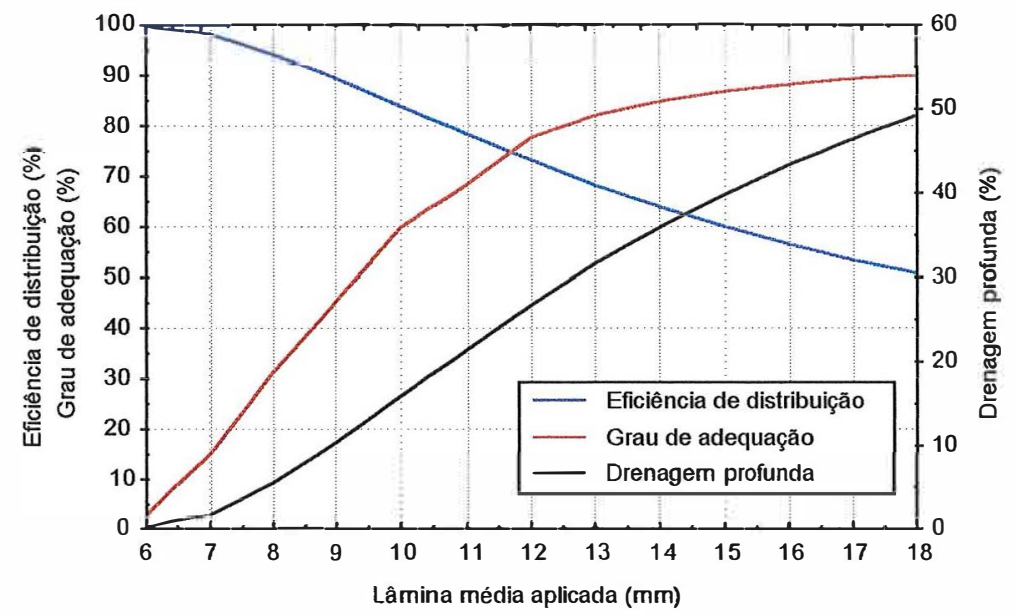

Figura 27. Parâmetros de desempenho obtidos no ensaio de irrigação.

Provavelmente, a melhor opção seria aplicar uma lâmina média de aproximadamente $12 \mathrm{~mm}$, valor próximo da lâmina aplicada no ponto de interseção das curvas de eficiência de distribuição e de grau de adequação (Figura 27). Nessas condições, a irrigação proporcionaria índices de drenagem profunda de $27 \%$ e grau de adequação de $78 \%$. Para irrigação por aspersão, Cuenca (1989) considera grau de adequação de $75 \%$ e uniformidade de aplicação de $80 \%$ como uma combinação razoável para culturas de campo como o trigo.

A interação da variabilidade espacial do armazenamento da água no solo e da lâmina aplicada resultou em áreas de dimensões consideráveis com excesso ou déficit hídrico superior a $3 \mathrm{~mm}$. Portanto, não é recomendado utilizar o sistema autopropelido na irrigação de experimentos que avaliem culturas e fertilizantes, pois as conseqüências da variabilidade espacial desses atributos poderia mascarar os resultados. 
A influência da variabilidade espacial do armazenamento hídrico nos parâmetros de qualidade da irrigação foi avaliada comparando-se os resultados determinados pelo somatório das lâminas armazenadas e percoladas na malha $1 \times 1$ m e os obtidos pelo modelo linear de Karmeli, que considera a lâmina real necessária constante e igual à média dos dados.

Analisando-se a curva de freqüência acumulada das lâminas de irrigação (Figura 28) pode-se perceber que o modelo linear ajustou-se satisfatoriamente aos dados, comportamento que também se expressou no alto coeficiente de correlação da reta ajustada.

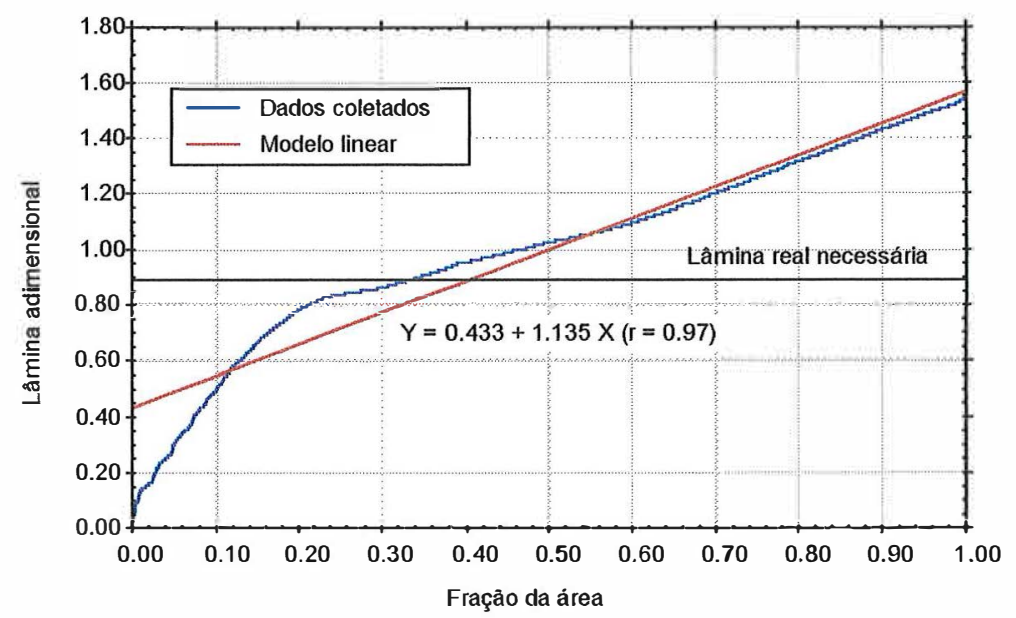

Figura 28. Curva de freqüência acumulada das lâminas de irrigação considerando a variabilidade espacial do armazenamento de água no solo e ajustada ao modelo linear.

Os valores de drenagem profunda foram maiores quando se considerou a variabilidade da lâmina real necessária (Figura 29a), mas os resultados foram muito próximos aos obtidos pelo modelo linear. Esse comportamento pode ser atribuído aos dados de lâmina real necessária que, apesar de não se ajustarem à normalidade, apresentaram uma distribuição relativamente simétrica, com uma forte concentração de valores próximo à média que resultou numa pequena amplitude interquartílica e num alto coeficiente de curtose. Nessas 
condições, a média foi uma estatística representativa, mas em situações em que os valores de lâmina real necessária apresentarem distribuição menos simétrica, a variabilidade espacial do armazenamento hídrico deverá influenciar os resultados de forma mais nítida.

O modelo linear foi menos sensível em diferenciar áreas deficientemente e adequadamente irrigadas (Figura 29b). No caso de uma irrigação com lâmina média $25 \%$ maior que a necessária $(\Delta=0,20)$, o grau de adequação considerando a variabilidade espacial do armazenamento hídrico seria de $79 \%$. Para as mesmas condições, o modelo linear estimou que apenas $68 \%$ da área foi adequadamente irrigada. Esse resultado deve-se ao modelo linear assumir que a distribuição de freqüência das lâminas de irrigação é totalmente simétrica. Com base no modelo linear, quando os valores de lâmina real necessária e lâmina aplicada forem iguais $(\Delta=0), 50 \%$ da área será subirrigada e $50 \%$ será irrigada adequadamente, sendo as variações do grau de adequação e da lâmina média aplicada diretamente proporcionais. Essa condição ideal dificilmente ocorre na prática, pois a distribuição das lâminas aplicadas geralmente apresenta assimetria e, portanto, o grau de adequação não varia linearmente com as alterações da lâmina média aplicada.

(a)

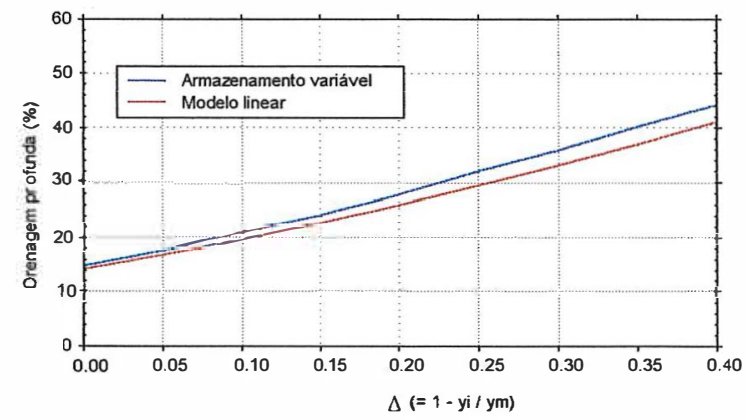

(b)

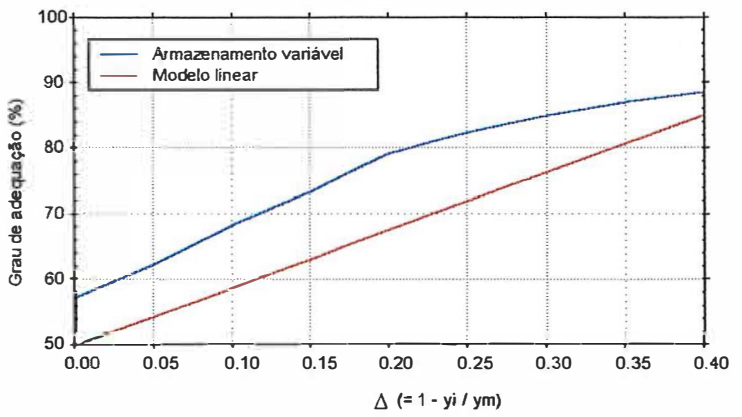

Figura 29. Valores de drenagem profunda (a) e de grau de adequação (b) considerando a variabilidade espacial do armazenamento e calculados pelo modelo linear. 


\section{CONCLUSÕES}

Os dados de umidade do solo em todas as tensões apresentaram distribuição normal, baixo grau de variabilidade e estrutura de dependência espacial, com valores de efeito pepita de 14 e $56 \%$ da variação total e alcance de $22 \mathrm{~m}$.

A exclusão dos valores discrepantes de umidade praticamente não influenciou as medidas de posição e de distribuição, mas proporcionou um melhor ajuste dos dados à distribuição normal.

Os dados de lâmina de irrigação não se ajustaram à distribuição normal, mas apresentaram um nível médio de variabilidade e forte dependência espacial, efeito pepita inferior a $3 \%$ da variação total e alcance de $28 \mathrm{~m}$.

O latossolo estudado apresentou pequena disponibildade hídrica devido, provavelmente, ao fenômeno da microagregação da fração argila. Para comprovar essa justificativa, recomenda-se que sejam realizados estudos detalhados da microestrutura e da composição mineralógica desse solo, visando identificar e quantificar os tipos de poros e de argila que o constituem.

Houve ajuste das curvas de retenção ao modelo de van Genuchten. Os parâmetros $\alpha$ e $n$ apresentaram uma grande assimetria, não se ajustando à distribuição normal.

As técnicas geoestatísticas detectaram e descreveram a variabilidade espacial do armazenamento de água no solo e da lâmina aplicada pelo sistema de irrigação. O mapeamento da área permitiu definir sub-áreas com menor variabilidade de lâmina real necessária e identificar regiões onde a irrigação 
proporcionou déficit ou excesso hídrico. O conhecimento dessas áreas possibilita definir um manejo racional da irrigação.

A variabilidade do armazenamento de água no solo não influenciou de forma relevante os índices de drenagem profunda devido à distribuição relativamente simétrica dos valores de lâmina real necessária. No entanto, o modelo linear foi pouco sensível em diferenciar áreas deficientemente $e$ adequadamente irrigadas, devido à assimetria dos dados de lâmina de irrigação. 


\section{REFERÊNCIAS BIBLIOGRÁFICAS}

ARYA, L.M. ; PARIS, J.F. A physicoempirical model to predict the soil moisture characteristic from particlesize distribution and bulk density data. Soil Science Society of America Journal, v. 45, n. 3, p. 1023-1034, 1981.

ASSIS, F.N.; ARRUDA, H.V.; PEREIRA, A.R. Aplicações de estatística à climatologia. Pelotas: Editora Universitária; Universidade Federal de Pelotas, 1996. $161 \mathrm{p}$.

BEIGUELMAN, B. Curso prático de bioestatística. 3. ed. Ribeirão Preto: Sociedade Brasileira de Genética, 1994. 244p.

BERNARDO, S. Manual de irrigação. 5. ed. Viçosa: UFV / Impressão Universitária, 1989. 596p.

CAHN, M. D. ; HUMMEL, J. W. ; BROUER, B. H. Spatial analysis of fertility for site-specific crop management. Soil Science Society of America Journal, v. 58, n. 4 , p. 1240-1248, 1994. 
CAMBARDELLA, C.A.; MOORMAN, T.B.; NOVAK, J.M; PARKIN, T.B.; KARLEN, D.L.; TURCO, R.F.; KONOPKA, A.E. Field -scale variability of soil properties in Central lowa Soils. Soil Science Society of America Journal, v. 58, n. 5 , p. $1501-1511,1994$.

CAMPOS, H. Estatística experimental não-paramétrica. 4. ed. Piracicaba: ESALQ, 1983. 349 p.

CARVALHO, T.M. de ; SILVA, A. M. da ; OLIVEIRA, M. S. de ; AQUINO, L. H. de ; FERREIRA, M.M. Variabilidade espacial da retenção de água em um latossolo vermelho-amarelo através da geoestatística. Ciência e Prática, v.16, n.4, p. 521 - 528, out./ dez., 1992.

CHRISTIANSEN, J. E. Irrigation by sprinkler. Berkeley: California Agricultural Experiment Station, 1942. 124 p. (Bulletin,670).

CUENCA, R. H. Irrigation system design: an engineering approach. Englewood Cliffs: Prentice Hall, ,1989. 552 p.

DANIELSON, R.E. ; SUTHERLAND, P.L. Porosity. In: BLACK, C.A. , ed. Methods of soil analysis. 2. ed. Madison: American Society of Agronomy Soil Science Society of America, 1986. cap. 18, p. 443-461.

DOORENBOS, J.; KASSAN, A, H. Efectos del água sobre el rendimento de los cultivos. Roma: FAO, 1979. 212 p.

DOURADO NETO, D.; LIER, Q. de J. V. ; BOTREL, T.A.; LIBARDI, P.L. Programa para confecção da curva de retenção da água no solo utilizando o modelo de Genuchten. Engenharia Rural, v. 1, n. 2, p. 92-102, dez. 1990. 
EMBRAPA. Centro Nacional de Pesquisa de Solos (Rio de Janeiro, RJ). Manual de métodos de análise de solo. 2. ed. Rio de Janeiro, 1997. 212 p. (EMBRAPA-CNPS. Documentos, 1).

ENGLUND, E. ; SPARKS, A. Geo-EAS (Geoestatistical Enviromental Assessment Software). Las Vegas: U.S. Enviromental Protection Agency, 1988. não paginado. (EPA/600/4-88/033a)

FIETZ, C. R. ; HERNANI, L. C. Determinação da capacidade de campo de Latossolo Roxo distrófico argiloso por diferentes métodos. In: CONGRESSO NACIONAL DE IRRIGAÇÃO E DRENAGEM, 9., Natal, 1991. Anais. Fortaleza: ABID, 1992. v.1, t.2, p.665-682.

FOLEGATTI, M. V. Estabilidade temporal e variabilidade espacial da umidade e do armazenamento de água em solo siltoso. Piracicaba, 1996. 84p. Tese (Livre Docente) - Escola Superior de Agricultura "Luiz de Queiroz", Universidade de São Paulo.

FRIZZONE, J. A. Irrigação por aspersão: uniformidade e eficiência. Piracicaba: ESALQ / Departamento de Engenharia Rural, 1992. 53 p.

FRIZZONE, J. A. Uniformidade e eficiência da irrigação. Piracicaba: ESALQ / Departamento de Engenharia Rural, 1998. 40p. /no prelo/.

GAJEM, J. M. ; WARRICK, A. W. ; MYERS, D.E. Spatial dependence of physical properties of a typic torrifluvent soil. Soil Science Society of America Journal, v. 45, n. 2, p. 709 - 715, 1981. 
GONÇALVES, A.C.A. Variabilidade espacial de propriedades físicas do solo para fins de manejo da irrigação. Piracicaba, 1997. 118p. Tese (Doutorado) - Escola Superior de Agricultura "Luiz de Queiroz", Universidade de São Paulo.

GONÇALVES, A.C.A.; FOLEGATTI, M.V.; SILVA, A.P. Retenção de água no solo em área irrigada por pivô-central. In: CONGRESSO LATINOAMERICANO DE CIÊNCIA DO SOLO, 13., Águas de Lindóia, 1996. Solosuelo 96: Campinas: SBCS/SLCS, 1996. 6p. CD-ROOM. Seção trabalhos.

GREMINGER, P. J. ; SUD, Y. K. ; NIELSEN, D. R. Spatial variability of fieldmeasured soil-water characteristics. Soil Science Society of America Journal, v. 49, n. 5, p.1075-1082, 1985.

HANN, C. T. Statistical methods in hidrology. Ames: lowa State University Press, 1994. 378p.

IEMMA, A. F. Estatística descritiva. Piracicaba: $\varphi \sigma \rho$ Publicações, 1992. $182 p$.

ISAAKS, H.E.; SRIVASTAVA, R.M. An introduction to applied geostatistics. New York: Oxford University Press, 1989. 560 p.

KARMELI, D. Estimating sprinkler distribution patterns using linear regression. Transactions of the ASAE, v. 21, n. 4, p. 682-686, 1978. 
KERTZMAN, F.F. Modificações na estrutura e no comportamento de um latossolo roxo provocadas pela compactação. São Paulo, 1996. 153p. Tese (Doutorado) - Faculdade de Filosofia, Letras e Ciências Humanas, Universidade de São Paulo.

KIEHL, E.J. Manual de edafologia. São Paulo: Agronômica Ceres, 1979. $262 p$.

KLUTE, A. Water retention: laboratory methods. In: BLACK, C.A. , ed. Methods of soil analysis. 2. ed. Madison: American Society of Agronomy Soil Science Society of America, 1986. cap. 26, p. 635-662.

LAMBOOY, A.M. Relationship between cation exchange capacity, clay content and water retention of Highveld soils. South African Journal Plant Soil, v. 1, n. 2, p. 33-38, 1984.

LIBARDI, P.L. Dinâmica da água no solo. Piracicaba: o Autor, 1995. 497p.

LIBARDI, P.L.; MANFRON, P.A.; MORAES,S.O. Variabilidade da umidade gravimétrica de um solo hidromórfico. Revista Brasileira de Ciência do Solo, v. 20, n. 1, p. 1-12, 1996.

LOPES, A.S. Solos sob "cerrado": características, propriedades e manejo. Piracicaba: CIGEL, 1983. 162p.

MALLANTS, D.; MOHANTY, B.P.; JACQUES, D.; FEYEN, J. Spatial variability of hydraulic properties in a multilayered soil profile. Soil Science, v. 161, n. 3, p.167-181, mar. 1996. 
MARTORANO, L. G. ; LAZZAROTO, C. ; MOTHCI, E. ; TUON, R. L. Avaliação de condições climatológicas em Dourados-MS. In: CONGRESSO BRASILEIRO DE METEOROLOGIA, 11., Campos do Jordão, 1996. Anais. Rio de Janeiro: SBMET, 1996. p.1168-1171.

MENEZES, H. A. de ; CORRÊA, N. I. ; MOREIRA, J. A. A. Caracterização química, física e físico-hídrica de dois solos para fins de irrigação. Goiânia: EMGOPA, 1992. 31p.

MORAES, S. O. ; LIBARDI, P. L. ; DOURADO NETO, D. Problemas metodológicos na obtenção da curva de retenção da água pelo solo. Scientia Agricola, v. 50, n. 3, p. 383-392, out./dez., 1993(a).

MORAES, S. O. ; LIBARDI, P. L. ; REICHARDT, K. Heterogeneidade dos pontos experimentais de curvas de retenção da água no solo. Scientia Agricola, v. 50, n. 3, p. 393-403, out./dez., 1993(b).

MUALEN, Y. A new model for predicting the hydraulic conductivity of unsaturated porus media. Water Resources Research, v. 12, n. 3, p. 513522, 1976.

OLIVEIRA, J. B. de ; JACOMINE, P. K. T. ; CAMARGO, M. N. Classes gerais de solos do Brasil. Jaboticabal: FUNEP, 1992. 201 p.

QUEIROZ, J.E. Parâmetros hidrodinâmicos de um solo de várzea para fins de drenagem subterrânea. Piracicaba, 1995. 167p. Tese (Doutorado) Escola Superior de Agricultura "Luiz de Queiroz", Universidade de São Paulo. 
RAIJ, B. van; QUAGGIO, J.A.; CANTARELLA, H.; FERREIRA, M.E.; LOPES, E.S.; BATAGLIA, O.C. Análise química do solo para fins de fertilidade . Campinas: Fundação Cargill, 1987. 170 p.

RECOMENDAÇÕES da comissão Centro-Sul Brasileira de Pesquisa de Trigo para 1995. In: REUNIÃO DA COMISSÃO CENTRO-SUL BRASILEIRA DE PESQUISA DE TRIGO, 11., Cascavel, 1995. Cascavel: Organização das Cooperativas do Estado do paraná - OCEPAR, 1995, $203 p$.

REEVE, M. J. ; CARTER, A. D. Water release characteristic. In: SMITH, K. A.; MULLINS, C. E. Soil analysis: physical methods. New York: Marcel Dekker, 1991. cap. 3, p. 111-160.

REEVE, M. J. ; SMITH, P. D. ; THOMASSON, A. J. The effect of density on water retention properties of field soils. Journal of Soil Science, v. 24, n. 3, p. 355-367, 1973.

REICHARDT, K. A água em sistemas agrícolas. São Paulo: Manole, 1987. $188 p$.

REICHARDT, K. Dinâmica da matéria e da energia em ecossistemas. 2. ed. Piracicaba: ESALQ / Departamento de Física e Meteorologia, 1996. 513 p.

RIBEIRO JUNIOR, P.J. Métodos geoestatísticos no estudo da variabilidade espacial de parâmetros do solo. Piracicaba, 1995. 99p. Dissertação (M.S.) - Escola Superior de Agricultura "Luiz de Queiroz", Universidade de São Paulo. 
RODRIGUES NETTO, A. A influência da minerologia da fração argila sobre propriedades físico-químicas de solos brasileiros. Viçosa, 1996. 144 p. Dissertação (Mestrado) - Universidade Federal de Viçosa.

SALTER, P. J. ; WILLIAMS, J. B. The influence of texture on the moisture characteristics of soils. Part I: A critical comparison of techniques for determining the available water capacity and moisture characteristic curve of a soil. Journal of Soil Science, v. 16, n.1, p. 1-15, 1965.

SCALOPPI, E. J. Eficiência de aplicação de água em sistemas de irrigação por aspersão. ITEM - Irrigação e Tecnologia Moderna, n. 16, p.37-40, 1984.

SHARMA, M.L.; UEHARA, G. Influence of soil structure on water relations in low humic latosols: I. Water retention. Soil Science Society of American Proceedings, v. 32, n. 4, p. 765-770, 1968.

SHOUSE, P.J.; RUSSEL, W.B.; BURDEN, D.S.; SELIM, H.M.; SISSON, J.B.; VAN GENUCHTEN, M. Th. Spatial variability of soil water retention functions in a silt loam soil. Soil Science, v. 159, n. 1, p. 1-12, Jan. 1995.

SILVA, A. P. da ; LIBARDI, P. L. ; CAMARGO, O. A. Influência da compactação nas propriedades físicas de dois latossolos. Revista Brasileira de Ciência do Solo, v. 10, n. 1, p. 91-95, 1986.

SOUZA, F. de ; RIBEIRO, J. M. Aplicação do modelo linear de Karmeli na avaliação do sistema de irrigação por aspersão. ITEM- Irrigação e Tecnologia Moderna, n. 16, p.7-10, 1984.

SPIEGEL, M. R. Estatística. 3. ed. São Paulo: Makron Books, 1993. 643p. 
TOGNON, A. A. Propriedades físico-hídricas do Latossolo Roxo da região de Guaíra-SP sob diferentes sistemas de cultivo. Piracicaba, 1992. 67p. Dissertação (Mestrado) - Escola Superior de Agricultura "Luiz de Queiroz", Universidade de São Paulo.

TSUJI, G. Y. ; WATANABE, R. T. ; SAKAI, W. S. Influence of soil microstructure on water characteristics of selected hawaiian soils. Soil Science Society of American Proceedings, v. 39, n. 1, p. 28-33, 1975.

TURATTI, A.L. Variabilidade do armazenamento de água em terra roxa estruturada. Piracicaba, 1990. 88p. Tese (Doutorado) - Escola Superior de Agricultura "Luiz de Queiroz", Universidade de São Paulo.

URCHEI, M. A. ; HERNANI, L. C. ; LAZZAROTO, C. ; FIETZ, C. R. Atributos físicos de Latossolos em dois sistemas de manejo, visando a irrigação em Mato Grosso do Sul. Dourados: EMBRAPACPAO, 1997. 5 p. (EMBRAPA-CPAO. Pesquisa em andamento, 3).

VAN GENUCHTEN, M. T. A closed-form equation for predicting the hydraulic condutivity of unsaturated soils. Soil Science Society of America Journal, v. 44, n. 5, p. 892-898, 1980.

VAUCLIN, M ; VIEIRA, S. R. ; VACHAUD, G. ; NIELSEN, D.R. The use of corriging with limited field soil observations. Soil Science Society of America Journal, v. 47, n. 2, p. 175-184, 1983.

VIEIRA, S. R. Tópicos especiais em geoestatística: semivariogramas e técnica de validação pelo "jack-knifing". Campinas: IAC, não paginado, 1997. 
VIEIRA, S.R. Geoestatística em estudos de variabilidade espacial. Campinas: IAC, paginação irregular, 1998 /no prelol.

VIEIRA, S.R.; HATFIELD, J.L.; NIELSEN, D.R.; BIGGAR, J.W. Geostatistical theory and application to variability of some agronomical properties. Hilgardia, v. 51, n.3, p. 1-75, 1983.

WALKER, W.R. Explicit sprinkler irrigation uniformity: efficiency model. Journal of the Irrigation and Drainage Division, ASCE, n. IR2, p. 129-136, 1979.

WARRICK, A. W. ; NIELSEN, D. R. Spatial variability of soil physical properties in the field. In: HILLEL, D. (Ed.) Application of soils physics. New York: Academic Press, 1980. cap.3, p. 319-344.

WEBSTER, R. ; OLIVER, M. A. Statistical methods in soil and land resource survey. Oxford: Oxford University Press, 1990. 316p. 